BNZ 21023

\title{
OSCIL: \\ One-Dimensional Spring-Mass System Simulator \\ for Seismic Analysis \\ of High Temperature Gas Cooled Reactor Core
}

\author{
L. Iasker, Editor \\ Contributors \\ p. Bezler \\ J. Curreri \\ B. Koplik M. Reich \\ January, 1976
}

NOTICE

PORTIONS OF THIS REPORT ARE ILIESIBLE: It has been reprodiced from the best availablo

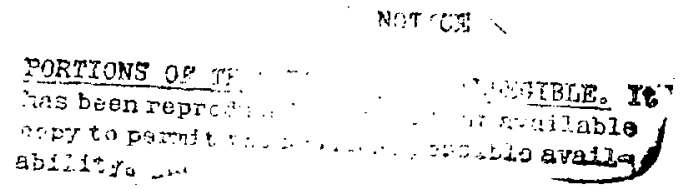


BROOKHAVEN NATIONAL LABORATORY

\author{
OSCIL: \\ One-Dimensional Spring-Mass System Simulator for Seismic Analysis \\ of High Temperature Gas Cooled Reactor Core
}

January 1976

\begin{abstract}
Structural Analysis Group Brookhaven kational Laboratory

Associated Universities, Inc.

Upton, New York 11973
\end{abstract}


PROGRAM OSCIL

L. Lasker, Editor

Contributors
P. Bezler
J. Curreri
B. Koplik
M. Reich

This is the first version of oscII. The code has been extensively tested using all the different options described in the following pages and it has been used many production luns with realistic data.

Due to the current interest in HIGR core safety studies, it is felt that it would ve worthwhile to release the code in its present unpolished form. In the near future a fully self-explanatory version with detailed coment statements in each subroutine will be issued. A major execution time improvement in that version will be the replacement of the GEAR integration routine with one that handles banded Jacobians. 
Abstract .... . . . . . . . . . . . . . . . . . . . . . . iii

PART I

Code Description .. . . . . . . . . . . . . . . . . . . . . . 1

a) General ..... . . . . . . . . . . . . . . . . 1

b) Features ... . . . . . . . . . . . . . . . . . . 3

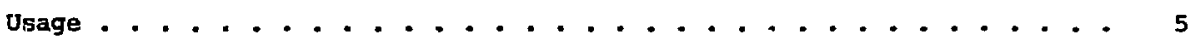

a) Input - Full Description . . . . . . . . . . . . . . . 5

b) Input - Deck List . . . . . . . . . . . . . . . . . . 15

Numerical Integration Technique . . . . . . . . . . . . . . . . . . 20

Program Description . . . . . . . . . . . . . . . . . . . . . . . . 22

a) Subroutine Hierarchy . . . . . . . . . . . . . . . . . . 22

b) Subroutine Functions . . . . . . . . . . . . . . . . 23

c) Macroscopic Flow Chart . . . . . . . . . . . . . . . . . 24

d) Sample Input . . . . . . . . . . . . . . . . . . . 25

e) Sample cutput . . . . . . . . . . . . . . . . . . . 26

PART II

Testing and Results . . . . . . . . . . . . . . . . . . . . . . 28

a) Model Description . . . . . . . . . . . . . . . . . 28

b) Test Cases ............................ . . 32

c) Paianetric Study of 7-Mass System . . . . . . . . . . . . . . 48

d) Non-linearity Effects . . . . . . . . . . . . . . . . 61

References . . . . . . . . . . . . . . . . . . . . . . 70

APPENDIX

Ilsting of Program . . . . . . . . . . . . . . . . . . . . . 71 


\section{Abstract}

OSCII is a program to predict the effects of seismic input on a HTGR core. The present model is a one-dimensional array of blocks with appropriate spring constants, inter-elemental and ground damping, and clearances. It can be used more generally for systems of moving masses separated by non-linear springs and dampers. 


\section{Code Description: General}

Present code handles one-dimensional wall-spring-mass configuration for up to 70 masses. Mcre than 70 masses can be accomodated by increasing the dimensions of the appropriate arrays. Plans axe being made to expand OscIl to two and three dimensional versions.

The code determines the time evolution of the system of masses depicted in Figure 1.

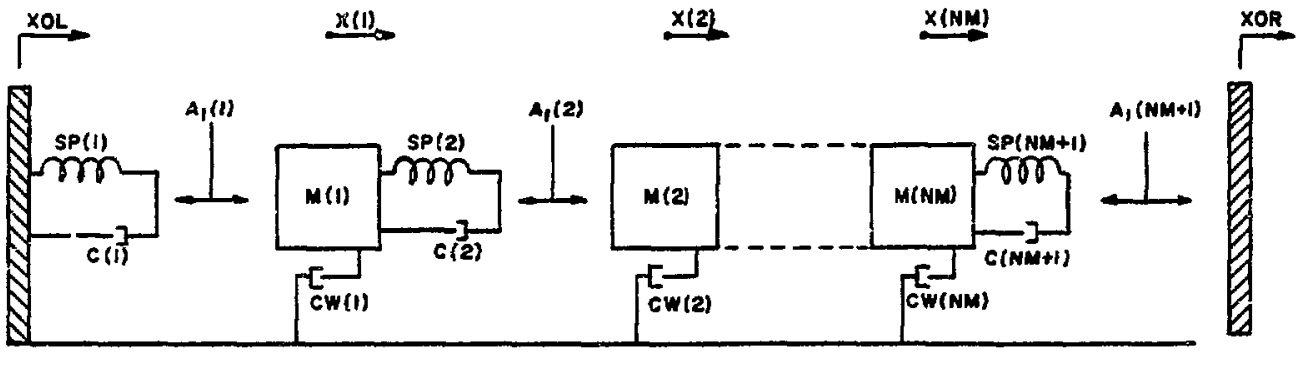

Fig. 1

XOL, XOR are the driving outside walls.

$M(1), M(\mathrm{NM})$ are the reflector blocks.

$M(2), \ldots \ldots, M(N M-1)$ are the internal blocks.

$\mathrm{SP}(1), \mathrm{SP}(\mathrm{NM}+1)$ are the reflector springs.

SP(2), ..., SP(IM) are springs which simulate the material properties of the

blocks.

$C(1), \ldots ., C(M M)$ spring dampers.

CW(1), ..., CW (NM) ground dampers.

Al (l), .... Al (NM) initial clearances. 
The simplest set of coupled differential equations describing this systen

are:

$$
\begin{aligned}
& M_{1} \ddot{x}_{1}+x_{1}\left(x_{1}-x O L\right)+c_{1}\left(x_{1}-x_{0 L}\right)+k_{2}\left(x_{1}-x_{2}\right)+c_{2}\left(\dot{x}_{1}-x_{2}\right) \\
& +\operatorname{cw}(1)\left(\dot{x}_{1}-\dot{x} O L\right)=0 \text {. } \\
& M_{i} \ddot{x}_{i}+x_{i}\left(x_{i}-x_{i-1}\right)+c_{i}\left(x_{i}-x_{i}-1\right)+x_{i}+l\left(x_{i}-x_{i+1}\right) \\
& c_{i+1}\left(x_{i}-x_{i+1}\right)+c N(i)\left(x_{i}-x_{0}\right)=0 \text {. } \\
& 2 \leq 1 \leq \mathrm{NM}-1 \\
& M_{N M} \ddot{x}_{N M}+x_{N M}\left(x_{M N}-x_{N M-1}\right)+c_{N M}\left(z_{N M}-\ddot{x}_{N M-1}\right)+x_{N M+1}\left(x_{N M}-x O R\right) \\
& +C_{\mathrm{NM}+1}\left(\mathrm{X}_{\mathrm{NR}}-\mathrm{XOR}\right)+\mathrm{CW}(\mathrm{NM})\left(\mathrm{X}_{\mathrm{NM}}-\mathrm{XOL}_{\mathrm{N}}=0\right. \text {. }
\end{aligned}
$$

where the $k_{i}$ and $c_{i}$ are non-linear functions of the displacements $\left(x_{i}-x_{i-1}\right)$. as described in the Input Section.

The integration scheme used was the GEAR package written by A.C. Hindmarsh (5). This package automatically varies the tine integration step and order of integration. The reasons for using it are described in detail in the section on the numerical methods. 


\section{Some Features of OSCIL}

1). The execution time for a 70 mass example is an order of magnitude larger than that for a 9 mass system. viz. 3000 cpu secs vs. 250 cpin. secs. At present it is uncertain whether this is caused by the many multiple collisions with consequent short integration steps, or due to the fact that in the GEAR integration routine a $2 n \times 2 n(n=$ \# of masses) matrix inversion takes place at each time step. Presently planning to replace GEAR with GEARB (7), which integrates systems of stiff ordinary differential equations with banded Jacobian. Since the Jacobian of OSCrL is banded with band width $=6$, substantial time saving is expected.

2). OSCII has a RESTAFE option so that a new run can begin where a previous one stopped.

3). Each major set of operations is completed in semi-independent modules. This makes it fairly simple to replace or modify any of these modules without affecting the remainder of the code. This is of particular concern in the subroutines

a) FORCE - which computes force on springs as functions of displacertents

b) SHOK - specifies nature of seismic osicllations of walls

c) STORE - stores quantities to be plotted

d) COEF - computes damping coefficients

e) DIFFUN - called by GEAR, DIFFUN computes accelerations from displacements

The present optiens in FORCE, SHOK and STORE are described in the INPUT section. New options can easily be added. The output can be varied with calls to PRNTF (see Input section) or modifications to PROUT. 
4). Because it is believed that-a visual presentation of the core motion will eventually be required, the techniques for generating conputer movies using CALCCHP to display program solutions are being investigated. At present, single but visually powerful plots are made of 1-dimensional systems.

5). Any number of input sets can be read in simultaneousiy. A separate run will be made for each set and execution will stop when an end-of-file is encountered. 
USAGE

Input

Card 1

Variables: TITE.

Format: 8 silo.

Cara 2

Variables: NEUN, NM, NIIME.

Format: $\quad 3 I 10$.

Description:

NFUN is used in subroutine SHOK to determine, the nature of the forcing

function of the outside walls XOL, XOR.

NFUN $=1$ Step function XOL $=$ XOR $=$ A, DIXI $=$ DIXR $=0$.

NFUN $=2$ Forcing function sinusoidal in-phase

XOL $=$ XOR $=A \cdot \operatorname{Sin}(B, D E L T)$.

$D I X I=D I X R=A \cdot B \cdot \operatorname{COS}(B, D E E I)$.

NFUN $=3$ Forcing function sinuisoidal out-of-phase.

$$
\begin{aligned}
& \text { XOL }--X O R=A . S I n \text { (B. DELT) } \\
& \text { DIXL = DIXR = A.B. COS (B. DELT). }
\end{aligned}
$$

NFUN $=4$ This is a special option used for the situation depicted in Fig. 2.

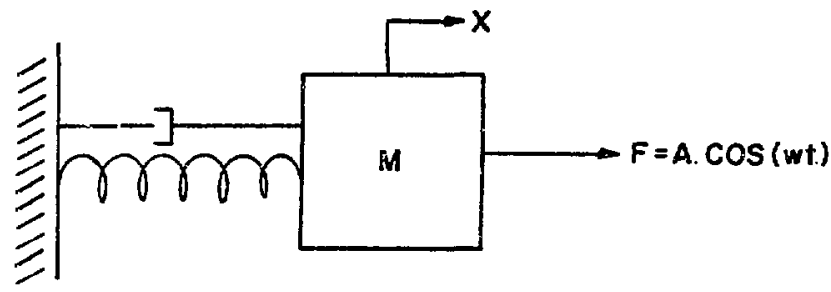

Eig. 2 . 
The wall remains stationary and the spring is of cubic type i.e., NGAP(1) = 3 (see card 5' with a predetermined driving force $F=A$ cos (ut). The equation describing this system is given by

$$
\left.\ddot{x}=\llbracket A \cos (\omega t)-K(1,1) * x^{3}-1000 * x\right\rfloor / M \text {. }
$$

This option is useful for testing integrated solutions of non-linear' spring equations, as these solutions can be determined analytically, and the solutions are not unique. (See section "Testing of Program".)

N.B. NFUN $=4$ can only be used with a single mass, single spring and NGiP (1) $=3$. A, $\omega=$ BINT are given on card 3 as for NFUN $=2$ or 3 . Other forcing functions can be added to OSCII by including them in SHOK and using corresponding new NFUN options.

Nor is the number of masses.

NTIME If NFUN $=2$ or 3 , NITME is \# of passes to be made, each iute incrementing the first angular velocity BINT by FRQ.

\section{$\underline{\operatorname{card} 3}$}

Variables: A, BINY, FRQ, ALPHAI, NSTFP, IWAVE

Format: $\quad 4 F 10.2,2 I 10$

\section{Description:}

B Amplitude of oscillation

BINT For NFon $=2$ or 3 - initial value of $\omega$ for each pass

FRQ Increment of BINT for each pass if NIME $\geq 2$

ALPHAI Slope for linear increase (decrease) of frequency (angralar velocity) with time according to

$$
\omega=\omega_{0}+\text { ArPfraI } * t
$$

where

$$
\begin{aligned}
& \omega_{0}=\text { BINT if IWAVE }=0 \\
& \omega_{0}=\text { BINT }+2 \pi \text { if IWAVE }=1
\end{aligned}
$$


NSTEP * 1 All mass and wall afsplacements plotted relative to origin, i.e., origin considered to be equilibrium position for all walls and masses

2 This option can only be used if all the springs have gaps, and alit springs between the masses have equal gaps.

For the plotting routine the equilibrium positions of the masses are separated by the gap size = AI(I) and the ecililibrium positions of the walls are separated from the outer masses by $\mathrm{A2}(1)$, where $\mathrm{A} 2$ (1) is the length of the outer springs plus gap size.

The use of this option leads to a clear pictorial representation of the relative motions of the linear array of masses. With this option, no two trajectories (mass or wall) should cross for a realistic run.

If NEUN $=2$ or 3

IWAVE IWAVE $\approx 0$ BINT is initial angular vel wo IWAVE $=1$ BINT is initial frequency.

\section{Card 4}

Variables: NSTART, NIN, NCOE, NOR, UMU.

Format: $\quad$ I7, 3Il, E10.2.

\section{Description:}

NSTART $=0$ start from scratch at $T=0$.

$=N$ This is used to restart a run from $T_{0} * N *(10 *$ PRI) where PRI is the print interval.

To use this option, the previous run must have functioned for $T \geq T_{0}$ and since the results are stored in a file Rast, this file nust have been saved. 

spring is to be read in the following cards. (See below.)

NIN = I Fizquires separate data for each mass, each spring and the initial aisplacement.

NIN = 2 This can only be used if the two outer masses and springs are equal, the second and next to last springs are equal, and all the inner springs and masses are equal. A smaller input deck is needed and this option is usually used in conjuncticn with NSTEP $=2$.

NCOF $=I$ The ground dampers $C F \equiv 0$ and the value of spring dampers $C$ are the values read in card 5.

NCOF $=2 \mathrm{CW}$ and $\mathrm{C}$ are computed in subroutine cogr according to: $C(I)=.02 * \sqrt{M(I) \star R(I, 2)} \quad$ For $I=1, N M$. $C(I)=.02 * \frac{M(I-I)+M(I)}{2} * K(I, 2)$

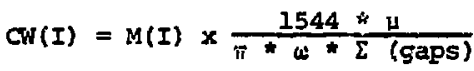

If different formulas are desired, corf can be easily modified.

NOR $=1$ Both walls and all masses are plotted on one graph.

NOR $=2$ Two graphs are plotted.

Graph 1. Displacement of xor and the two left wost masses. Graph 2. Displacements of the six center masses.

UMU Value of coefficient of friction for MCOr $=2$.

\section{Cards $5 i$}

Different sets of cards are used to describe masses and springs depending on value of NIN. 
NIN $=1$

\section{Cards 5a-5d}

Variable: (5a) PM(I)

(5) $\operatorname{xINT}(I)$

(5i:) D1XINT(I)

$$
I=1, \mathrm{NM} \text {. }
$$

(5d) D2XINT(I) .

\section{Fonmat: $\quad 22 \$ 6.2$.}

Description:

FM(I) Value of I'th mass.

XINT(I) Initial displacement from equilibrium of I'th mass.

DlXINT(I) Initial velocity of I'th mass.

D2XINT(I) Initial acceleration of I'th mass.

$$
\text { Dards 5I: I } \quad 1 \text {, NSPR } \quad \text { NSPR }=N M+1
$$

This is actually NM +1 cards, one for each spring.

Variable: $\operatorname{NGAP}(I), K(I, 1), K(I, 2), A I(I), C(I), A 2(I)$.

Format: $\quad$ I10, 5E10.2.

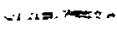

Description:

NGAP(I) determines the nature of the non-linearity of the I'th spring in SUBROUTINE FORiE. Other optional functions can be added to FORCE.

The spring retarding forces on the masses are computed in FORCE. This routine considers the masses to be solid bodies which cannot pass one another.

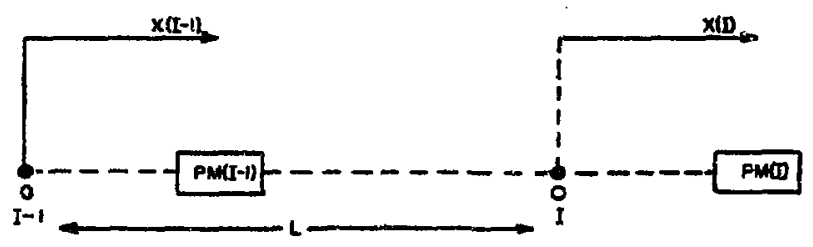

Fig. 3. 
$I$ is the distance between the equilibrium positions of masses I and I - $I$. For the bodies not to pass one another need DIF(I) $=x(I)-x(I-I) \geq-I$. Thus it is necessary for the retarding force $\rightarrow \infty$ as $X(I)-X(I-1)+-I$. In the program this is done by setting $A 2(I)=-L+\varepsilon$ where $\varepsilon>0$ is small and FORCE " $10^{9}$ for $X(I)-X(I-I)<2(I)$ or FORCE $\sim$ Exponential. The present options for the retarding force are

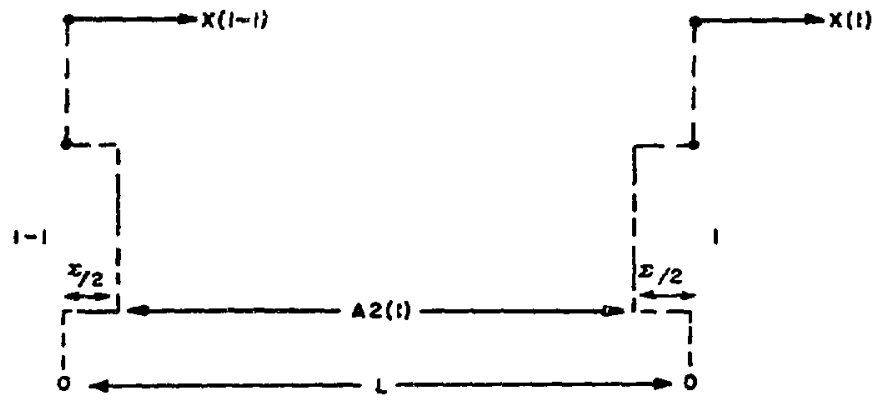

Fig. 4

a) $N G A P=1$

Force $=$ 2-slope linear .

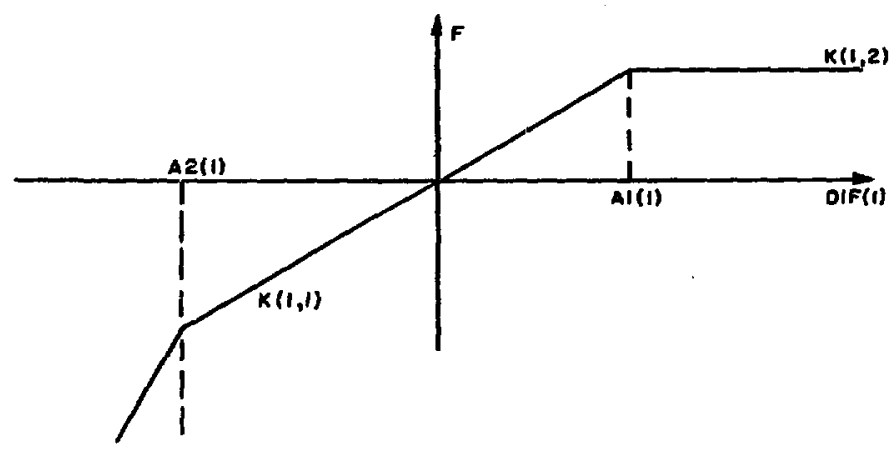

Fig. 5 


$$
\begin{aligned}
& \text { For DIF(I) }<\text { A2 (I) } \quad F(I)=10^{9} \star(D I F(I)-A 2(I))+K(I, 1) \star A 2(I) \\
& A 2(I) \leq D I F(I) \leq A I(I) \quad F(I)=K(I, 1) * D I F(I) \text {. } \\
& A I(I)<\operatorname{DIF}(I) \quad F(I)=K(I, 2) *(D I F(I)-A I(I) ;-K(I, 1) * A I(I)
\end{aligned}
$$

b) $\operatorname{MGAP}=2$

Springs with gaps.

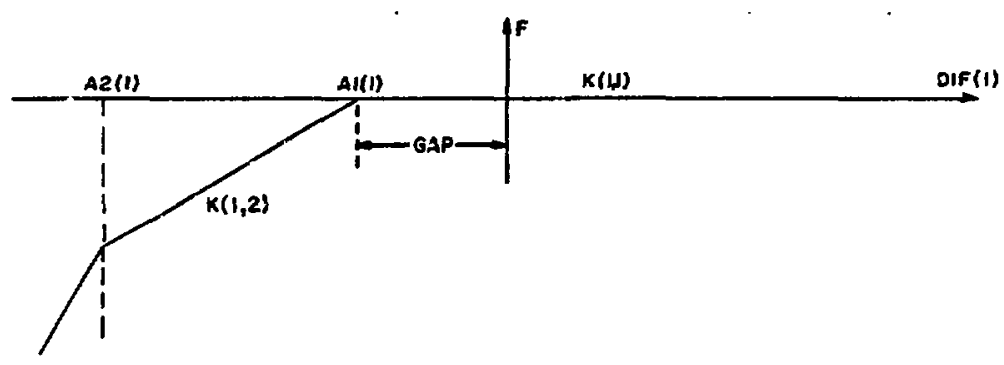

Fig. 6

$$
\begin{aligned}
& \mathrm{DIF}(\mathrm{I})<\mathrm{A2}(\mathrm{I}) \quad F(I)=10^{9} \star[\mathrm{DIF}(\mathrm{I})-\mathrm{A} 2(\mathrm{I})]+\mathrm{K}(2, \mathrm{I}) \star(\mathrm{A} 2(\mathrm{I})-\mathrm{A} I(\mathrm{I})) \\
& A 2(I) \leq D I F(I) \leq A I(I) \quad F(I)=K(I, 2) \times(D I F(I)-A I(I)) \\
& A I(I)<D I F(I) \quad F(I)=K(I, I) * D I F(I) .
\end{aligned}
$$

Note: $\mathrm{A} 2(I)<0, \mathrm{Al}(I)<0$ and must be negative on data card.

For these options, for $\operatorname{DIF}(I)<A 2(I)$ an alternative exponential form for

$F(I)$ can be used viz:

$$
F(I)=K(I, 2) *(1-\operatorname{ExP}(A 2(I)-D I F(I))+\text { other tern }
$$

The exponential function $=\mathrm{K} *(1-\mathrm{e} \quad)$ is taken so that for

$$
\begin{aligned}
& \left|A_{2}-\operatorname{DIF}(I)\right|<\delta, \delta \text { small } \\
& K *\left(1-e^{A 2-D I F(I)}\right) \simeq K *(D I F(I)-A 2(I)) .
\end{aligned}
$$


and

$F(I) \simeq K(I, 2) *(D I F(I)-A I(I))$

i.e. it approxinates the linear part for

$$
A 2 \text { (I) } \leq \mathrm{DIF} \text { (I) } \leq \mathrm{Al} \text { (I). }
$$

However the steep slope seems more realistic.

c) $\operatorname{WGAP}=3$

Retarding force cubic

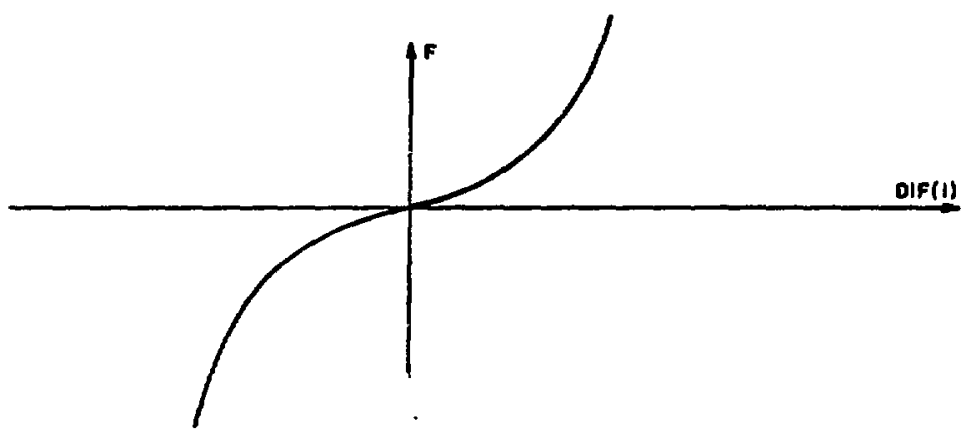

Fig. 7

$$
F(I)=R(I, 1) \star[D I F(I)]^{3} \text {. }
$$

$C(I)$ - Thege are damping coeffieients to be used if $\mathrm{NCOF}=1$.

NIN $=2$.

\section{Card 5a}

Variable: PM(1), PM(2).

Format: $\quad 2$ F 6.2 .

\section{Degcription:}

PM(1) - value of 2 outer masses.

PM(2) - Value of all the inner masses. 
Here the initial displacments, velocities and accelerations are all taken to be zero if NSTART $=0$.

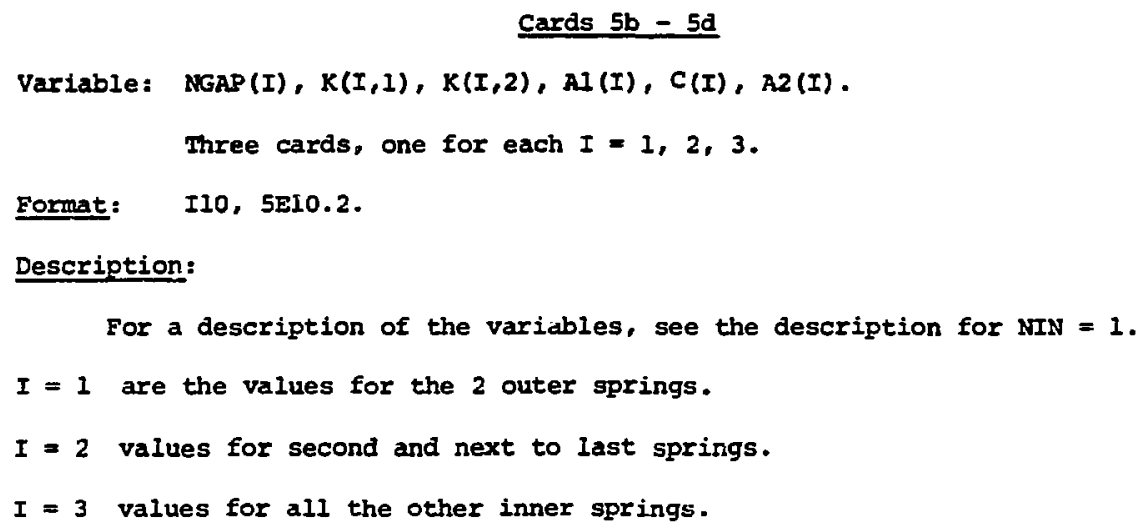

\section{Card 6}

Variables: PRI, FINTIM, TINT, METH, ERR.

Format: $\quad 3 E 10.2$, IIO, EIO.2.

\section{Description:}

PRI - Print interval of results. (seconds). At present displacements of XOL and first three masses are printed, as well as velocities of first three masses. Also the time, frequency (for NFUN $=2$ or 3), and present integration step size are printed. If different variables are desired, this can be done with a call to PRHYF (RRI, FINTIM, DONE, A, B, C, D, E, F, G, O, P, Q) where values of the alphabetic characters are the variables to be printed.

FINTIM - Camputations end at FINMIM. 


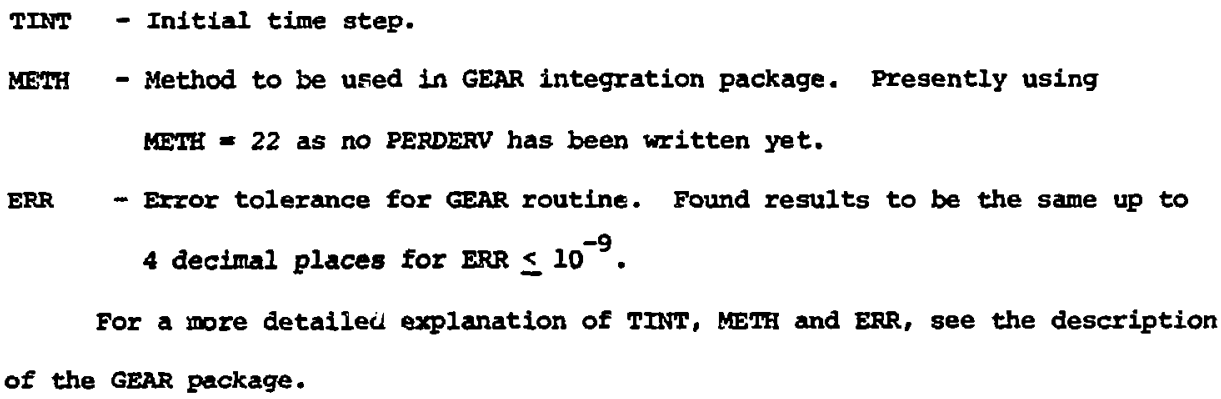

\section{Card 7}

Vaxiables: SCAI, CPT.

Format: $\quad 2 E I 0.2$.

\section{Description:}

SCAI - Scaling factor for graph. SCAL is the value of the tenth position from the origin (i.e. where the first I occurs). It was decided that the user should supply the scaling factor rather than have the scaling automatic, as usually many variables with vexy different orders of magnitude are plotted on the same graph. Thus, the scaling factor is chosen for the variable of most interest in the run.

CPT - Maximum machine time (CPU time) in decimal seconds to be allowed for a run. If this time is reached before the simulation time FINTIM, the run is automatically ended and the results at this point are printed and plotted. 
Input Deck - For a description of variables and how they should be used see the following section.

\begin{tabular}{|l|l|}
\hline WORO & \\
\hline COLUMN & \\
\hline FORMAT & $8 A 10$. \\
\hline & \\
\hline CARO & Descriptive title for problem. \\
& \\
\hline SYMQOL & TITLE \\
\hline
\end{tabular}

Card 1

problem title

Format 8 A10.

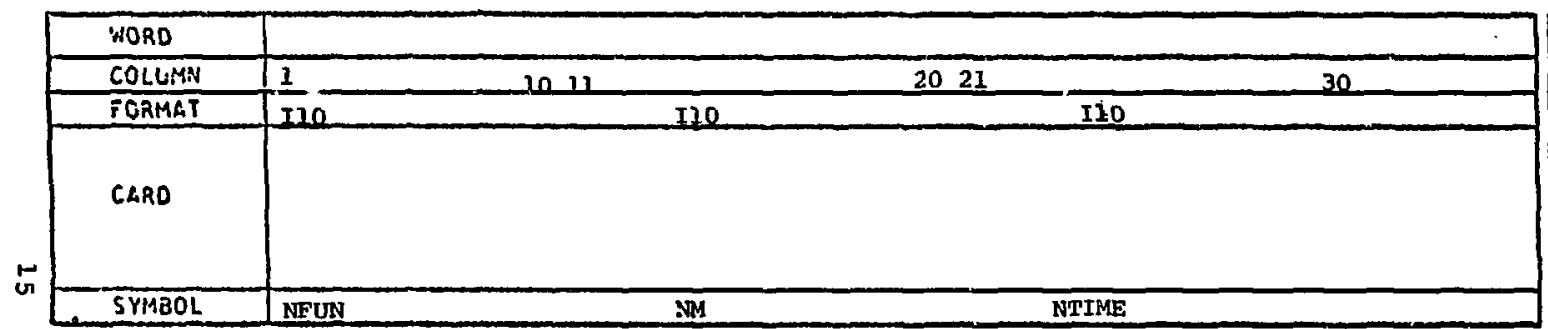

\section{Card 2}

Format 3 I10

NM - * of masses

NTIME $=\#$ of runs

NFUN = Nature of

Forcing Function

\begin{tabular}{|c|c|c|c|c|c|c|}
\hline WORD & & & & & & \\
\hline COLUMN & 10 & 20 & 30 & 40 & 50 & 60 \\
\hline FORMAT & 520.2 & 510.2 & E10.2 & F10.2 & I10 & IIO \\
\hline CARD & Factors & bing Eor & Function & Nature of & lem. & \\
\hline SYMBOL & $A$ & BINT & FRQ & ALPHAI & NSTEP & IWAVE \\
\hline
\end{tabular}

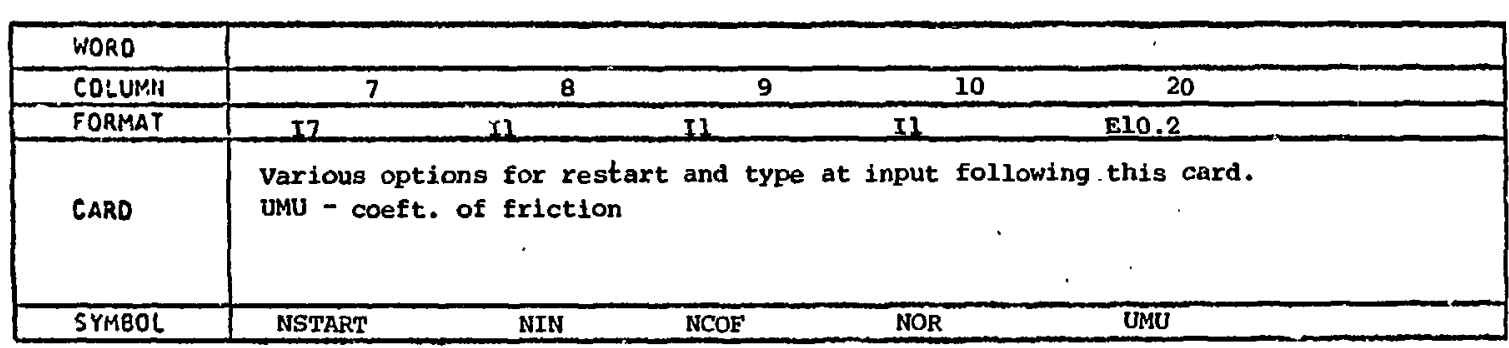

\section{Carà 4}

Format I7, 3I1, E10.2 Input data options.

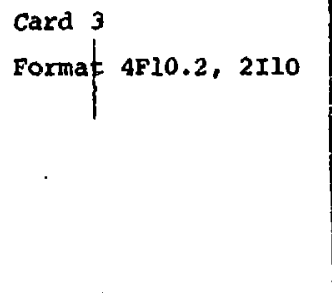

.


The following caids for NIN=1

\begin{tabular}{|l|l|l|}
\hline WORO & This card only if NIN=1 \\
\hline COLUMN & 6 & 12 \\
\hline FORMAT & F6.2 & F6.2 \\
\hline & & \\
CARO & Value of masses. \\
& & \\
\hline SYMEOL & PM(1) & PM(2) \\
\hline
\end{tabular}

Card 5a. NIrml

12 F 6.2

$P M(I) \quad I=1, N M$

Card 5b. NIN=1

12 F 6.2

XINT (1) $I=1, N M$. XINT (12)

เด

\begin{tabular}{|c|c|c|}
\hline WORD & This card only if NTNel & . \\
\hline COLUMN & 12 & 72 \\
\hline FORMAT & $\begin{array}{ll}56.2 & F 6.2 \\
\end{array}$ & $F G .2$ \\
\hline CARO & XINT - Initial positions. & \\
\hline
\end{tabular}

\begin{tabular}{|c|c|c|}
\hline WORD & This card only if NIN=1 & \\
\hline COLUM: & 6 & 72 \\
\hline FORMAT & F6.2 & 56.2 \\
\hline CARD & DlXINT - Initial velocjties. & \\
\hline cyungl & 27 & \\
\hline
\end{tabular}

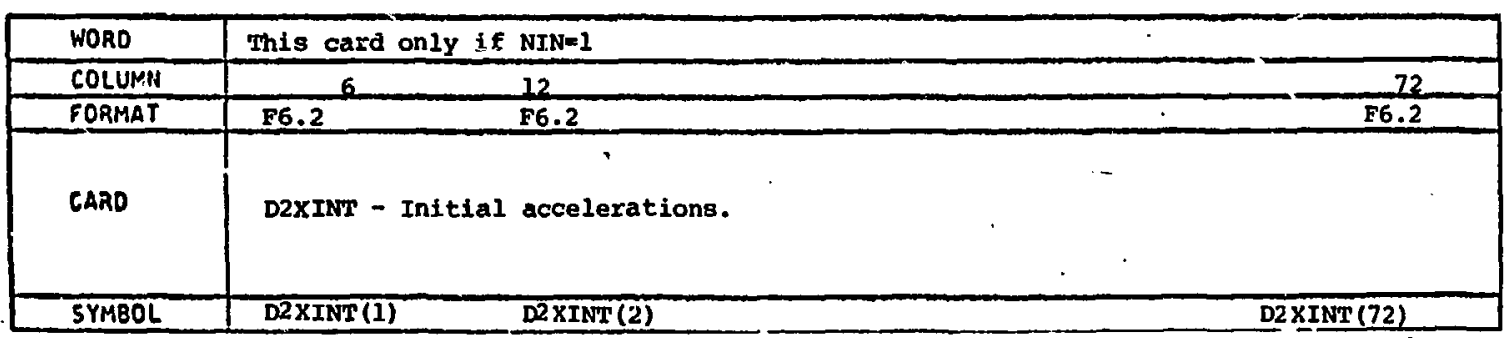

Card 5c NIN=1

12 F 6.2

DlXINT (I) I-1, NM

Card 5d NIN=1

12 F6.2

D2XINT(I) $I=1$, NM 


\begin{tabular}{|c|c|c|c|c|c|}
\hline WORO & \multicolumn{5}{|c|}{ These cards only if NIN=1, NISPR cards. } \\
\hline COLUMN & 10 & 30 & 40 & 50 & 60 \\
\hline FORMAT & E10.2 & E10.2 & E10.2 & EI0.2 & E10.2 \\
\hline CARO & Spring parameters $f$ & ach spri & {$[=1, \quad$ I'SPF } & & \\
\hline SYMEOL & $K(x, 1)$ & $K(I, 2)$ & Al(I) & $C(I)$ & A2 (I) \\
\hline
\end{tabular}

Card 5 I NIN=1

$I=1$, NSPR

One card for each

spring

Format I10, 5E20.2

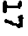

\begin{tabular}{|l|l|}
\hline WORO & \\
\hline COLUMN & \\
\hline BCRMAT & \\
\hline CARO & \\
& \\
\hline SYMBOL & \\
\hline
\end{tabular}

\begin{tabular}{|l|l|}
\hline WORD & \\
\hline COLUMH & \\
\hline FORMAT & \\
\hline & \\
\hline CARD & \\
& \\
\hline SYMBOL & \\
\hline
\end{tabular}

\begin{tabular}{|l|l|}
\hline WORO & \\
\hline COLURAN & \\
\hline FORMAT & \\
\hline CAKO & \\
\hline SYMEOL & \\
\hline
\end{tabular}
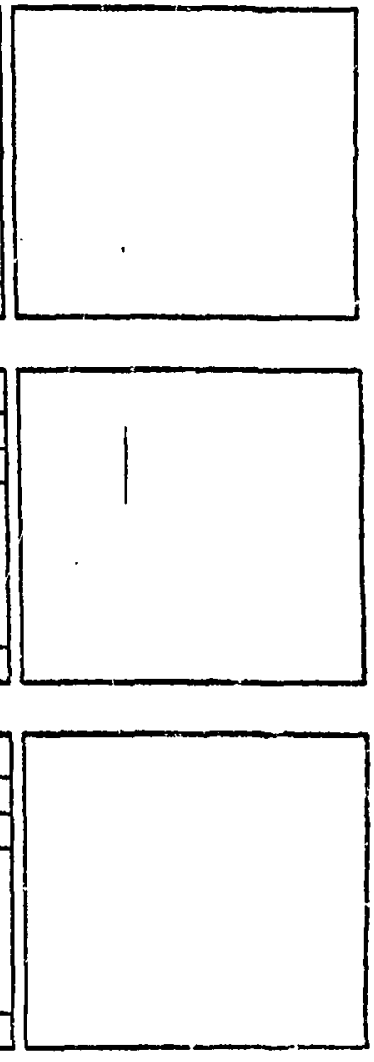
The following cards for $N I N=2$

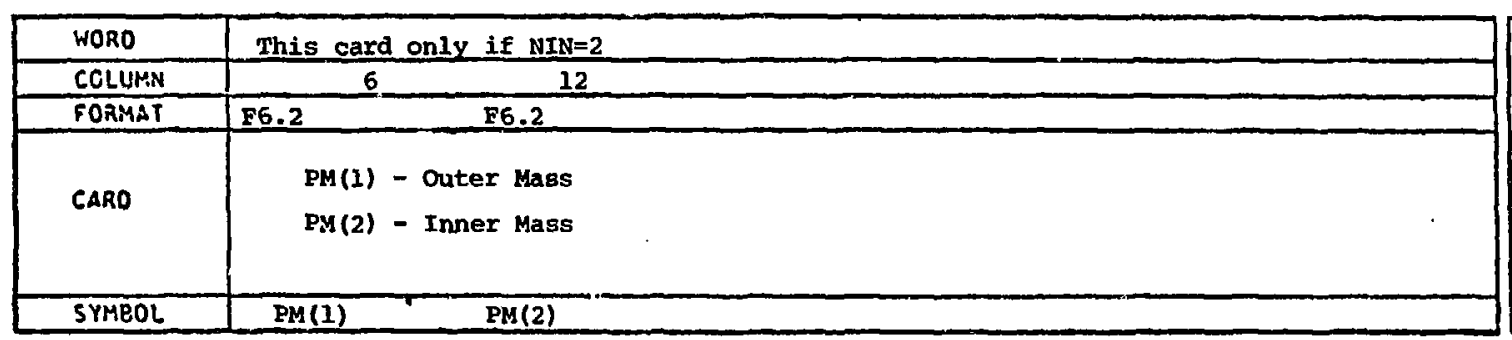

Card 5a. $\quad \mathrm{NIN}=2$

Format 2F6.2

symmetric problems

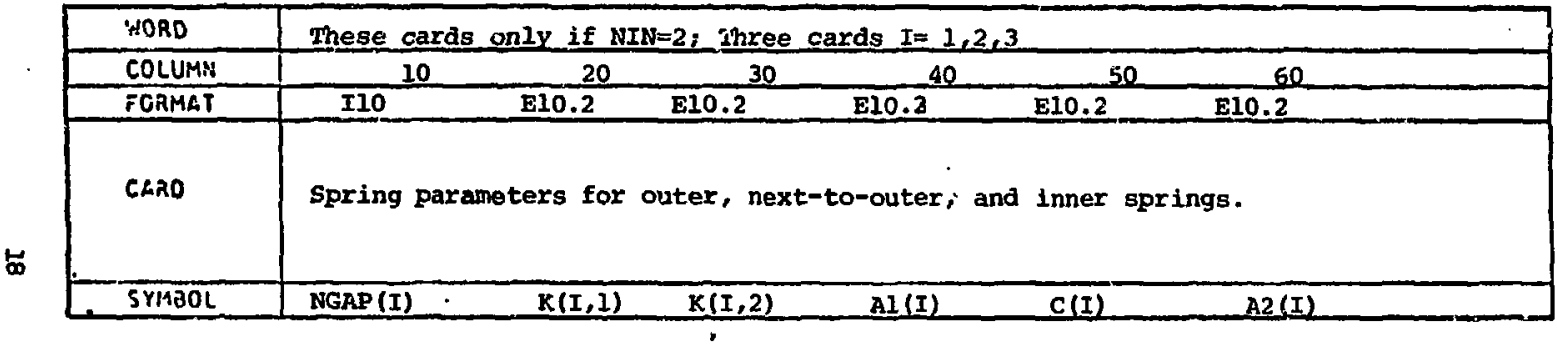

Cards $5 b-5 d \quad$ NIN $=2$

$I=1,2,3$

Format I1C, 5E10.2

\begin{tabular}{|l|l|}
\hline WORD & \\
\hline COLUMM & \\
\hline FORMAT & \\
\hline CARO & \\
\hline SYMCOL & \\
\hline
\end{tabular}

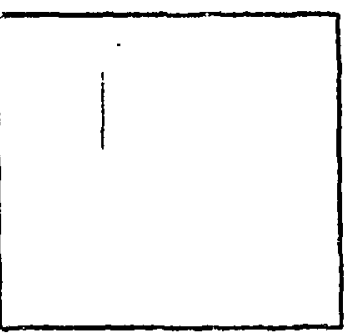

\begin{tabular}{|l|l|}
\hline WORD & \\
\hline COLUMA & \\
\hline FORMAT & \\
\hline CARO & \\
& \\
\hline SYMEOL & \\
\hline
\end{tabular}

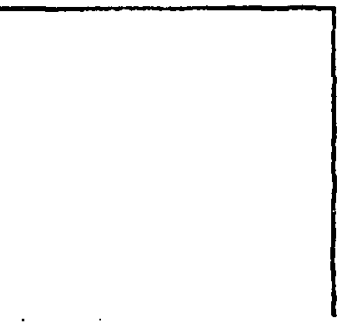




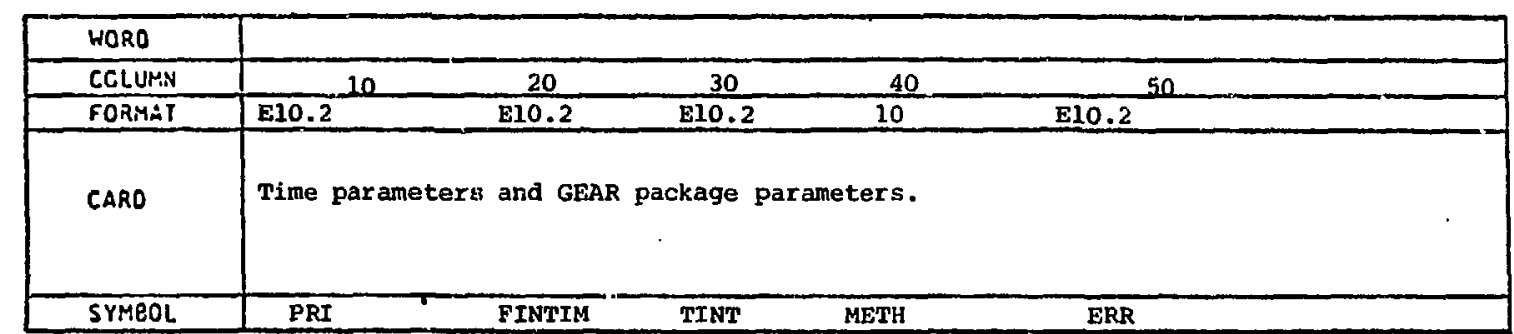

card 6

- crmat

j=10.2, Ilo, E10.2

PRI - Print interval

FINTIM - Finish time

TINT

METH- Gear package

ERR Parameters.

\begin{tabular}{|c|c|}
\hline WORD & \\
\hline COLUM:I & 10 \\
\hline BCAMAT & E10.2 \\
\hline CARD & $\begin{array}{l}\text { SCAL - Scale for graph } \\
\text { CPT - Max execution time allowed for problem. }\end{array}$ \\
\hline SYMROL & SCAI \\
\hline
\end{tabular}

Card 7

Format 2E10.2

\begin{tabular}{|l|l|}
\hline WORO & \\
\hline COLUMA & \\
\hline FORMAT & \\
\hline CARD & \\
\hline SYMEOL & \\
\hline
\end{tabular}

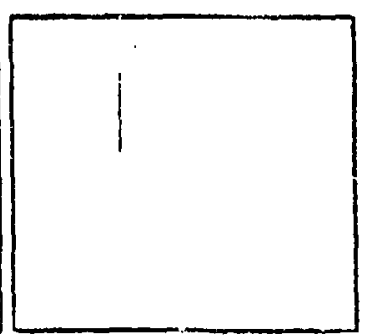

\begin{tabular}{|l|l|}
\hline WORO & \\
\hline CO:UMM & \\
\hline FORMAT & \\
\hline CARO & \\
\hline
\end{tabular}

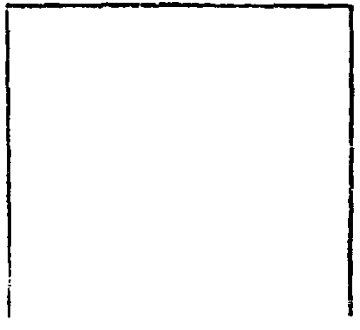


Mumerical Integration Technique - Methods of c.W. GEAR

Very little mention is made of the nature of the numerical methods used in the reports of other core seismic analysis codes $(1),(2),(3)$. However, there should be concern about the convergence and the stability of the solutions of the type of differential equation that arise in this analysis.

Since the system of equations have rapidly varying terms and widely varying time constants, they fall into the class of sifif differential equations, which need particular methods of solution as deteloped by GEAR ${ }^{(4)}$ over the last few years. OSCII uses a GEAR package written by A.C. Hindmarsh ${ }^{(5)}$.

In the model the springs used to simulate collisions between blocks is depicted by the graph below

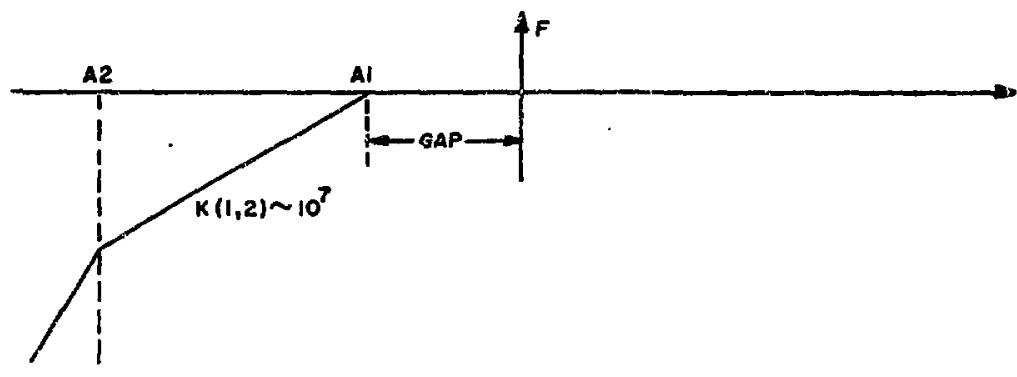

Fig. 8

As in GEAR (4) the system of equations with $k_{i}$ as in the above figure are stiff for two reasons:

i) The high stiffness constants $O[R] 210^{6}-10^{7}$ of the blocis imply a ver, small time constant and small integration step $h$. Must have $O[h] \approx 10^{-12}$ $10^{-15}$ sec when the blocks are in contact to maintain a relative error $\leq 10^{-7}$ at a particular time step. But the time constants corresponding to the seismic oscillations $0[1 / \omega] \sim 1$ sec. 
ii) Since there are gaps between the blocks, the forces (and hence the accelerations $\ddot{x}_{i}$ ) on the blocks have discontinuous first derivatives. Mis means that the equations are stiff around Al even if the springs are soft. The property of stiffness is local; the equations are stiff for some regions of $t$ and not in others. For this system of equations the time constants are widely varying. Most conventional methods for solving ODE's require incremental values of $t$ ccmmengurate with min $\tau_{i}$ (where $\tau_{i}$ are the t.jme constants associated with the sysrem, and obtained from the eigenvalues of the Jacobian). Min $\tau_{i}$ is small for large $K_{i}$, while the size $\mid T$ - to| of the problem range is commensurate with the period of the forcing function $\sim$ secs. As a result, the problem cannot ba run to completion in a reasonable number of steps using conventional methods.

In the GEAR package the step size and order of integration are automatically varied to maintain optimun efficiency within an error tolerance set by the user. It iterates at each step until an equilibrium solution is found (within error tolerance).

To test the reliability of any given calculation, the user increases or decreases the error tolerance rather than the step size as in other methods of numerical integration. It was found that for $K \simeq 3 \times 10^{7}$ the solutions are constant for an error tojerance $\leq 10^{-9}$ for any number of masses.

For a detailed explanation of these terms and features, see (6). The use of GEAR is described in (5), attached with this report. 


\section{Program Description:}

The subroutines of OSCIL - RDIN, COEF, CLEAN, RESTART, F... DRIVE, DIFE'TN, FORCE, PRWTF, PROUT, STORE, PLOTV PIUs the subrouicines of DRIVE ars progranmed in a fairly well-structured manner.

\section{Diagram (1)}

Overall structure of oscIL. A downwara sloping line from one box to another indicates that the lower routine is called by the upper one.

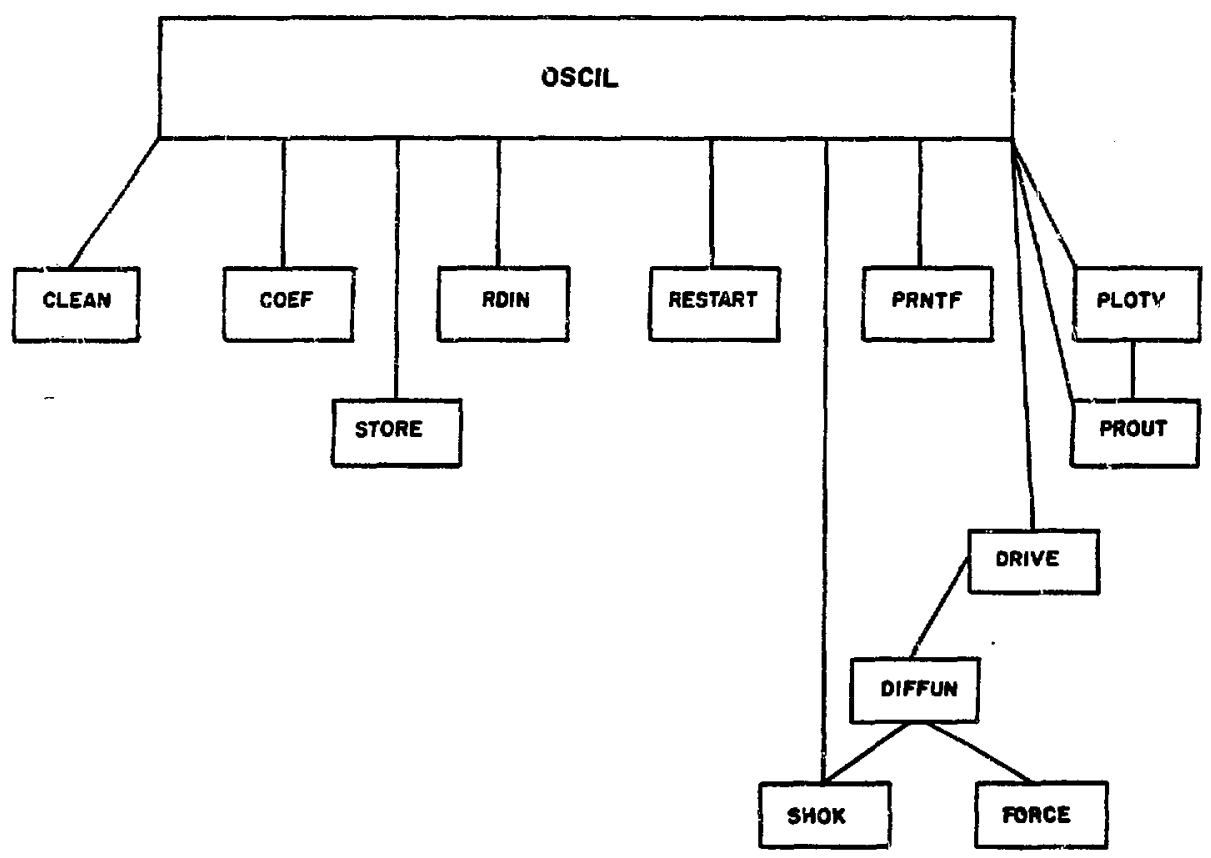


Subroutine Functions

1) CLEAN - Initializes at start of run

2) COEF - Evaluates damping coefflcients - See description of input

3) RDIN - Reads in data

4) PROUT - Prints some regults

5) PRNTF - Prints results and increases print interval

6) RESTART - Reads tapes for restarting

7) STORE - Stores displacements for use in PLOTV

8) PLOTV - Plots displacements of masses

9) DRIVE - Integrates system of differential equations

10) DIFFUN - Sets up equations for given time $T$

11) SHOK - Describes forcing fusction of walls

12) FORCE - Determines forces on springs 


\section{Diagram (2)}

Macroscopic flow chart of OSCII showing main features. For flow chart of DRTVE, SES (5).

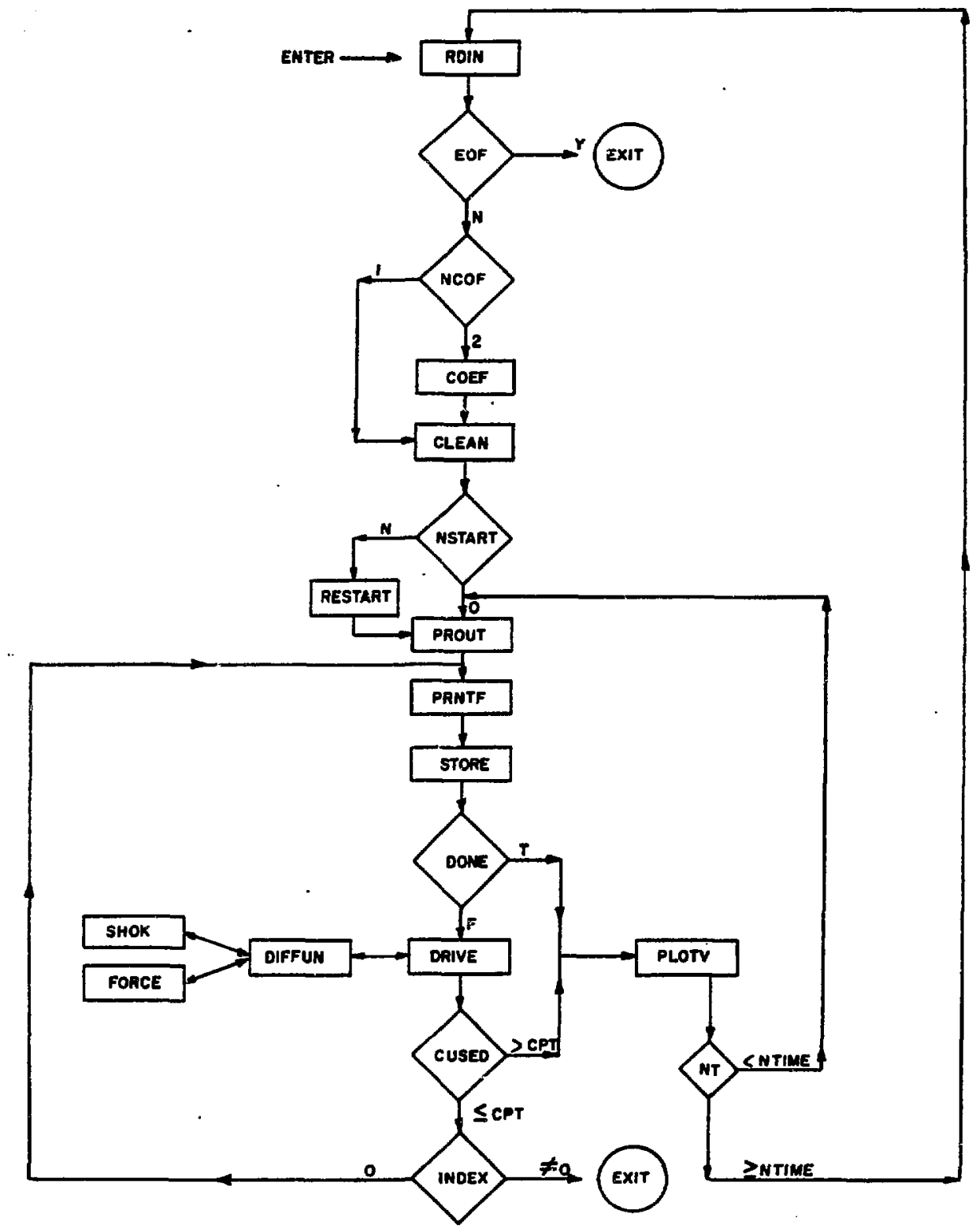


Sample Input

Seven mass symmetric problem. The input deck for this problem is given below using both the option NIN $=1$ and NIN $=2$.

A: NIN $=1$

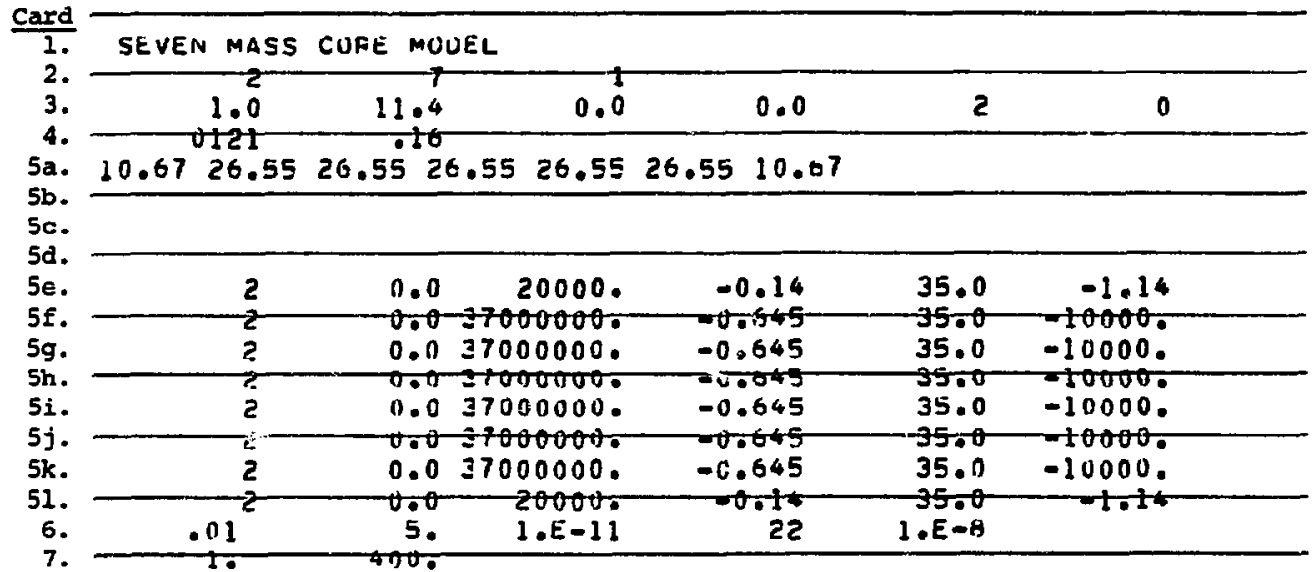

B: $N I N=2$

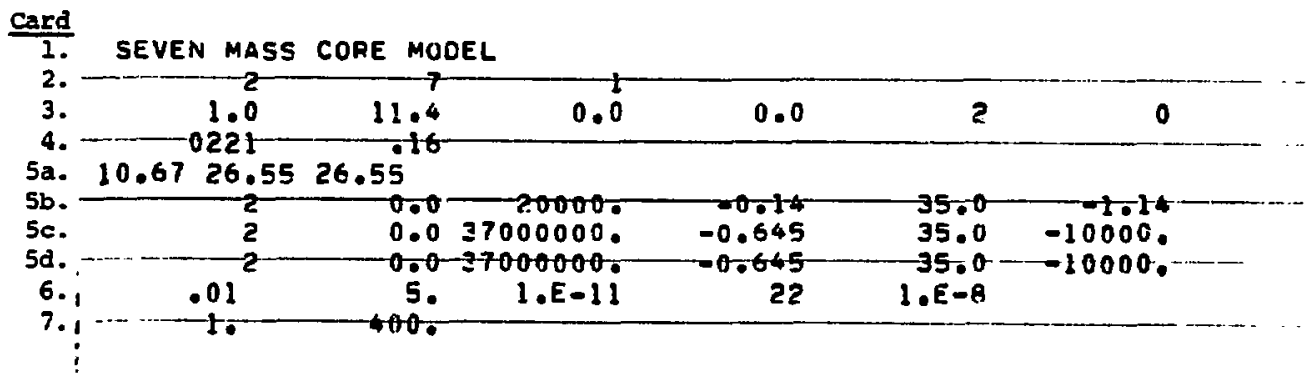




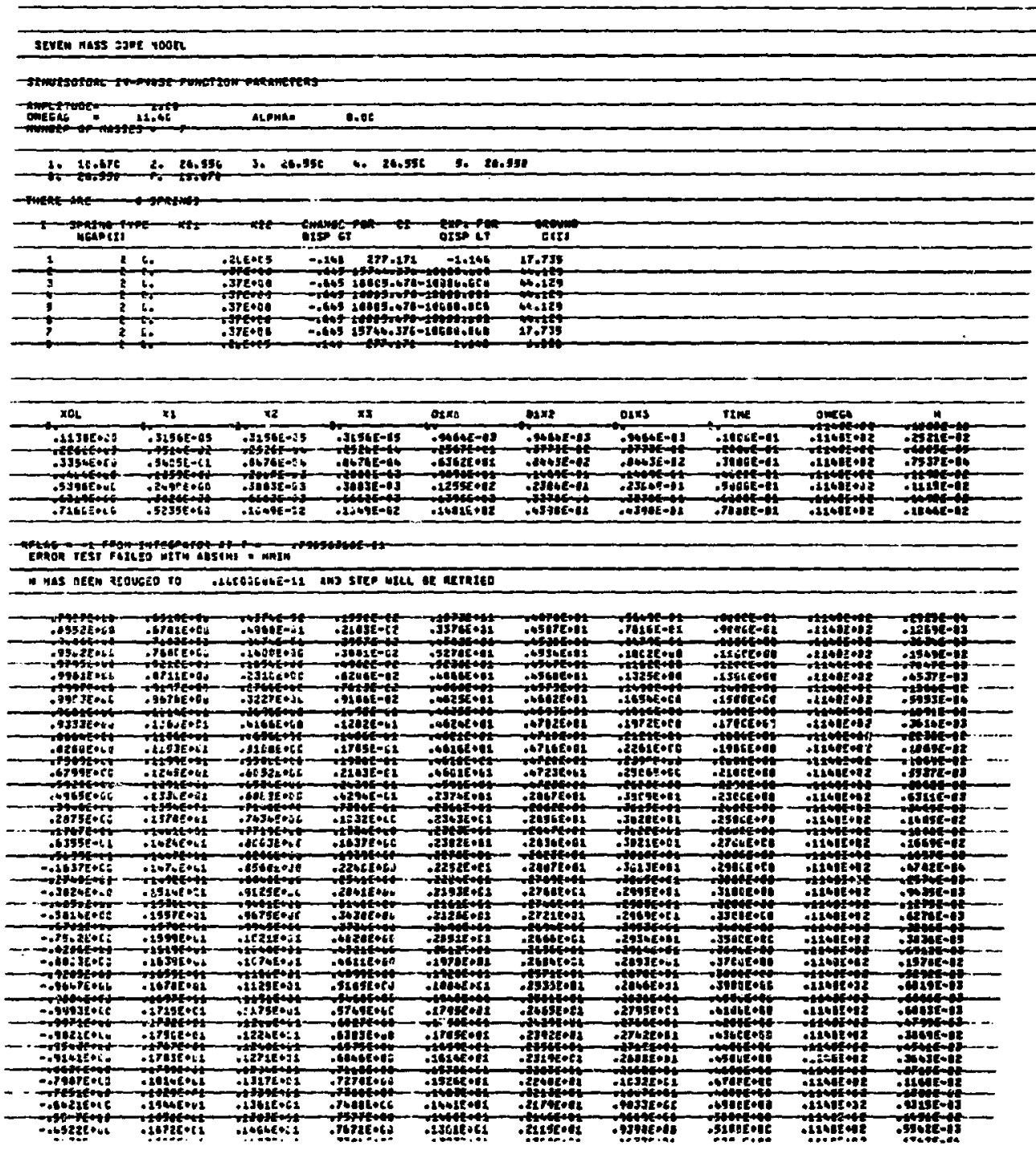




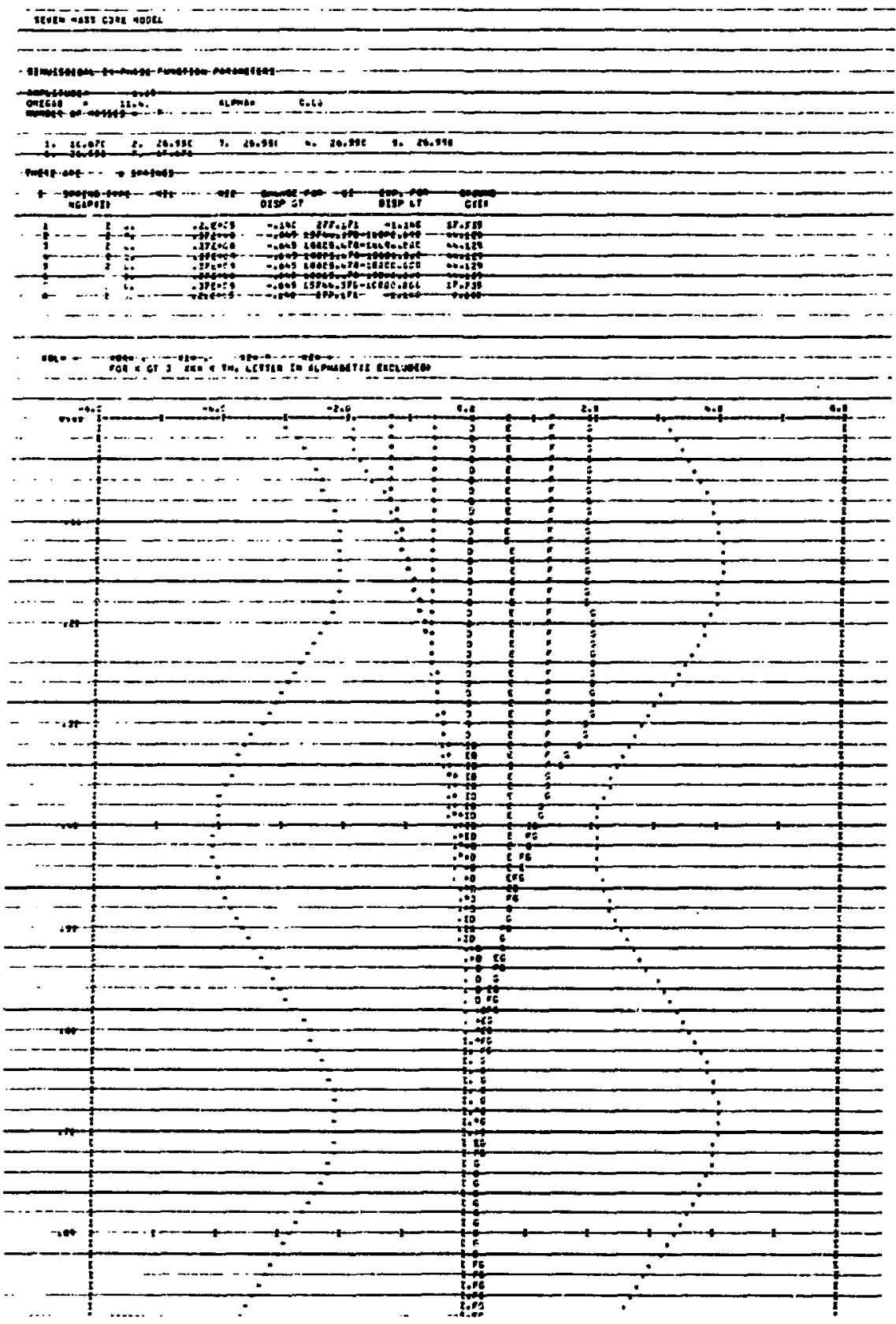


PART II

Testing of oscII

\section{Hodel Description}

To evaluate the effects of selsmic response, the following quantities must be known.

(1) Material properties - the modulus of elasticity, poisson's ratio, density and yield strength applicable to the fuel elements, the top, botton and side reflector elements, the supnort posts and blocks, the borinated shields and the dowels.

(2) Geometric conditions - dimensions of all reflector elements, support blocks and posts, borinated shield, spring packs and dowels; the operational clearances between all elements including the dowel pin and hole clearances.

(3) The scaling method used in three dimensions as applied to the various blocks, clearances, springs and posts, the forcing function characteristics; the tegt fixture structural and dynamic characteristics.

An analytical evaluation of the seismic response informstion presented in the HugR Nuclear Training Manual has been made. In particular, Section 5 of the Manual is concerned with the Core Seismic Program. A figure in the Hanual shows the core motion characteristics in response to an input of $3.5 \mathrm{~Hz}$. The core is pictured as consisting of three masses with clearances between each. Springs are located at the outside ends of the segmented core masses. The central mass represents the core while the two outer masses represent the reflector blocks. The springs represent the spring packs.

One of the cores lookid at was composed of 3944 blocks arranged in 493 vertical stacks. Reflector blocks are arranged around the outside circumference 
of the core stacks. Radial springs are located between a borinated shield and the outer shell of the structure. The borinated shield is adjacent to the outside surface of the reflector blocks. The model represented in the HTGR Manual and shown in Figure 9 shows a single layer through a typical cross section of the core.

It was decided that the information presented in the FTGR Manual soula be evaluated analytically. To do this a mathematical model representing a single layer of elements was considered. This is shown in Figure 1 . The core structure is represented by a series of masses $m_{1}, m_{2}, \ldots, m_{i}, \ldots, m_{n}$ The elastic properties between adjacent masses are indicated by $k_{i}$. The elements designated by $K_{1}$ and $k_{n+1}$ represent the elastic constants of the reflector blocks when in contact with the spring packs and borinated shield. The elements designated by $\mathrm{K}_{2}$ to $\mathrm{x}_{\mathrm{n}}$ represent the elastic properties of adjacent fuel elements when in contact. For the initial model, general damping is assumed to occur whenever there is a relative velocity between adjacent masses. clearances between adjacent masses are given by $A_{i}$. Motional inputs to the system are provided by xOL on the left and xOR on the right.

The equations of motion for the system in Figure 1 are given on p. 2. OSCIL was written to describe the motion of the general, in-line, $n$ degree of Ereedom system. 


\section{CORE MOTION CHARACTERISTICS}

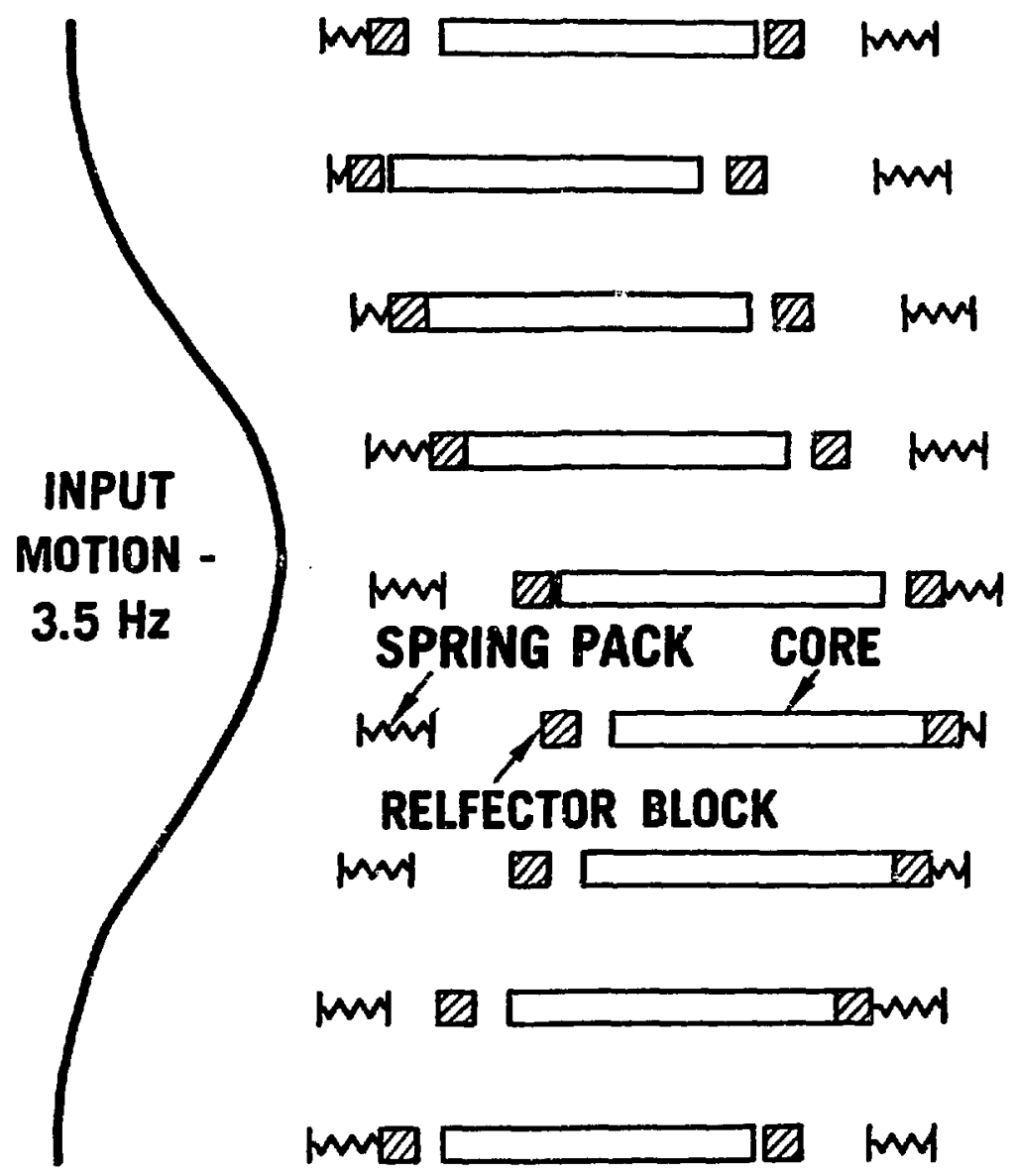

FIGURE 9 


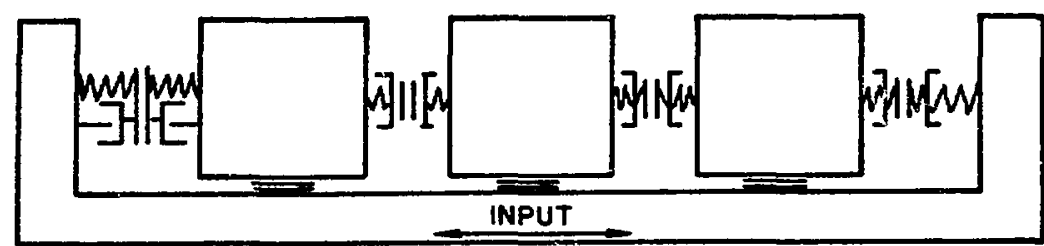

3 MASS SYSTEM

WHERE :

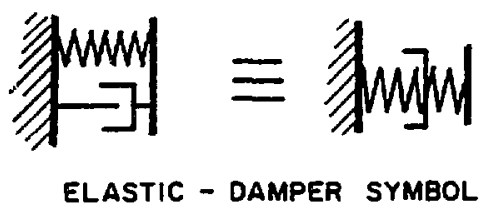

FIGURE 10

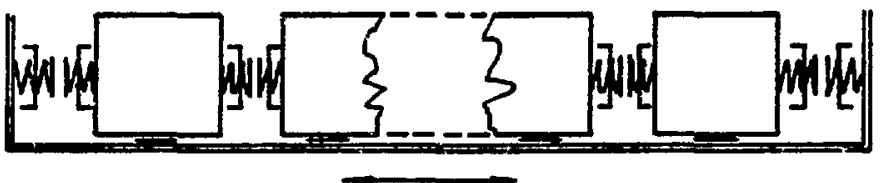

"N" MASS SYSTEM

FIGURE I| 
Test Cases

Initially several simple cases were considered. In partjcular, two and three degree of freedom systems were investigated for harmonic inputs at either end. The inputs were either in phase or out of phase with each other. These cases were investigated since some response characteristics could bs predicted. These known solutions were used to check out the accuracy of the computer program.

Six cases were solved and the results examined to check out the program. Specifically, the program was tested to determine whether the introduction of non-linearity into some of the parameters could be properly processed. These parameters include the clearances, the non-linearities, the damping and the inputs, The six cases, and the range of the parameters used in each, are shown in Eigures 12a through 12f. For all of these, a simple sinusoidal forcing function of unit amplitude $(A=1)$ and adjustable frequency (B) was used. In the general proskam, the inputs may be independently specified. However, for the test cases to be presented the inpits are of equal magnitude and either in phase or 180 degrees out of phase with each other.

Case 1, Figure 12a, was a simple, undamped, linear, two degree of freedom system with symuetr: cal inputs at either end. Equal masses and springs were used. Because of symetry, the response should be equivalent to that of a single degree of frtedom system. Ithis occurs if both masses respond with equal displacement so that the relative motion $\left(x_{1}-x_{2}\right)$ j.s zero. A typical output from the computer for case I is show in Table I. This shows the values uf displacements $X_{1}$ and $x_{2}$, the frequency $B$, the inputs $x_{0}$ and the velcaities of each mass. The range of the frequency (B) was varied frcm zero to a value of 
$10 \mathrm{rad} / \mathrm{sec}$. This range of inputs covers the resinance characteristics of thr: system. The printout is in interyals of $0.5 \mathrm{rad} / \mathrm{sec}$. As exproted, the 1 is:ed values of $x_{1}$ and $x_{2}$ in Table $I$ are identical.

Case 2, shown in rigure $12 \mathrm{~b}$, depicts a linear, damped, sprirg-mass system. The damping was introduced only at the outer ends because the response for such a condition is known to be essentially equivalent to that of a one degree of freedom system. Figure 13 is a plot of the computer results for an input frequency of $6.0 \mathrm{rad} / \mathrm{sec}$ and a damping coefficient of 0.1256 . Figure $.3 \mathrm{a}$ shows the response for the first 10 seconds. The response has within it the: initial conditions of zero displacement and zero velocity. Figrure $13 \mathrm{~b}$ shows an extended plot of the maximum values only. As can be seen from the figures the initial transient has diminished and the response is attaining its steady state level. This checks with the known response for these conditions.

Case 3, shown in Figure 12c, involves a damped, spxing-mass system with a non-linear breakpoint. This case is introduced to estatilish the capability of the program to handle non-linear spring characteristics. For this case, the spring has a hard-soft breakpoint characteristic. $\mathfrak{K}_{11}$ is the spring constant for small deflections while $\mathrm{K}_{12}$ is the spring constant for larger relative deflections. The breakpoint occurs at a relative displacement of 10. Springs $K_{1}$ and $k_{3}$ both have this non-linear characterist:ic. $K_{2}$ is a linear sping over the entire range.

Figure 14 shows a plot of the displacments $x_{1}$ and $x_{2}$. Comparing these results with Figure 13a, the plot for an identical but linear system, the effects of the non-linear springs are readily identified. Beyond this the breakpoint is encountered which introduces the non-linearity and hence, as expected, the curves differ. 
CASE I UNDAMPED LINEAR SPRING - MASS SYSTEM

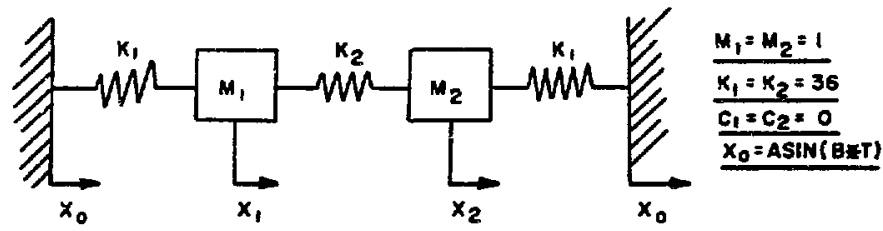

FIGURE 120

\section{CASE 2 DAMPED LINEAR SPRING - MASS STSTEM}

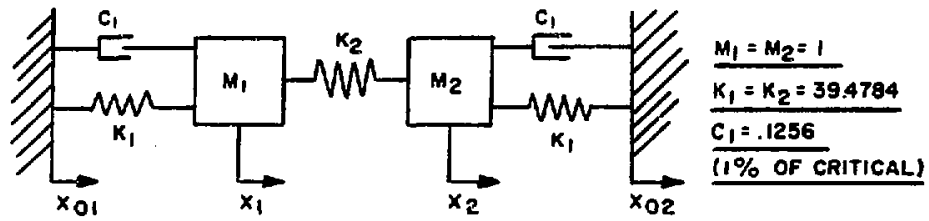

FIGURE I2b

\section{CASE 3 DAMPED SPRING -MASS SYSTEM WITH}

\section{NONLINEAR BREAK - POINT}

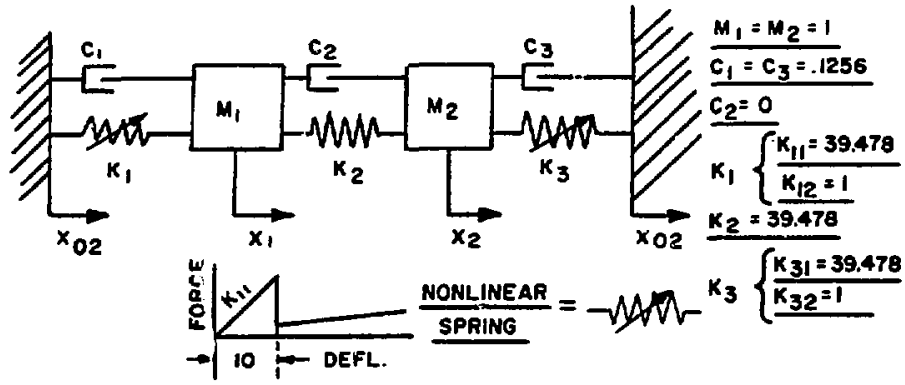

- FIGURE I2e 


\section{CASE 4 DAMPEO SPRING - MASS SYSTEM WITH}

\section{NONLINEAR BREAK-POINT}

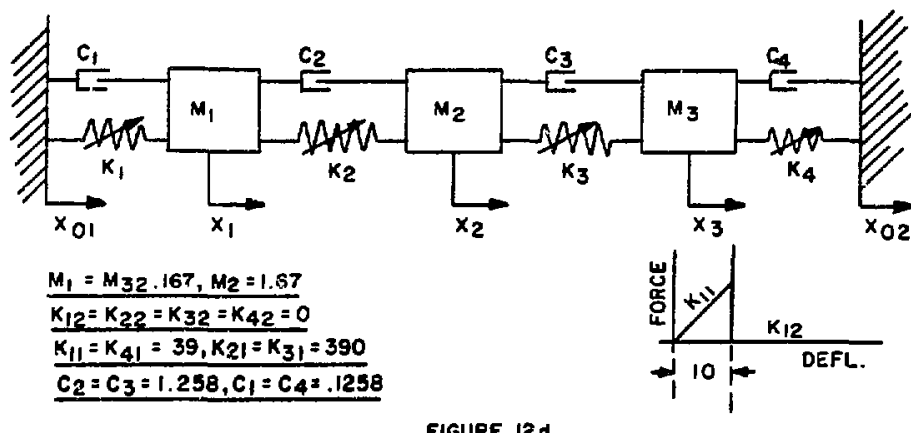

FIGURE 12d

\section{CASE 5 DAMPED SPRING - MASS SYSTEM WITH CLEARANCE}

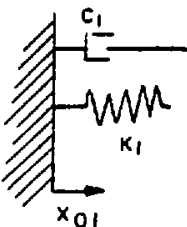

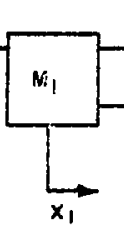

$\mathrm{C}_{2}$

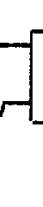

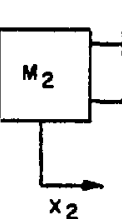

$c_{3}$

$\mathrm{WW}_{3}$

$x_{2}$

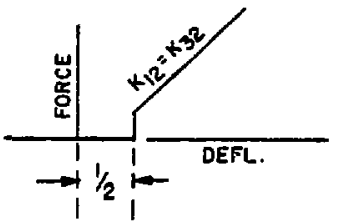

FIGURE 12 e
$M_{1}=M_{2}=1$

$C_{1}=C_{3}=.1256$

$c_{2}=0$

$K_{2}=39.478$

$K_{11}=K_{31}=0$

$K_{12}=K_{32}=39.478$

$\mathrm{a}=6$ 


\section{CASE 6 DAMPED SPRING-MASS SYSTEM WITH CLEARANCE}

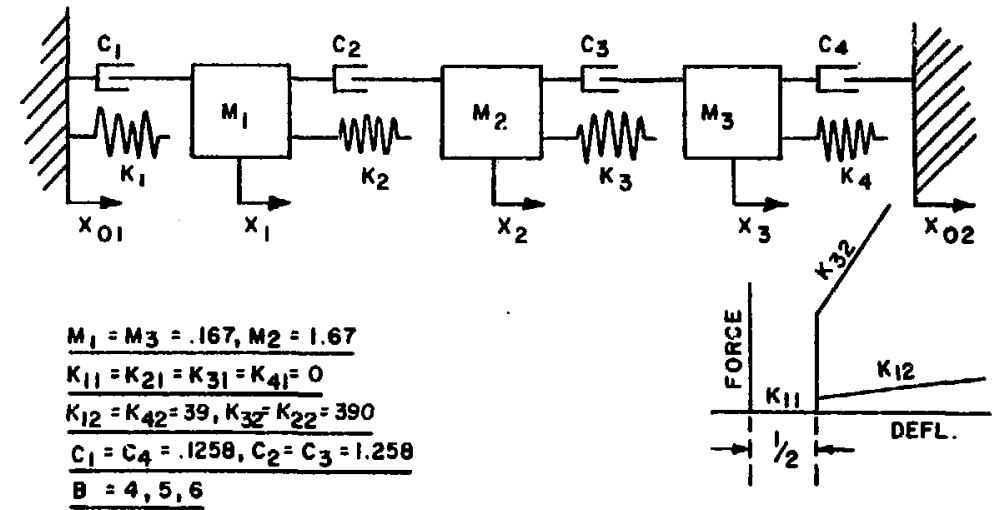

FIGURE 121 
LE

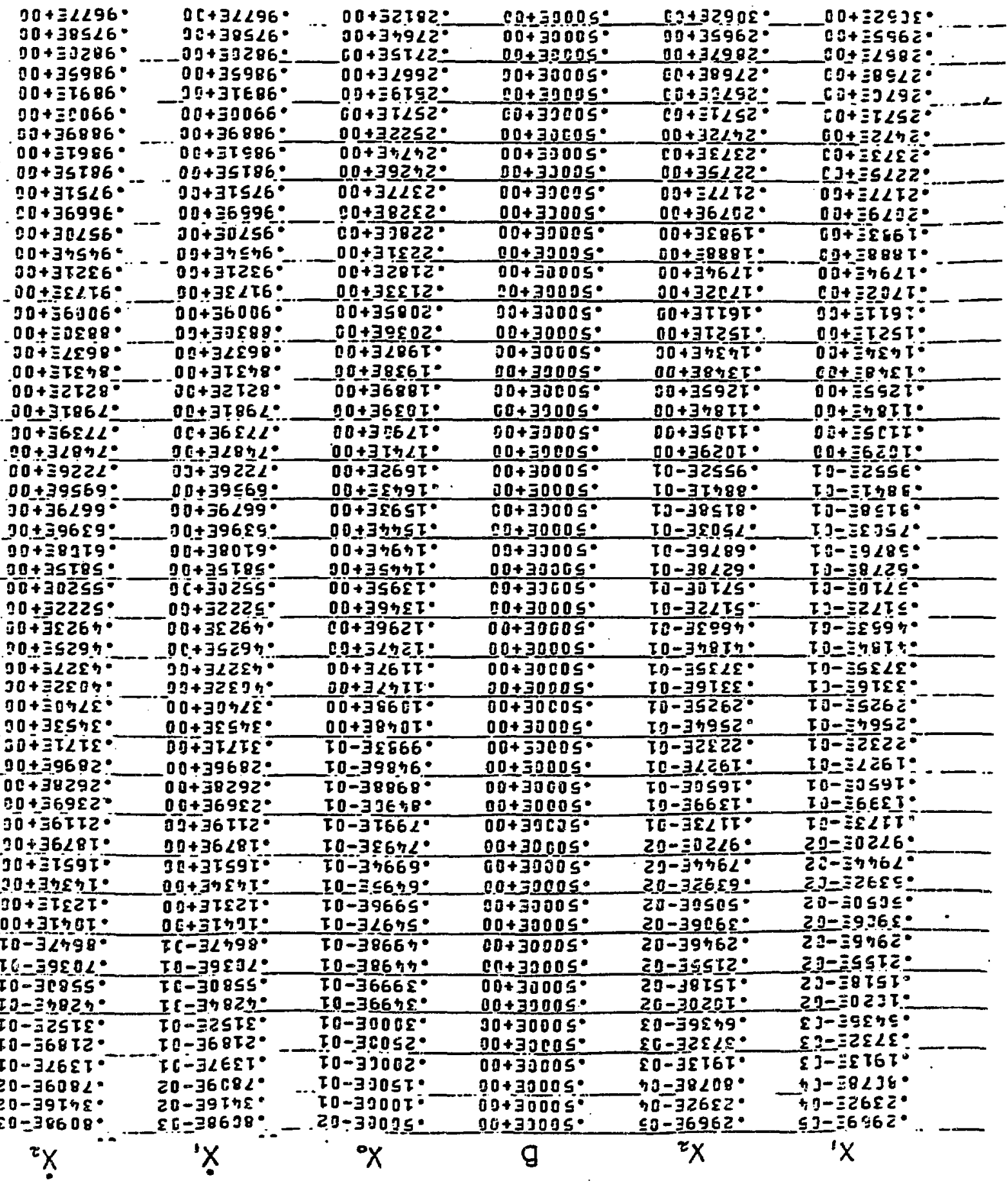



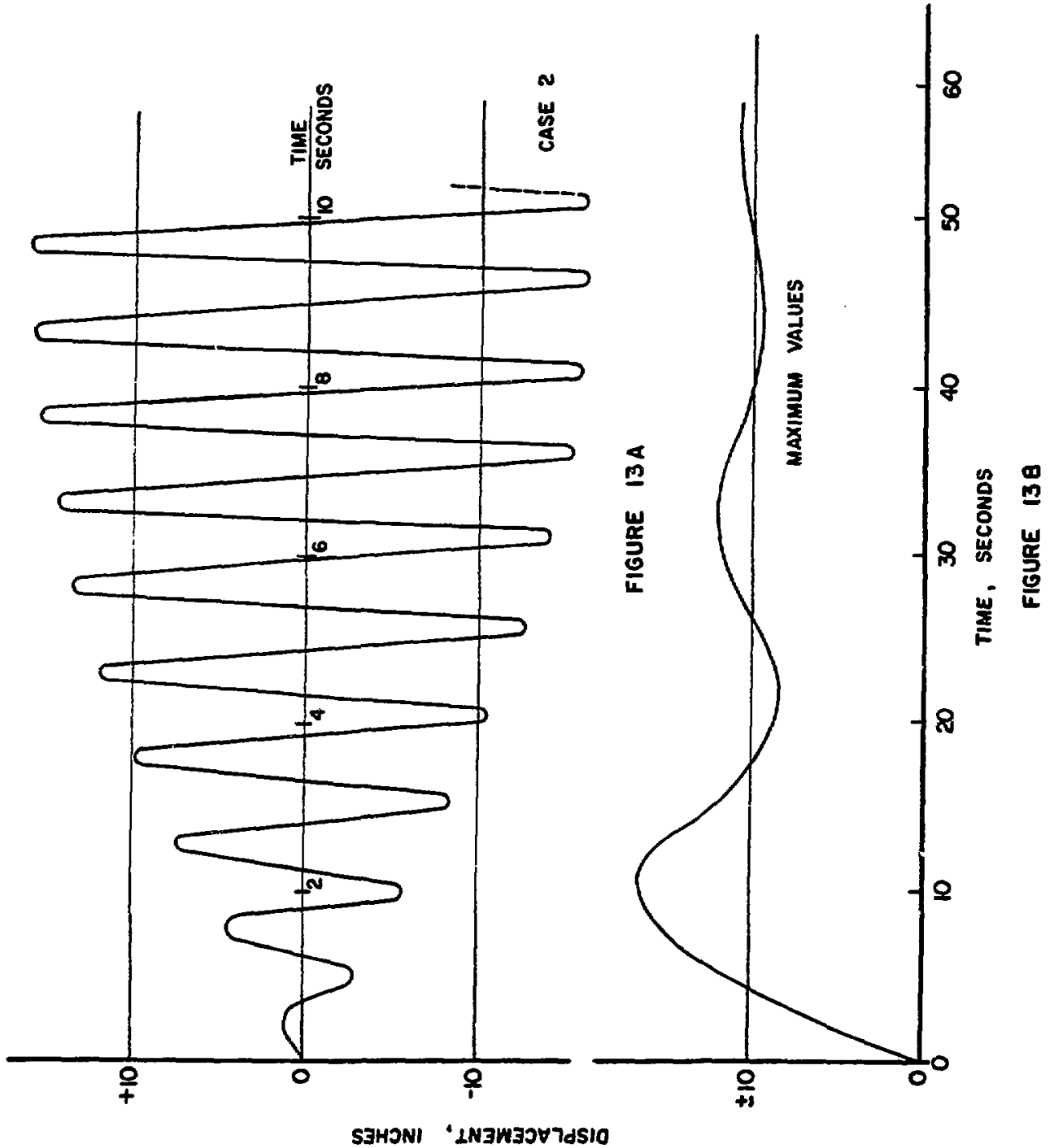


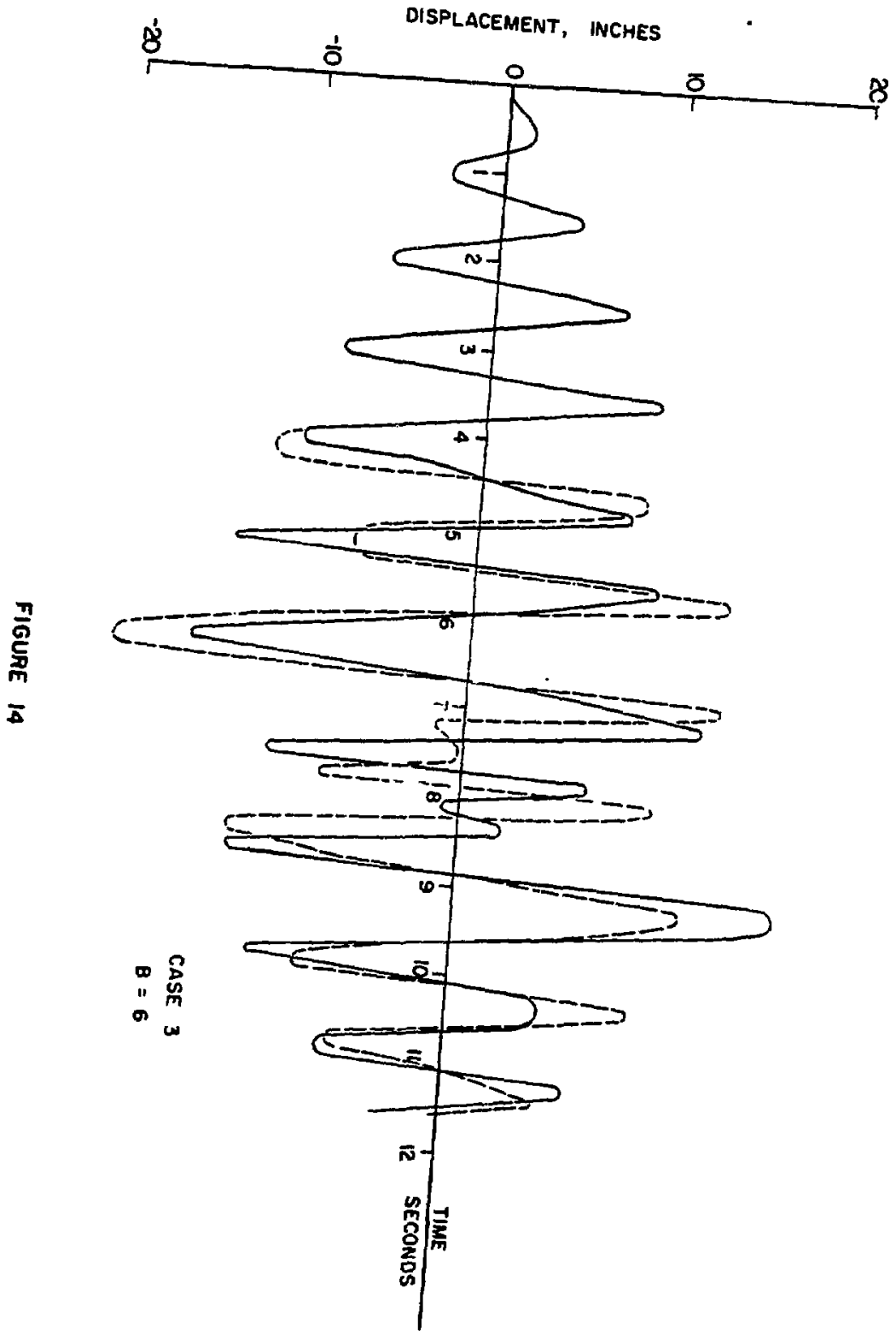


Case 4, show in Figure 12d, is similax to case 3 except that it is a three degree of freedom system. Results for inphase inputs and response less than that which 1 s necessary to reach the breakpoint as shown in Table II, reveal that $x_{3}$ is identical to $x_{1}$, while $x_{2}$ is greater than either. This is as expected for a linear three degree of freedon system. After 4 seconds, which is in accoxdance with the time required for the breakpoint to be reached In the previous case, the values for $x_{3}$ differ from those of $x_{1}$. Results for out of phase inguts are given in Table III. Here it should be noted that the response agrees with linear theory. $x_{3}$ is equal but opposite to $x_{1}$ and $x_{2}$ is essentially zero. The reason for this is that the displacements are small and the breakpoint is not reached. Thus the response should Indeed remain linear.

Case 5, shown in Figure 12e, represents a damped, spring-mass system with clearances. The two external springs have a spring constant of zero until the relative displacement is equal to the clearance. At this point, the spring assumes a value of 39.470 . The center spring is lisear over the entire range. Computer resulcs for the response are plotted in Figure 15. The effects of the non-linearity are identifiable by the double curvature in both the response curves for $x_{1}$ and $x_{2}$. As depicted in the Figuxe, the double curvature for one variable occurs in the negative region while the double curvature for the other takes place in the positive region. The reason for this phenomena is due to the non-linear, non-symetric spring constant employed for this problem. Nefther $K_{1}$ nor $K_{3}$ can support tensile loads. Consequently, for relative in phase motion, when $k_{1}$ is in compression, $k_{3}$ is zero and vice versa. This leads to the symetric-antisymetric response depicted. 


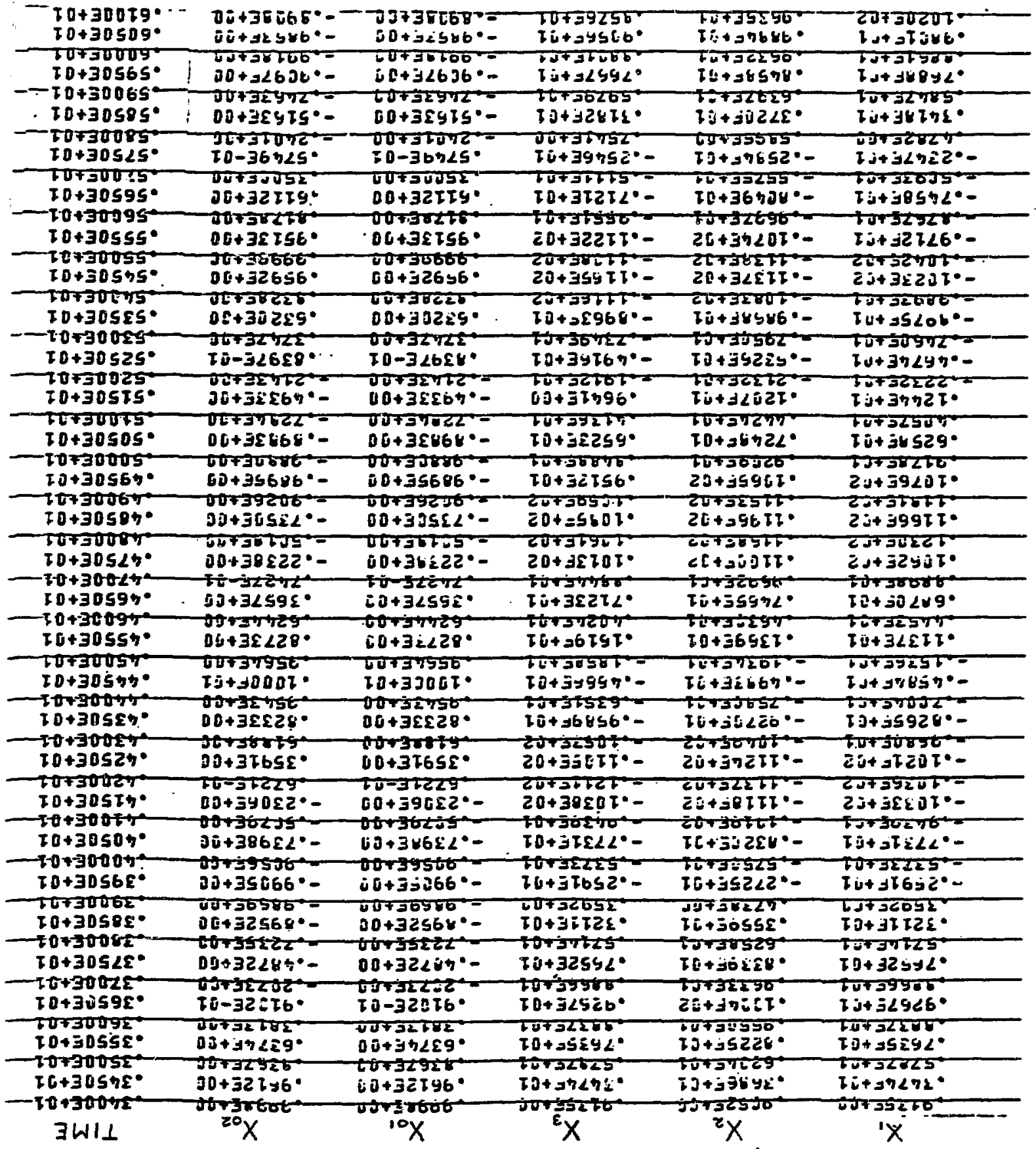

$$
{ }^{20} x=19 x+35 \forall 9 \text { J } \exists 78 \forall 1
$$




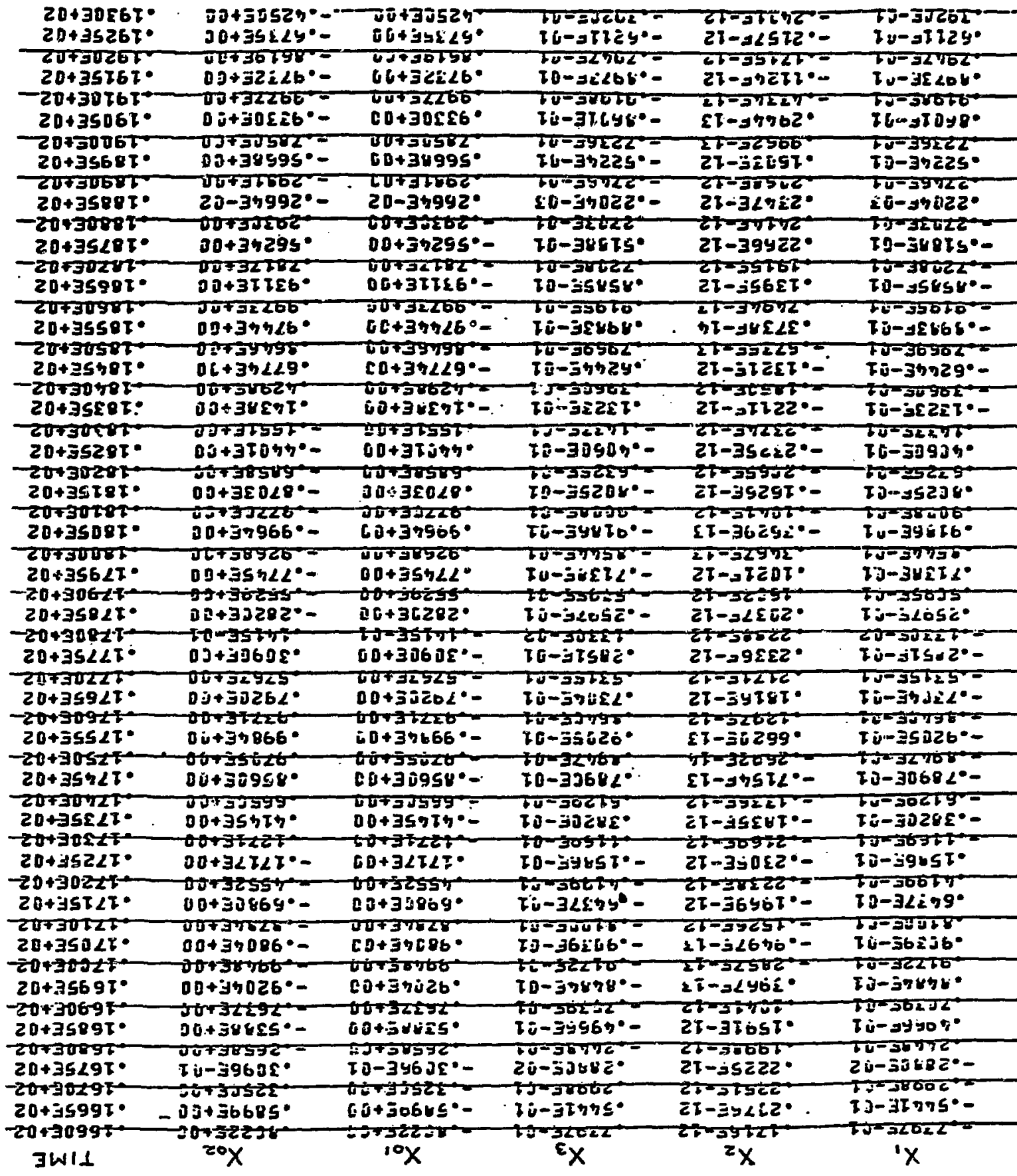

$$
20 x-=10 x .+35 \vee 5
$$$$
\text { III } 378 \forall I
$$ 


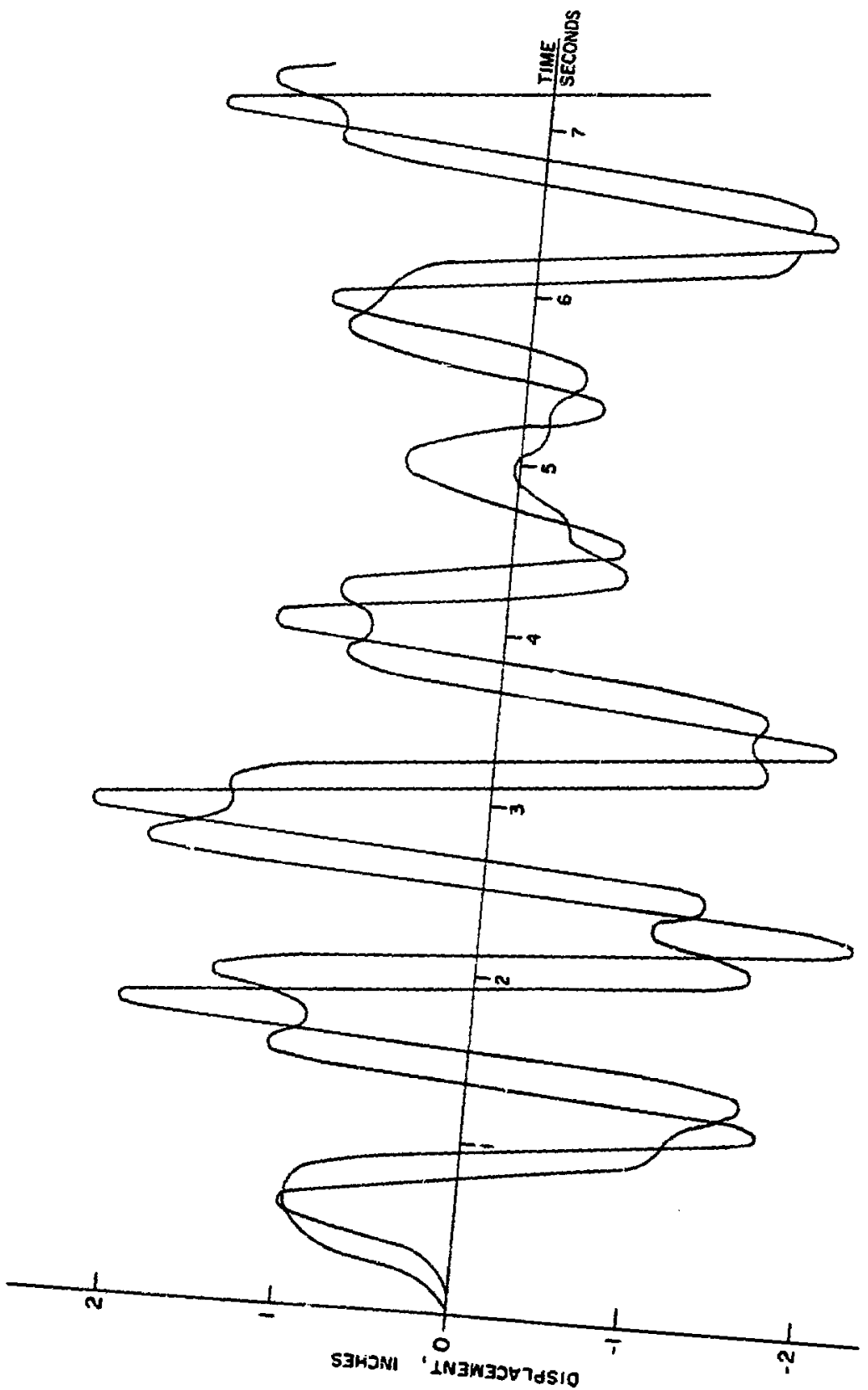

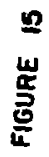

43 
Case 6, shown in Figure 12f, is a three degree of freedom system with all four springs having similar non-linear characteristics. The designated clearances are all equal. Figure 16 shows the response for B=4.0 inphase inputs. As is indicated, $x_{1}$ and $x_{3}$ are equal in magnitude exrept that the ordinate is displaced differently for each. This is due to the clearance effect associated with every spring wich results in a cyclic reversal of the effective spring constant acting on masses $m_{1}$ and $m_{3}$. As is to be expected the ayclic change for $m_{1}$ and $m_{3}$ is 180 degrees out of phase.

Figure 17 shows a plot of maxima for the $x_{1}$ displacement at different frequencies, B=4.0, 5.0 and 6.0. Note that the maximum response occurs at the lower Exequency. The reason for this is that symetric elearances will iower the system natural frequencies bela those predicted for the linsar system.

Figure 18 depiets the response of Case 6 for each mass, resulting from out of phase inputs. In this case, $x_{3}$ is a mirror lmage of $x_{2}$ while $x_{2}$ is essentially zero. Because of the symetrical configuration of the system, this characteristic is to be expecred. The results for this case are expecially interesting since this configuration is closely related to the single plane core model.

Results Eram Cases 1 through 6 show that the program can predict the response behavior of non-linear, multi-degrae of freedom systems. Dmployed with proper input data it should permit a realistic assesswent of hnGR esre seismic response. 
․

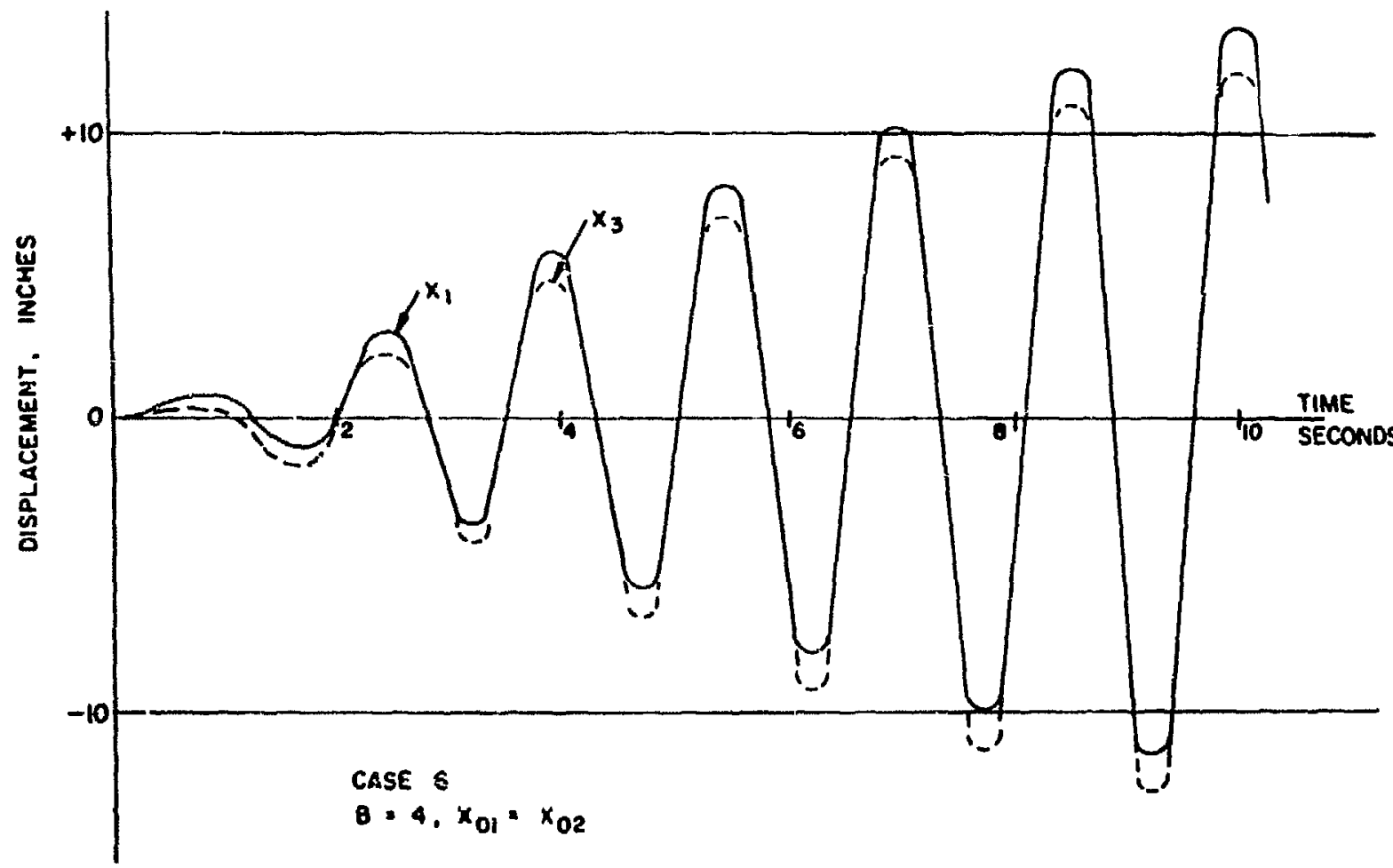

figure 16 


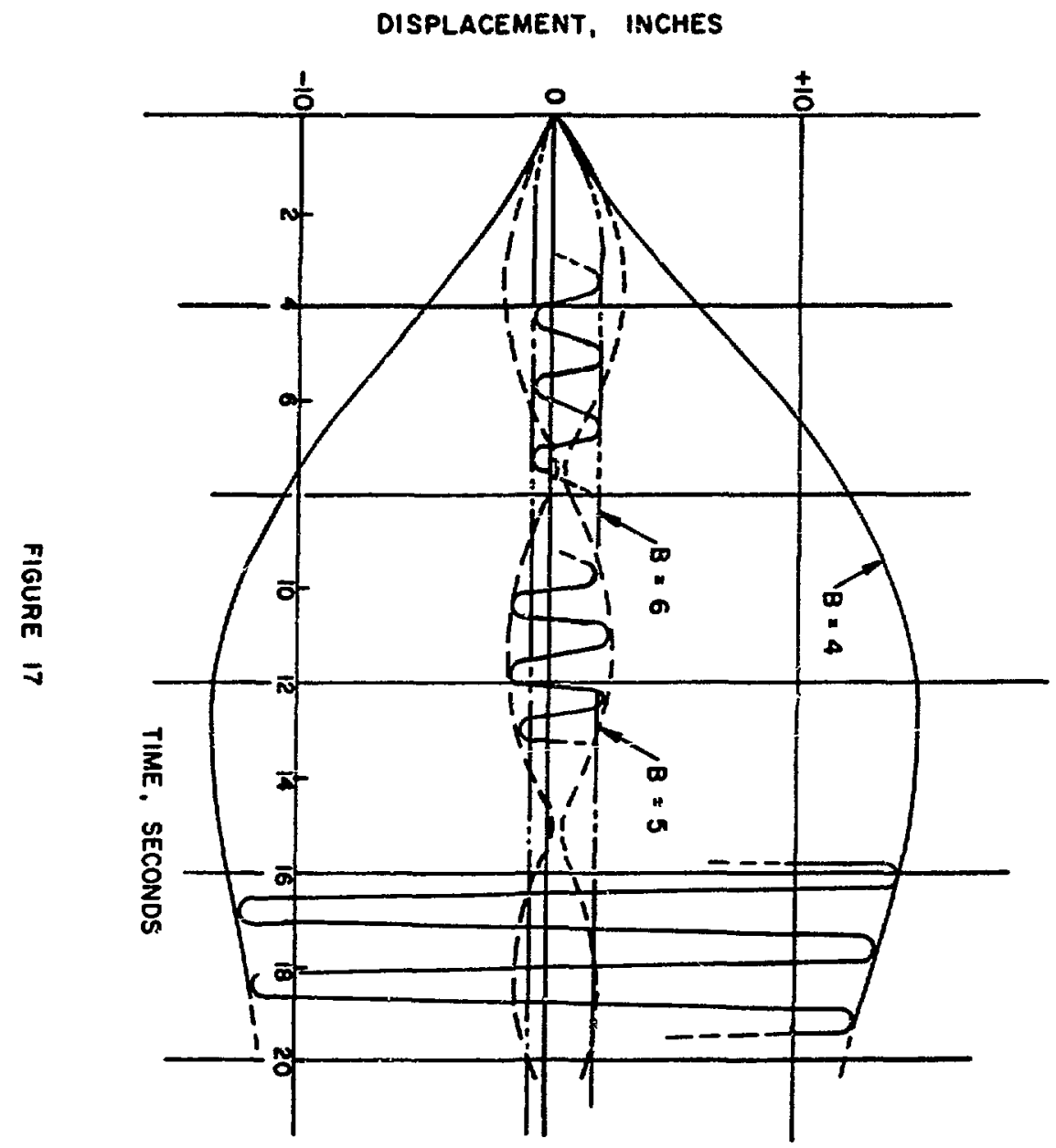




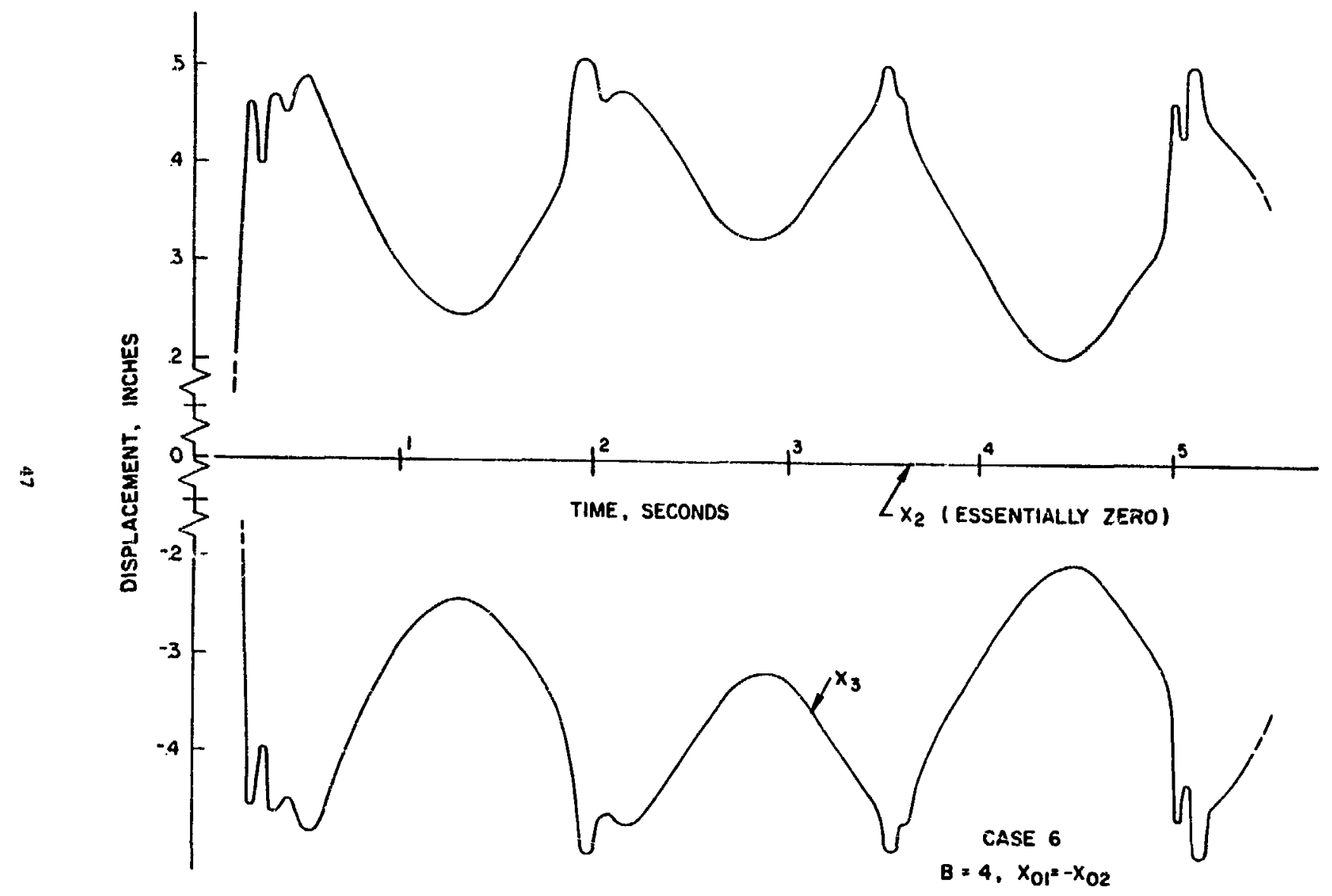

FIC. 18 


\section{Parametric Study of 7-Mass System}

The first detailed analysis of a complete hortzontal section of the HIGR core using OSCIL was made with 7 masses. The masses $M_{1}$ and $M_{7}$ represent a pair of diametrically opposed side reflector blocks while the interior masses $M_{2}$ through $M_{6}$ represent a lumped arrangement of the associated horizortal fuel elements. The springs $K_{1}$ and, $K_{8}$ represent the spring packs placed between the wall and reflector blocks. The spring constants $k_{3}$ through $k_{6}$ represent the stiffnesses between the fuel elements, while the spring constants $k_{2}$ and $k_{7}$ represent the stiffnesses between the reflector block and the adjacent fuel elements. A total operating clearance of 4.15 inches was distributed symmetrically across the entire horizontal array with a different clearance assigned for the spring pack as opposed to the fuel elements. In this model damping was accounted for by lumped equivalent viscous coefficients between the adjacent structural components of the core. Although both the material stiffness and the energy dissipation in the system are known to be nonlinear, it was decided that the two effects should be studied separately. Til:1s, in the initial model, viscous damping was assumed and the non-linear features were assigned only to the elastic forces. Numerous runs were made with the 7 mass representation. (See figures 21-25). Damping was varied from zero to large amounts and clearances from $30 \%$ to 130 of normal. Figure 19 shows a typical computer generated plot. As shown in the figure, 9 variables are plotted. These include the two input displacements, the displacements of the two side reflector blocks, and the displacements of the 5 internal masses representing the fuel elements. The vertical axis represents the displacement amplitudes of each of the components is located in accordance with the initial clearances assumed for this problem with 
the centermost core block taken as the zero point of the system. The plot is intended to show the displacement-time history of the elements relative to the center of the model.

Referring to Figure 19, the uppermost and lowermost curves represent the wall inputs which in this case are harmonic. The next set of inner and outer curves represent the motion of the two reflector blocks, while the 5 inner curves represent the motions of the core blocks. As can be seen collisions between internal elements, reflactor block and the wall are apparent. The case illustrated is for moderate damping and normal clearance.

Cases with no damping show a greater number of collisions. These initiate sooner and involve higher velocities. With heavy damping, far fewer collisions take place. Those that occur result in substantially lower velocities. The motion for these cases appears to approach steady state behavior. However, too few cases involving variations of clearances were run, and thus : conclusions can be drawn at present.

In order to assess the validity of the model, systems with a different number of masses were also investigated. A typical result for a 12 mass model is shown in Figure 26. The same total clearance and total mass were used for both the 7 and 12 mass systems. Comparable input and damping conditions were assumed for the two solutions. 
옹

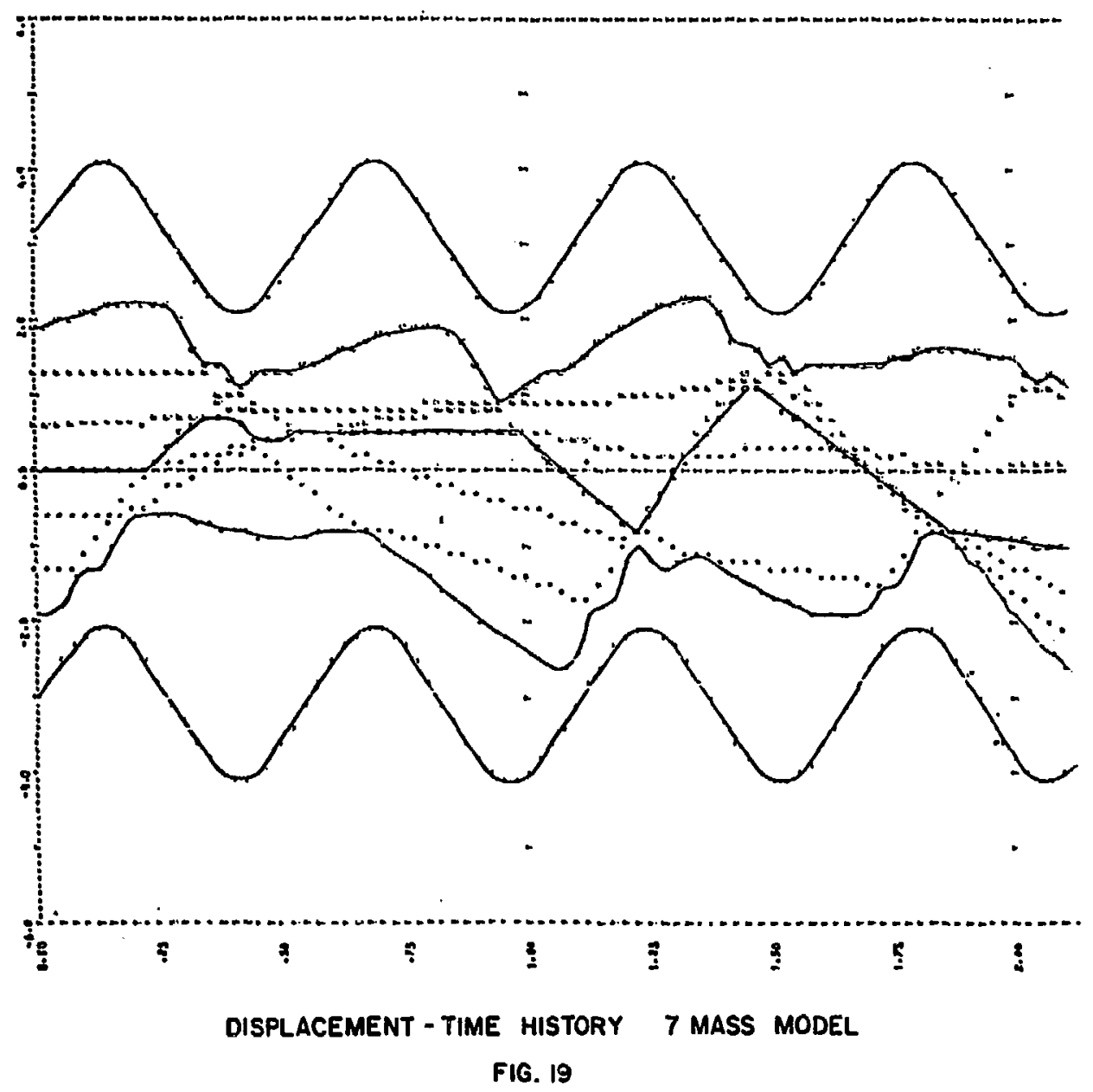




\section{SINUISOIOAL IN - PHASE FUNCTION PARAMETERS}

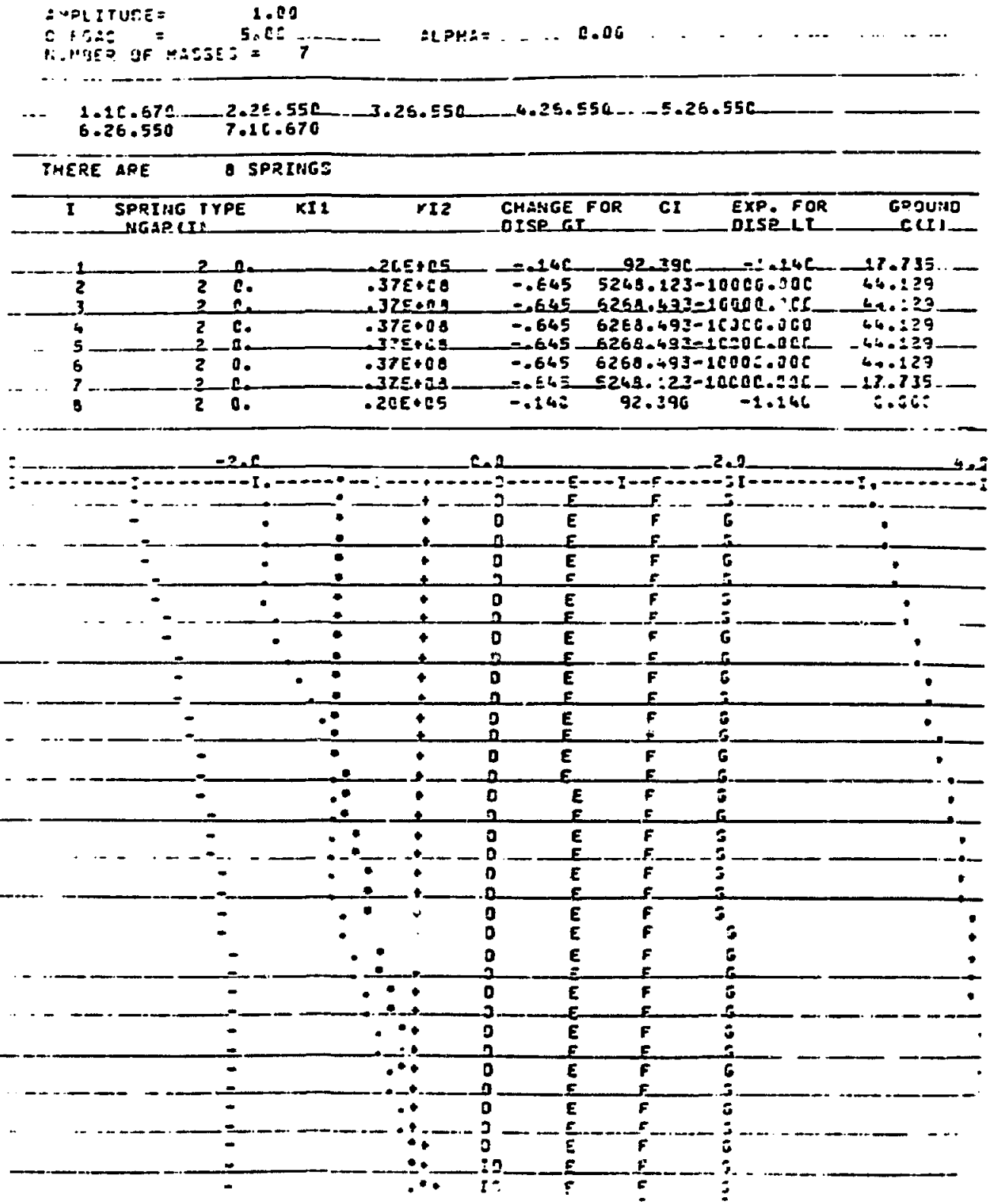

FIGURE 20 


\section{PARAMTETRIC EVAUUATION}

I. DETERMINE MINILUN NONBER OF MASSES FOR REALISTIC DYNAMIC SODEL

II. DETERUIAE SENSITIVITY TO:
A. DAMTing $\left\{\begin{array}{l}\text { INTER-ELEMIDNTAL } \\ \text { TO GROUND }\end{array}\right.$
B. clearance

III. INPUT CONDITIONS:
A. SINUSOIDAT $\left\{\begin{array}{l}\text { FREQUENCY } \\ \text { AYPLITUDE }\end{array}\right.$
B. EARTFQUEFE TIME HISTORY 
PARAMETRIC STUDY FOR HORIZONTAX MODEL

\begin{tabular}{|c|c|c|c|c|c|c|}
\hline & PARAMETER & M & (\& CRITICAL) & $\begin{array}{c}\text { CL } \\
\text { (8 NOMINAL) }\end{array}$ & $W\left(\frac{\operatorname{RAD}}{\mathrm{SEC}}\right)$ & XO (INCHES) \\
\hline I & $\begin{array}{l}\text { NUMBER OF } \\
\text { MASSES }\end{array}$ & $5,7,9,30$ & 308 & $\mathbf{N}$ & 11.4 & 1 \\
\hline I I & $\begin{array}{l}\text { INTERELEMENTAL } \\
\text { DAMPING }\end{array}$ & 7 & $\begin{array}{r}18,108 \\
.308,50\end{array}$ & $\mathbf{N}$ & 11.4 & 1 \\
\hline III & $\begin{array}{l}\text { TOTAL } \\
\text { CLEARANCE }\end{array}$ & 7 & 308 & $\begin{array}{l}0,308 \mathrm{~N} \\
\mathrm{~N}, 130 \mathrm{~N}\end{array}$ & 11.4 & 1 \\
\hline IV & $\begin{array}{c}\text { INPUT } \\
\text { FREQUENCY }\end{array}$ & 7 & 308 & $\mathbf{N}$ & $\begin{array}{c}2.5,2.525 \\
5.11 .4\end{array}$ & 1 \\
\hline $\mathbf{v}$ & $\begin{array}{c}\text { INPUT } \\
\text { AMPLITUDE }\end{array}$ & 7 & 30 & $\mathbf{N}$ & 11.4 & $.5,1,2$ \\
\hline
\end{tabular}


EVALUATION OF COEFFICIENT OF RFSTITUTION

FROM VISCOUSLY DAMPED MODEL

$\left(M=7\right.$, NORMAL CLEARANCE, $W=11.4, X_{0}=1$ )

\begin{tabular}{|c|c|c|}
\hline $\begin{array}{c}\text { INTERELEMENTAL } \\
\text { DAMPING } \\
\text { (Z CRITICAL) }\end{array}$ & $\begin{array}{c}\text { DAMPING } \\
\text { COEFFICIENT } \\
\left(\frac{\text { LB-SEC. }}{\text { INCH }}\right)\end{array}$ & $\begin{array}{c}\text { COEFFICIENT OF- } \\
\text { RESTITUTION } \\
\text { (EVALUATED FROM OUTPUT) }\end{array}$ \\
\hline 11 & 626 & 0.96 \\
\hline 108 & 6,260 & 0.64 \\
\hline 308 & 18,800 & 0.23 \\
\hline 508 & 31,300 & 0.044 \\
\hline 1008 & 62,600 & $<.001$ \\
\hline
\end{tabular}




\section{RUN I - NUMAER OF MASSES}

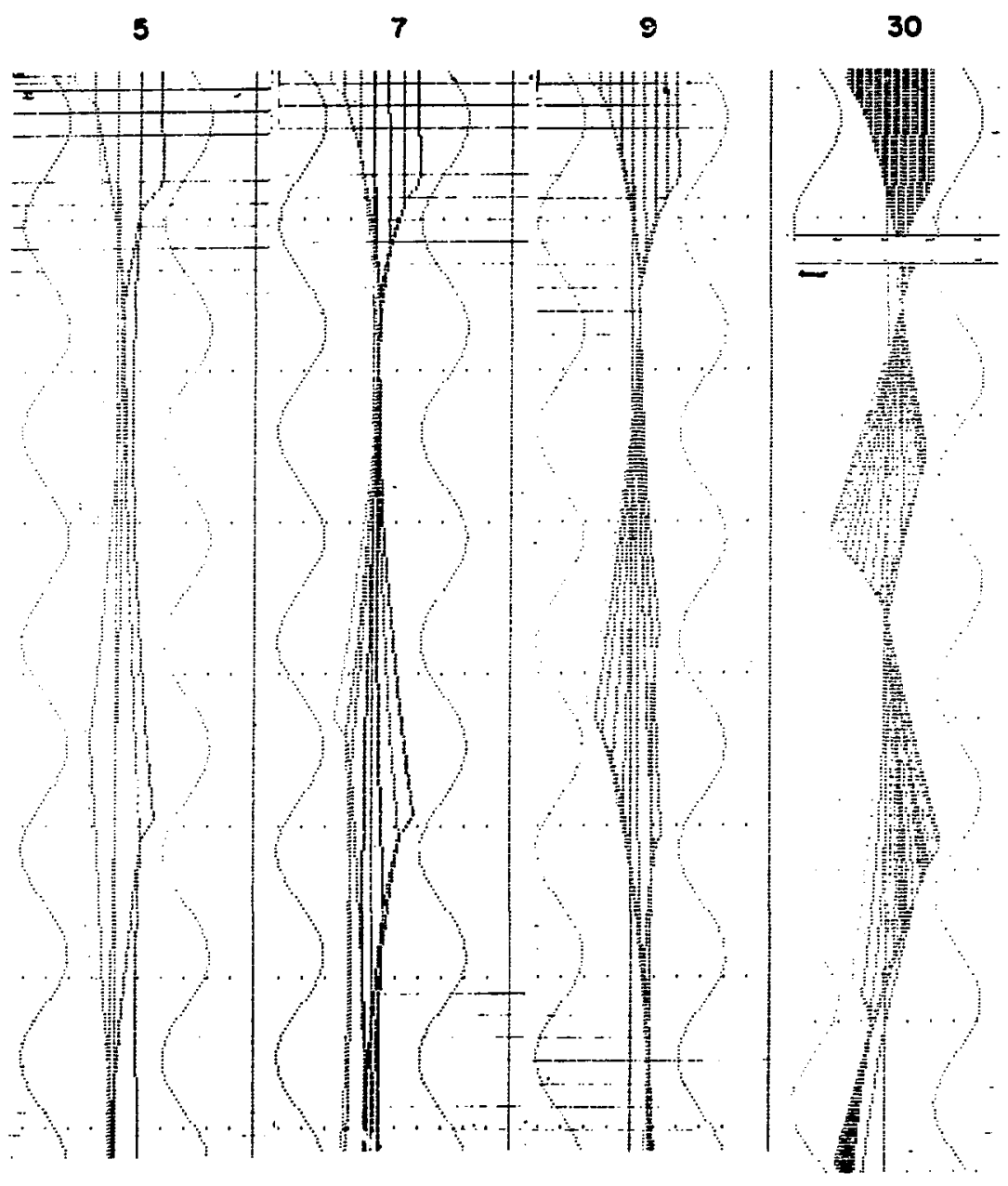

FIG. 2 I 


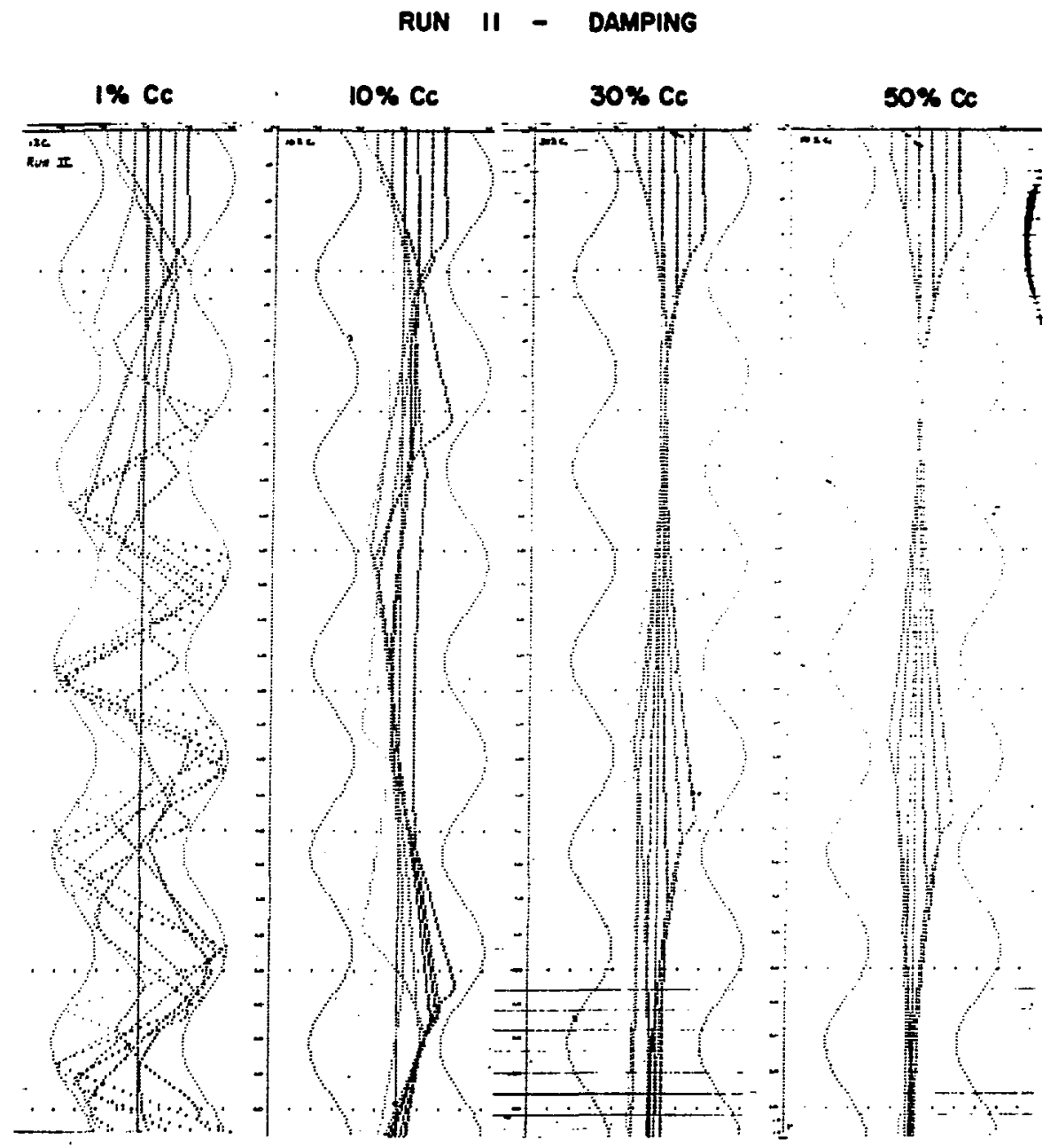

FIG. 22 


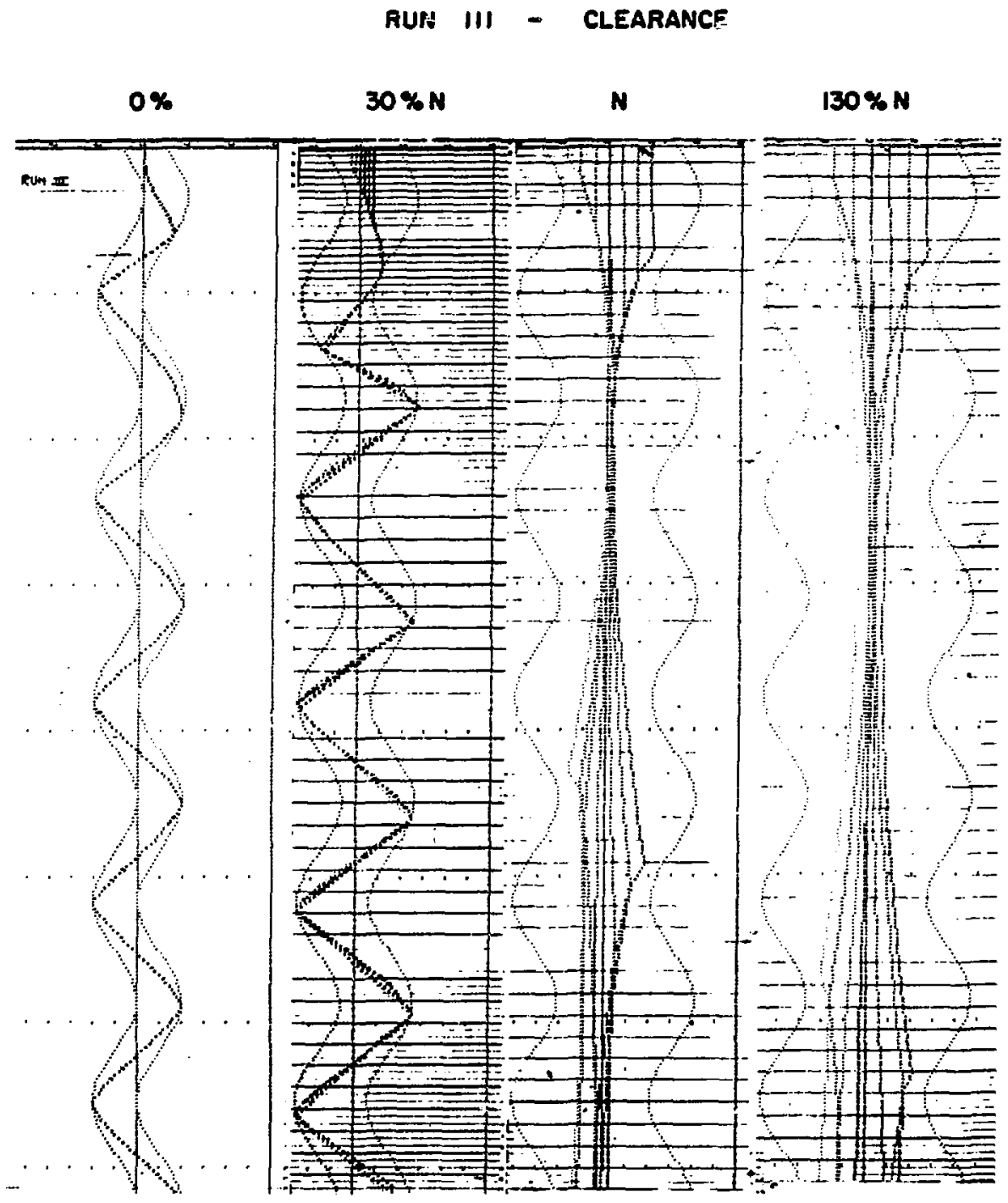

F16. 23 


\section{RUN IV - FREQUENCY (w)}

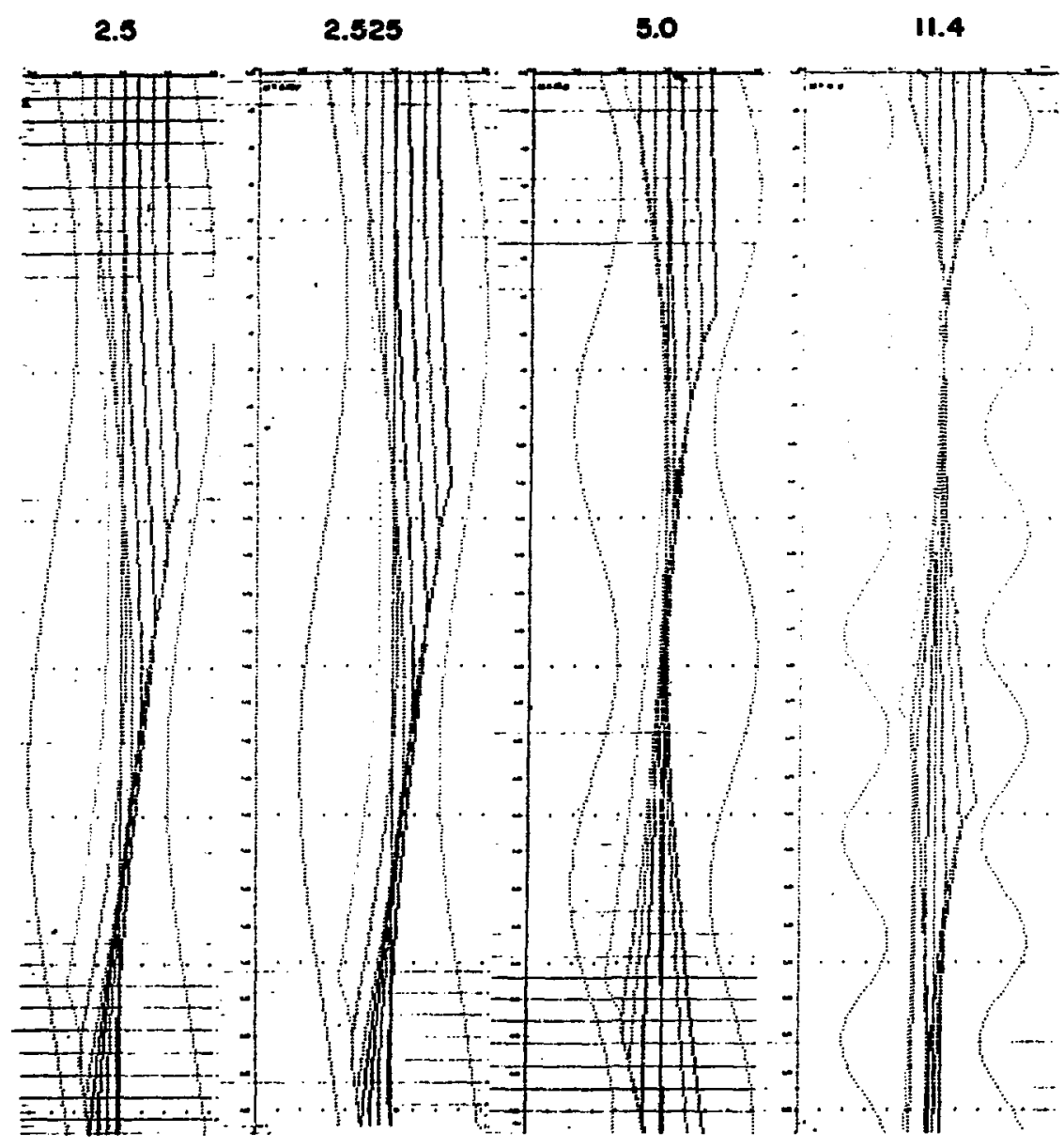

FIG. 24 


\section{RUN $V$ - INPUT AMPLITUDE}

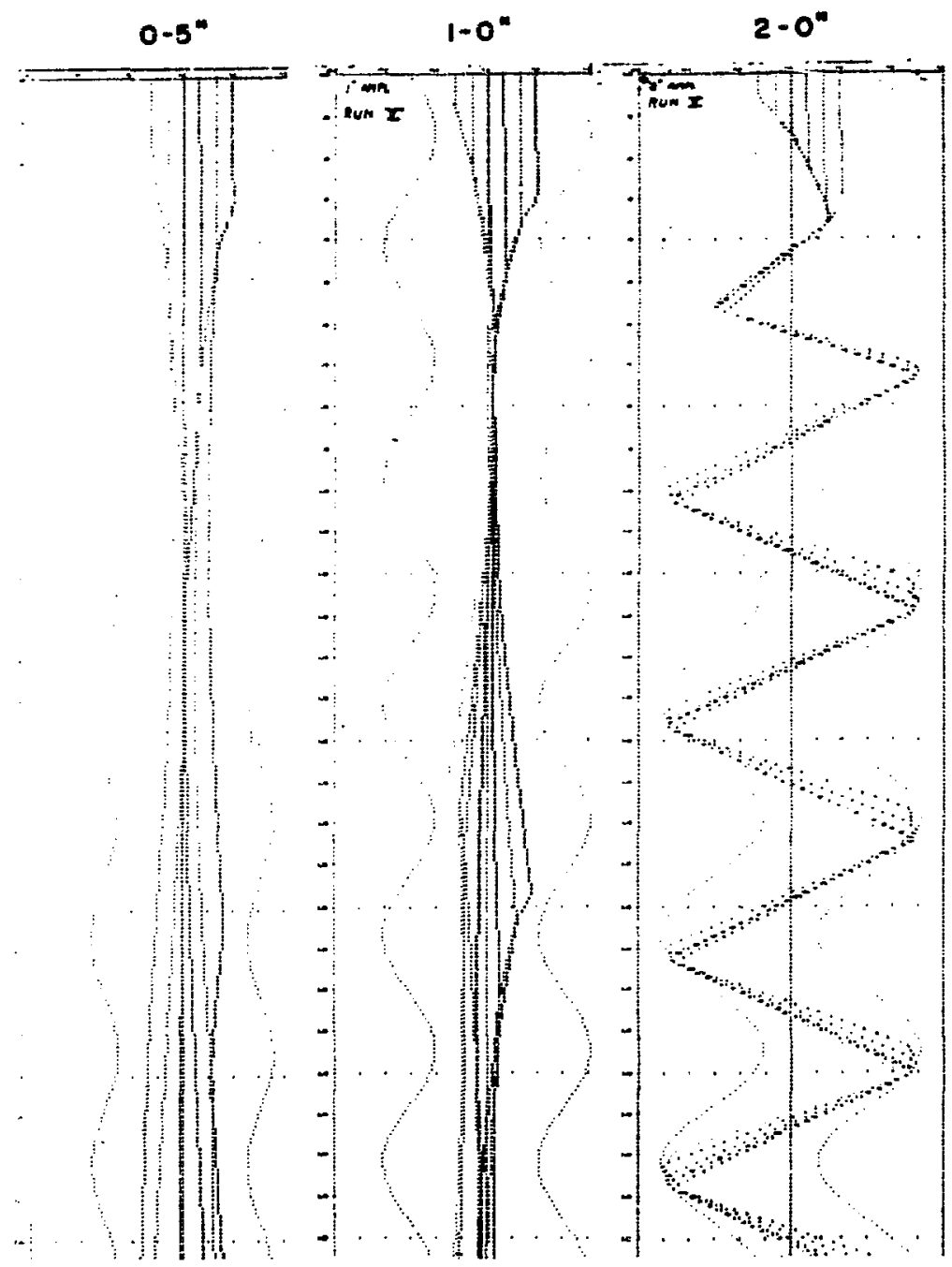

Fic. 25 


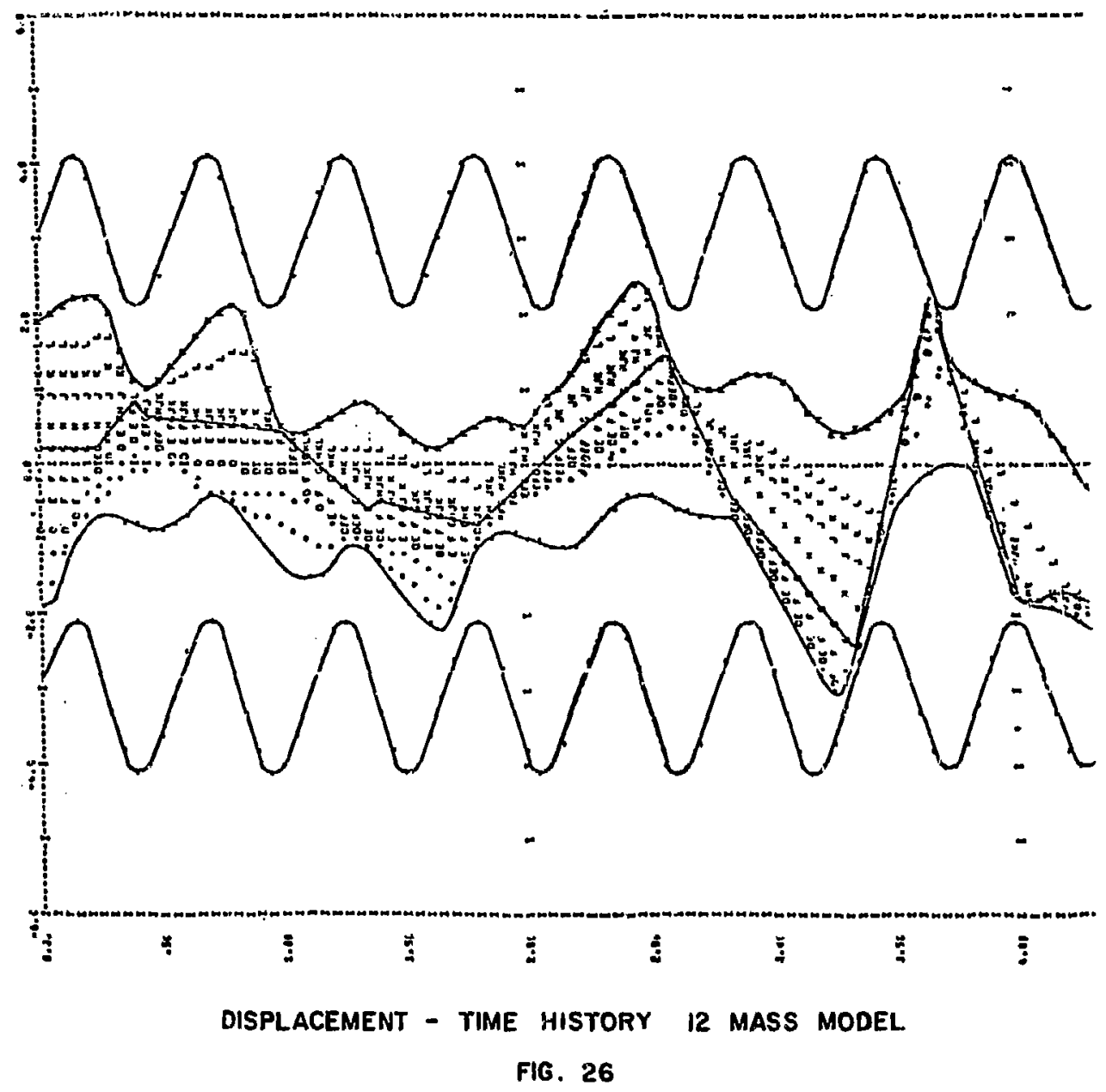




\section{Non-linearity Effects}

The collision process involves contact times that are extremely short, with large variations in force and rapid motion changes. A detailed knowledge of these effects is essential for the stress and failure calcriations. The computer program must be capable of accurately revealing the details of the collision process. In order to ascertain this, it is necessary to check the validity of the program in predicting accurate results for these circumstances when non-linear conditions predominate.

The literature dealing with forced vibrations of systems with non-linear restcring elements is almost entirely devoted to periodic solutions. For periodic, or even harmonic forcing functions, transient effects are generally not considered. This is the case even for the forced response of the one degree of freedom problem. However, the computer program solution includes both the transient as well as the steady state response.

In order to assess how well these solutions are handled in the program, two non-linear one degree of freedom problems for which some characteristics are known were investigated.

One system for which checks were carried out was a single mass supported by springs with clearance gaps. For this case the periodic oscillations are readily predicted. This is true even where steep changes in elastic characteristics are encountered. The importance of this procedure is that it permits the development of more efficient solution methods.

A second test problem intended to show how the computer solution reveals the jump phenomena assocfated with non-linear vibrations was also investigated. For this case a one degree of freedom system having a cubic type of restoring force was investigated. The governing equation for this type of problem can 
be written as

$$
\ddot{y}+2 \xi \omega_{n}^{2} \dot{y}+\omega_{D}^{2}\left(y+\varepsilon^{2} y^{3}\right)=F \cos (\omega t+\phi)
$$

where $\dot{y}=\frac{d y}{d t}, \omega_{n}^{2}=\frac{K}{m^{\prime}} \xi=\frac{C}{C_{c}}, \varepsilon^{2}=$ the non-1inearity $\left(i^{-2}\right)$. An exact solufor Equation [1] is not known, only approximate solutions are available. Following the standard procedure given in reference (8) a solution is assumed in the form $y=A \cos \omega t$, which after integrating twice yields:

$y=\left(\frac{\omega_{n} A}{\omega^{2}}+\frac{3}{4} \frac{\omega_{n}^{2} \varepsilon^{2} A^{3}}{\omega^{2}}-\frac{B_{1}}{\omega^{2}}\right) \cos \omega t+\left(\frac{B_{2}}{\omega^{2}}-\frac{2 \xi \omega_{n} A}{\omega^{2}}\right) \sin \omega t+\frac{\omega_{n}^{2} \varepsilon^{2} A^{3}}{36 \omega^{2}} \cos 3 \omega t$

where $\mathrm{F}^{2}=\mathrm{B}_{1}^{2}+\mathrm{B}_{2}^{2}$ and $\frac{\mathrm{B}_{2}}{\mathrm{~B}_{1}}=\tan \phi, A=$ the amplituile of the non-1inear response. After equating coefficients of appropriate tems it can be shown that the relationship between the excitation and the response is

$$
\left(\begin{array}{c}
\frac{\omega^{2}}{\omega_{n}^{2}} \\
\omega^{2}
\end{array}\right)^{2}\left(\frac{\omega^{2}}{\omega_{n}^{2}}\right)\left[-2+4 \xi^{2}-\frac{3}{2} \varepsilon^{2} A^{2}\right]+\left[1+\frac{3}{2} \varepsilon^{2} A^{2}+\frac{9}{16} \varepsilon^{4} A^{4}\right]=\left(\frac{F}{K}\right)^{2} \frac{1}{A^{2}}
$$

Figure 27 shows a piot of the computer generated solution for amplitude vs. frequency. Typical computer outputs are shown in Figures 28 and 29 in which the jump phenomena is seen. The results were obtaited by programing the conputer code to sweep-up in frequency and then to sweep-dow in frequency. The circles indicate the sireeg-up solutions wile the crosses indicate the maximum response for the sweep-down case. No solutions were obtained for the branch of the system that is mathematically unstable. Except for the points which invoive rapid jumps or transients, all points fall as predicted by Equation [3] since this equation is only for steady state conditions and for a single term approximation. To the results of Equation [3] the sweep rate was reduced to 


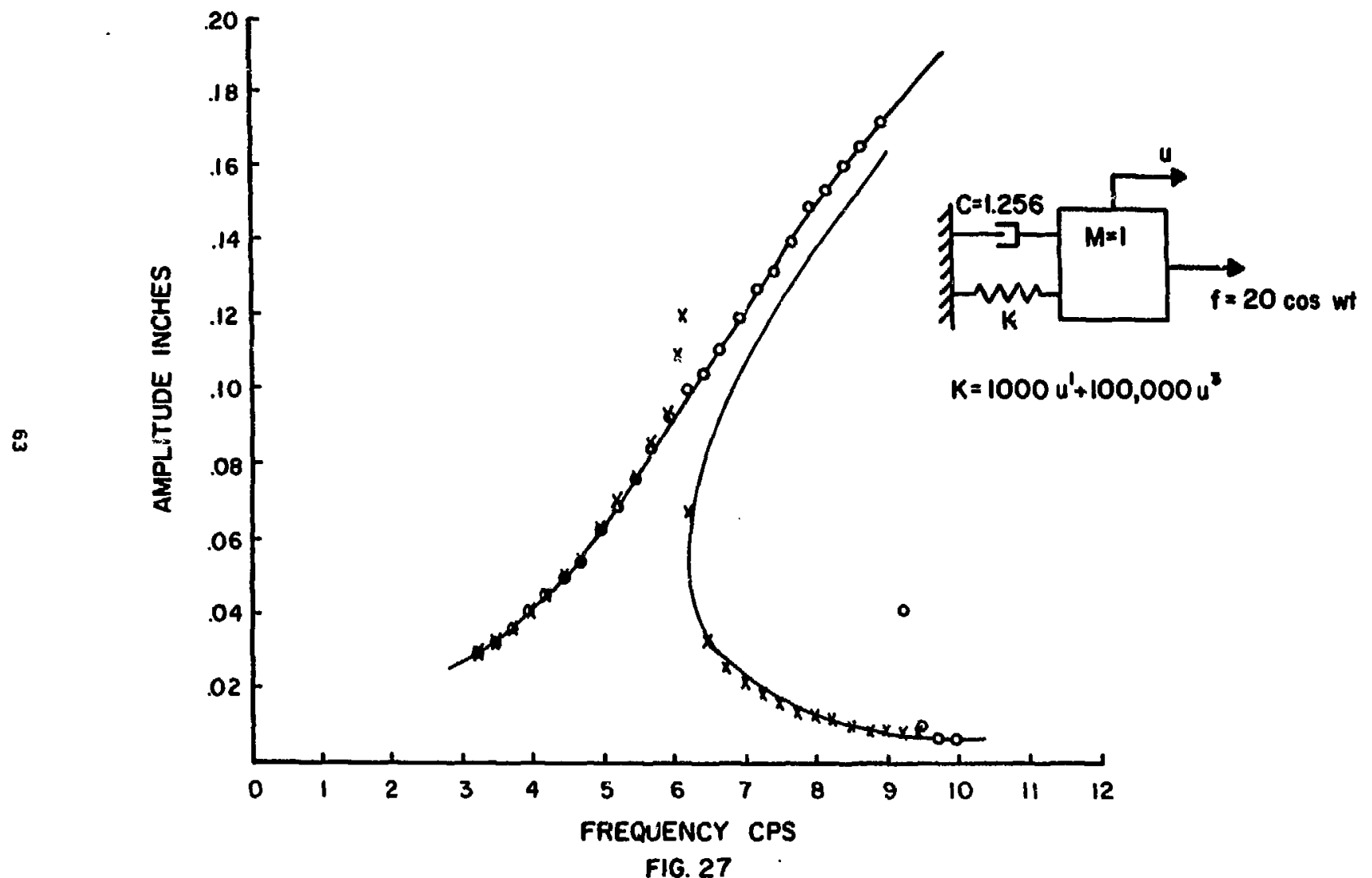




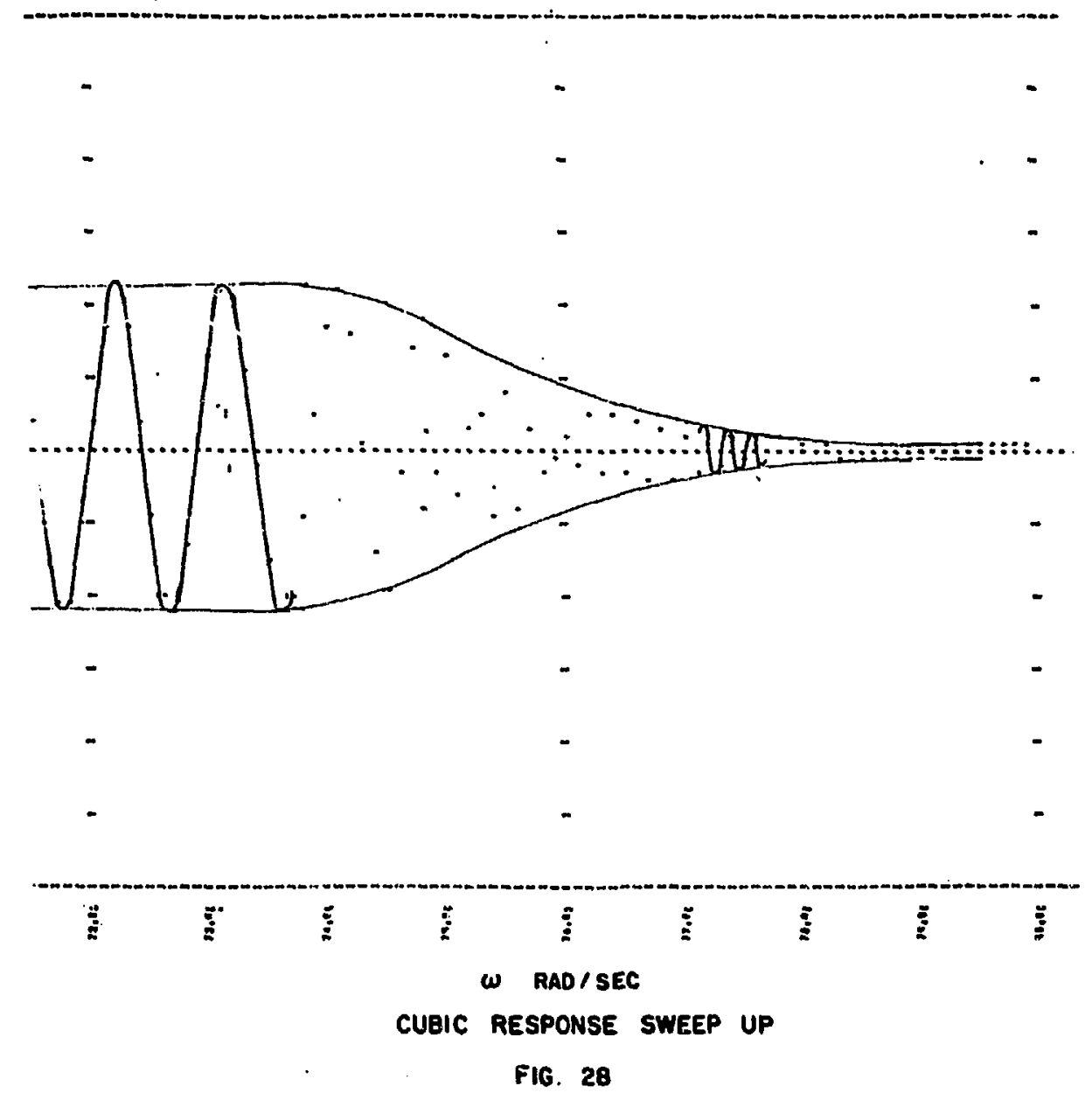




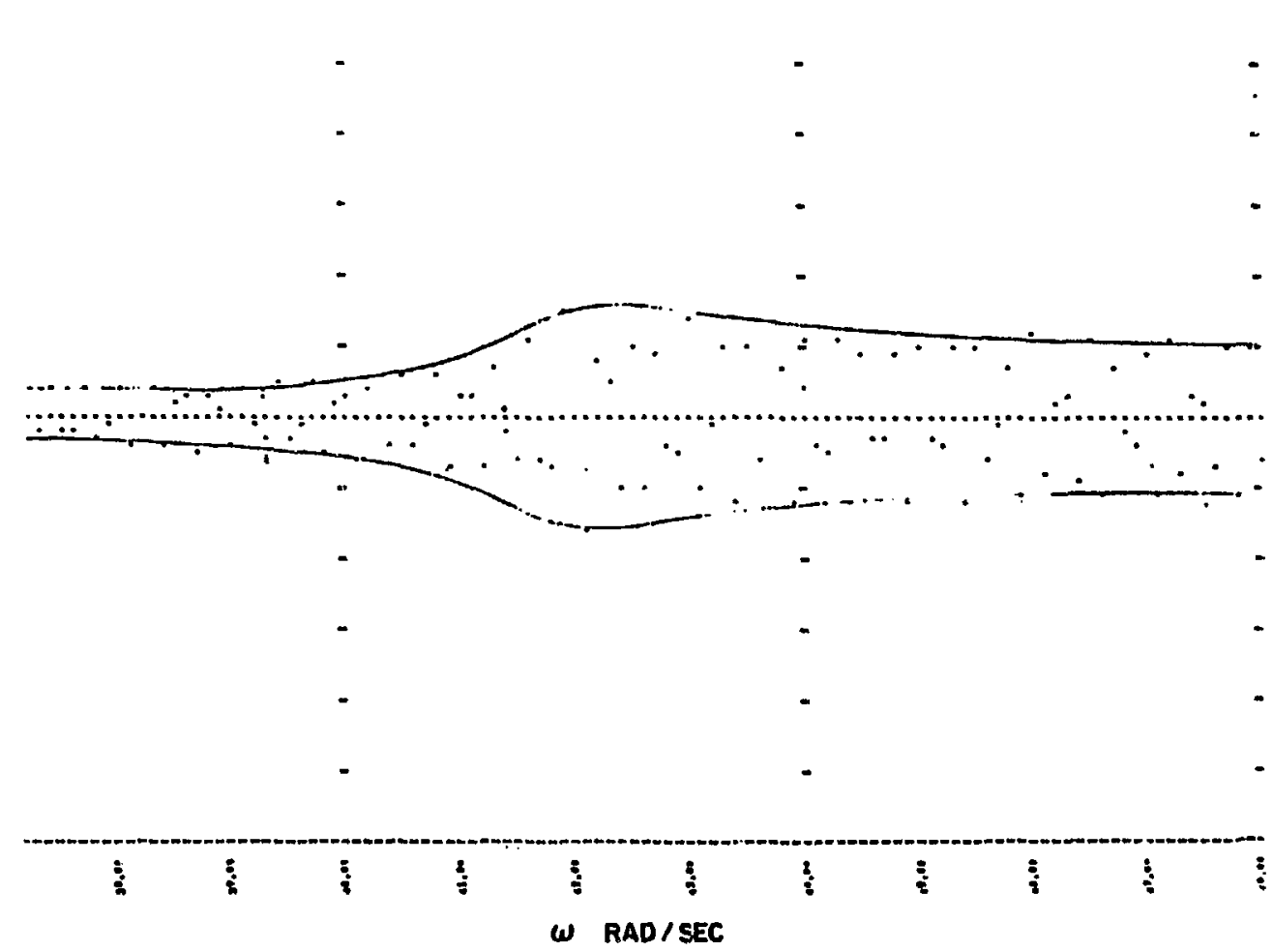

CUBIC RESPONSE SWEEP DOWN

FIG. 29 


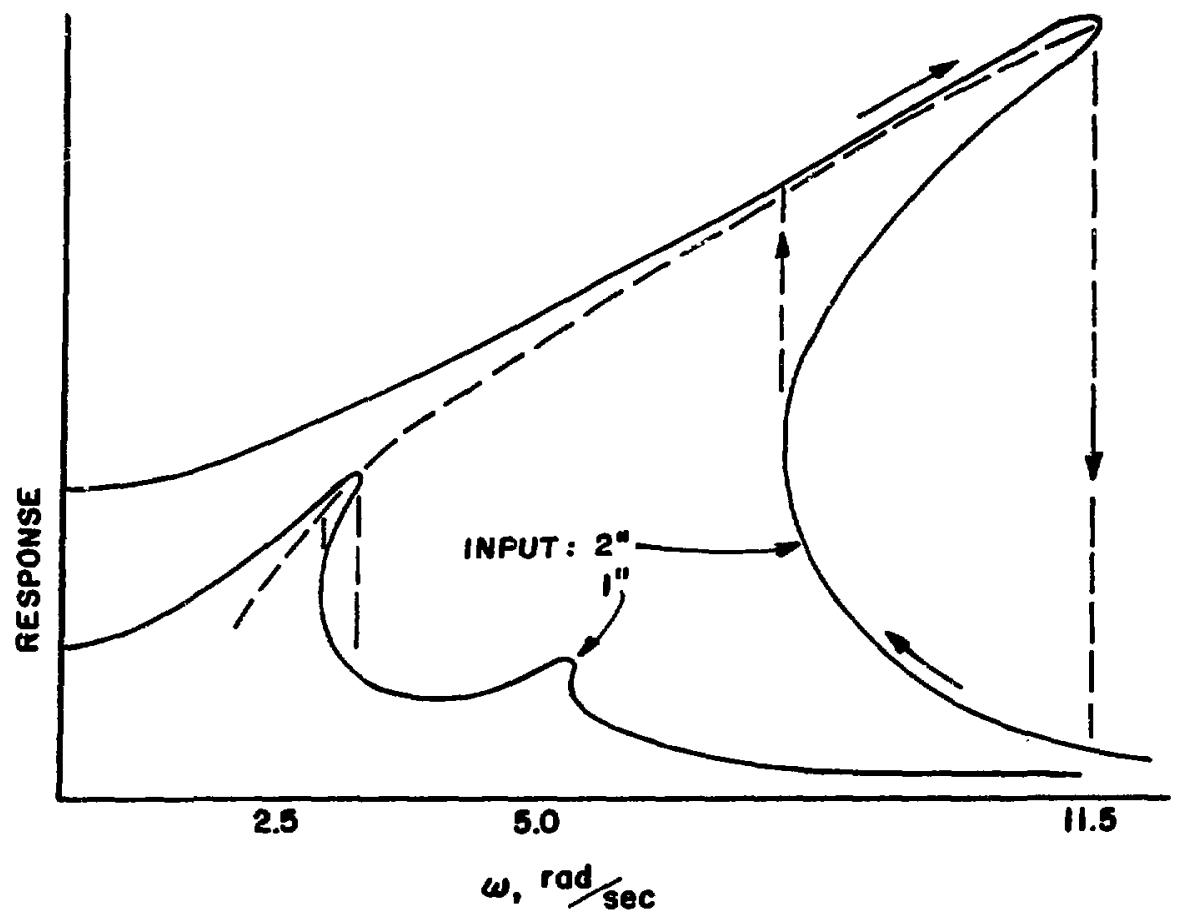

NONLINEAR RESPONSE

DIFFERENT INPUT AMPLITUDES SUBHARMONIC RESPONSE AT 5 rad/5oc

FIG 30

66 
the point where the steady state phenomena was revealed. Changing the sweep rate affects the sensitivity of the jump phenamena to the presence of third and figher harmonic components of the motion. Too rapid a sweep rate masks the severity of the Jump phencmena.

Since the actual problem involves collisions, the effects of initial conditions were also looked into. In particular, the effect of inftial arbitrary displacement conditions on the steady state respunse was investigated at one frequency in the frequency band where there are two stable roots. The specific purpose here was to determine which of the two stable roots would ultimately be obtained for various values of damping as well as for different conditions of initial displacement. Table IV summarizes the results of this investigation. For each of the Inftial displacements shown in colum 1 the initial velocity was assumed to be zero.

The table shows that for a fixed amount of damping either the upper or the lower root is established as the initial displacement condition is increased, the particular root obtained being a discontinuous function of the initial displacement. For instance, for 2 of critical damping, the upper root is established for an initial displacement $\left(x_{0}\right)$ of -0.16 through $-0.20,-0.22$ and -0.23. However, the lower root is established for $\left(x_{0}\right)$ values of -0.21 and -0.24 .

A similar characteristic is also revealed for changes in the damping constant. For example, at $\left(x_{0}\right)=-0.21$, the lower root occurs for 4 and 28 of critical damping while the upper root occurs for 1t. At $\left(x_{0}\right)=-0.23$, however, the lower root occurs at 48, the upper at 2\% and the lower again at 1\% of critical damping. 
It is seen that the response for even this simple non-linear system in which the determination of whether the upper or lower stable root is established is strongly dependent on initial conditions and damping. For a multicomponent system the response may be even more sensitive to these parameters. A thorough evaluation of the collision process is therefore important. In any case, these studies show that the computer program works and that care must be taken taken in selecting parameters.

Presently, the horizontal mass model is being used to conduct parametric studies. The effects of input level and type, clearance, damping and mass subdivisions are being evaluated. Simple model tests are planned to study the correlation between the computer and experimental results. In addition, an investigation has been initiated to predict the response characteristics of twodimensional vertical block arrays. 
Table IV

Stable roots of one-Mass Cubic System at Frequency 7 cos

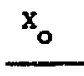

$-0.16$

$-0.20$

$-0.21$

$-0.22$

$-0.23$

$-0.24$

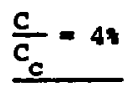

upper

upper

lower

lower

Iower

lower $\underline{c_{c}}=2$

upper

upper

lower

upper

upper

lower $\frac{c}{c_{c}}=18$

upper

upper

upper

upper

lower

upper 


\section{References}

1. Non linear Dynamic Analysis of a stacked Fuel Column Subjected to Boundary Motion. T.H. Lee, General Atomic Project 912, GA-Ail2933, Aug. 29, 1974 .

2. Analytical Model Development for Core Seismic Response, J.G. Bennett et. al., in HTGR Safety Research Program Quarterly Report, compiled by W.I. Kirk, Los Alamos Progress Report LA-5870-PR, Feb. 1975.

3. Proposal for Analysis of HTGR Core Response to Seismic Input, J.G. Bennett and R.C. Dove, IOs Alamos Informal Report, IA-5821-MS, Jan. 1975.

4. The Automatic Integration of Ordinary Differential Equations, C.W. Gear, Comm. of ACM, VI4, No. 3, March 1971.

5. GEAR: Ordinary Differential Equation System Solver, A.C. Hindmarsh, Lawrence Livermore Laboratory, UCID-30001, Rev. 3, Dec. 1974.

6. Linear Multistep Methods for Ordinary Differential Equations, A.C. Hindmarsh, Lawrence Livermore Laboratory UCRL-51126, Rev. 1, March 1972.

7. GEARB: Solution of Ordinary Differential Equations Having Banded Jacobian, A.C. Hindmarsh Lawrence Livermore Laboratory, UCID-30059, Rev. 1, July 1975. 
APPENDIX

Ilsting of Program and Subroutines.

OSCII
STORE
RDIN
COEF
RESTART
SHOK
PROUT
FORCE
DIFFUN
PLOTV
CLEAN
PRNTF


PROGRAM OSCILIINPUT, DUTPUT,REST, TAPE $5=$ INFUT, TAPE $3=$ OUTPI:T, TAPE $4=$ IRESTI

C

G PROGRAM OSCIL WRITTEN FOR SEISMIC PESPONCE OF BREEAER REACTOR CORE

G RESEARCH GROUP AF EROOKHAVEN NATIONAL LAB.

C AUTHOR... LESLIE LASKER JULY 1975 C

COMMON/GEARG/HUSED, NQUSED,NSTE F,NFE,NJE COMMON/CINT/T, OT,JS,JN, DXA $(25),, \times A(25 C), 10, .3 S 4$

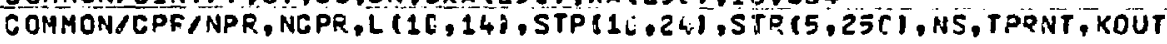
SOMMON

COMMON/PET/POUT

COMMON/CASE/TITLE (B)

COMMON/TIME/PFI,FINTIM,NT IME,TINT, METH,ERP, CPT

COMMON $/ P R T / A, B I N T, B, F F Q, A L P H A 1, N S T E P, N F U N$

COMMON/CONST/TWOP I, TAU, IWAVE

COMMON/CMAIN/NOR, NCOF,NSTART

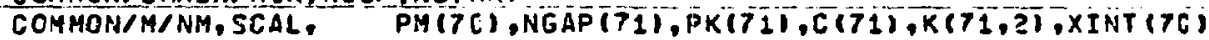

COMMON/M/ O1XIN (70),D2XINT 17:),A1(71),A2(71),DIF(71),OIF1(71)

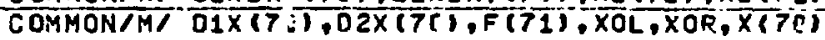

COMHON/CCOEF/UH, $\mathrm{CH}(7 \mathrm{C})$

LEVEL $2, \times \times 1$

DIMENSION Y(TC) QYDOT $17 C)$

LOGICAL KOUT, JS

LOG ICAL DONE, CHECK

LOG ICAL POUT

REAL K

DATA EMAX/.OQTII

CUSED $=\dot{O}$. 0

3! CALL RDIN

VDI $F=2 * N M$

TWOPI $=4.0$ DASIN $(1.0)$

$V S P F=N M+1$

$V T=1$

3 IFINCOF.EQ.21 CALL_COEF

CALL CLEAN

IFINSTART.GT O I CALL FESTART

. DO $24 I=1, \mathrm{NM}$

$X(I)=X I N T(I) \quad \& \quad 01 X(I)=01 X I N T(I) ; 02 X(I)=32 \times I N T(I)$

$Y(2+I-1)=\bar{X}(I) ; Y(2-I)=0 I \bar{X}(I)$

24 SONTINUE

INDEX $=1$

$K X=0$

DEL T $=3.5$

DONE $=$.TRUE.

KOU T=.FALSE.

$T A U=0.0$

IF (IHAVE. EO.1) BINT=BINT*THOPI

PRINT 5

PRINT 29,TITLE

29 FORMAT IBALL, $/, 1)$

CALL PPOUTT

1? CONTINUE

1 CALL SHOKTT .XOL,OIXL, XOR, OIXFI

IF(DONE) PRINT 5

5 FORMAT (1HI)

IF(DONE) PRINT 4 
4 FORMAT $11 X, 5 X, 3 H \times O L, 11 X, \quad 2 E X,-12 X, 2 H \times 2,11 X, 2 H X 3,3 X$,

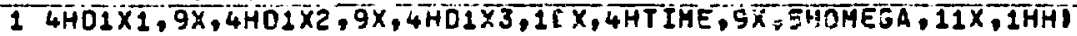

OT $=$. C C C 1

CALL PFNTFTPQI, FINTIM, DONE, XOLL.

$101 \times(3), T$, NQUSED, HUSEOI

IF (POUT) CALL STOFE $(K X)$

IFIOONEI SO TO 2

TOLD $=$ TPRNT

45 CUNTINUE

CALL DRIVETNDIF,T,TINT ,Y, TPRNT, ERR, HETH, INDEXI

$T=T$ PFNT

CPTIMESECONDCCPI

IF( (CPTIM-CUSEO) -LT.CPT) GO TO 5C

FINTI HET

5: CONTINUE

IF(INDEX.EQ.CT GO TO $4 \mathrm{C}$

PRINT 41, INOEX $2 T$

41 FORMATT INOEX = I5, AT TE F,FIC (3)

IF (INDEX.LT. -5.CR. INDEX.GT.-4) GO TO 43

CALL REHARK (27HRUN HALTED-CHECK PAFAMETEFS)

$43, E R P=E R F * 16 \cdot C$

PPINT $44, E$ ER

44 FOPMAT (* NEH ERR $\left.=*, E 10^{\circ} 4\right)$

INOEX $=-1$

TPRNT $=$ TOLD

IF (ERR-EMAX) $45,46.46$

46 CALL PEMARK + 5 HRUN HALTED-LOWER ERROR LIMIE HAS BEEV REACHEOJ

FIN TIM $=T$

4. INDEX $=2$

$0042 I=1, \mathrm{NH}$

$X(I)=Y(2 * I-1) \quad \& \quad D 1 X(I)=Y(2 * I)$

4? SONTINUE

SO TO 1

2 CONTINÜE

IF(MOO (NOP, 1:1.NE. 2$)$ GO TO 7

EALL PLOTV IPOI, KX,1,21

DO $8 \quad I=1, K X$

$x \times 1(2, I)=160$.

$3 \times X 1(1, I)=1<3$.

CALL PLOTVIPRI, KX, 3,

50 TO 6

i CALL PLOTV(PRI,KX,1,NM)

- CONTINUE

$B I N T=B I N T+F R Q$

$N T=N T+1$

IFINT.LE.NTTIME) GO TO 3

CUSED $=$ CUSED $+C P T$

GO TO 30

10: CONTINUE

END 


\section{SUBROOUTINE STOR.E $(K X)$}

c

6.THIS_RQUTINE_STOZES DISPLACEMENTS

COMMOH/CINT/T, OT, JS,JN, DXA $25 C), X A(25,1), I 0, J 54$

COMHON /CPR/NPR, NCPR, L $(16,14)$, STP $(1 C, 24), S T R(5,25 C), N S, T P R N T, K O U T T$ COHHON/ORD $X \times 132,2$ CLQ

COMHONIPLT/POUT

SOMMON/CASE/TITLE (B)

COMMON/TIME/PRI, FINTIM,NTIME, TINT,METH,ERR,CPT

COMMONYOHTA, SINT, B, FRO, ALPHA1,NSTEP, NFUN

COMMON/CONST/THOPI, TAU, I HAVE

OOMIHON/CHAIN/NOR, NCOF, NSTART

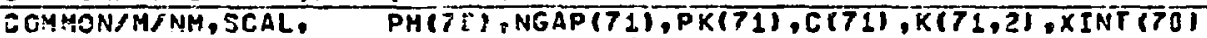

COMMON/MI DIXINT(70), D2XINT(7i), AI (71), A2 (71), OIF (71), DIF $1(71)$

COMMON/H, DIX (7S).D2X(7C), F(71), XOL, XOR, X(7t)

COMMON/ CCOEFI UMU, CW(TE)

LEVEL $2, \times X 1$

LOG ICAL POUT

$\mathrm{K} X=\mathrm{KX}+1$

$x \times 1(1,2, K x)=x 02$

$X \times 1(2, K X)=20 R$

$N C=(N M+1) / 2$

$N P=M O D(N O R, 13)$

$N C E=N C$

IF (NP.EO .2) NC $=4$

DO $1 I=1, \mathrm{NM}$

$X X \pm(I+2, K X)=X(1)$

$I F(N S T E P, E Q .2) \times X X 1(I+Z, X X)=X(I)+(N C-I) * A I(N C)$

1 CONTINUE

IF (NSTEP.NE. 2 ) GO TO 2

$X X 1(1, K X)=X O L+(N C-1)=A I(N C)+A 2[1)$

$X X 1(2, K X)=X O R+(N C-N M) * A 1(N C)-A 2(N M+1)$

2 GONTINUE

IF (NP.NE.2) GO TO 4

$\mathrm{N} C \mathrm{C}=\mathrm{S}$

DO $3 I=3,8$

$\overline{X X 1}(I+2, \overline{K X})=\bar{X}(\mathrm{NC}=\bar{E}+I)$

IF (NSTEP, EQ. 2$) \times X 1(I+2, K X)=x(N C C-6+I)+(N C-I)+A 1(N C C)$

3 CONTINUE E

4 CONTINUE

WRITE $(4) T, \bar{x}, 01 \mathrm{x}, \overline{02 x, F}$

6 IF (MOD $(K X-1,10), E Q, C)$ HRITE(4) $T, X, D \perp x, 02 X, F$

POUT $=$.FALSE.

RETURN

ENO 
SUBPCUTINE ROIN

C

C THIS ROUTINE READS IN ALL PERTINENT DATA. c

COMMON/CINT/T,DT, JS, JN, DXA (25C), XA (250), IO, JS4

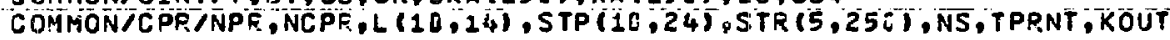
SOYMON/ORO/XXI(32,:DUO)

COMMON/PLT/POUT

CO:4MON/CASE/TITLE (8)

COMMONITIME/PRI, TNTIA,NTIME, TINT, HETH, ERR, CPT

COMMON/PRT/A, BINT,, ,FRQ, ALPHA I, NSTEP, NFUN

COMMON/CONSTITWOPI, TAU, I HÄVE

COHMON/CMA IN/NOR, NC OF, NSTART

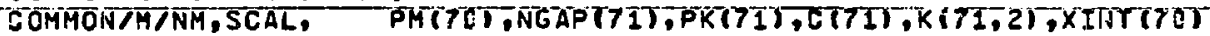

COMMON/MF D1XINT(7C),O2XINT(70),A1(71),A2(71), UIF (71),0IF1(71)

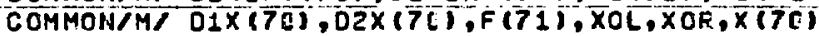

COMMON/CCOEF/UMU, $\mathrm{CH}(7 \mathrm{n})$

LEVEL $2, \times \times 1$

3: READ 28,TITLE

29 FORMAT(BA1C)

IF (EOF (5) $10 \mathrm{C}, 4 \mathrm{C}$

4 I REAO $15, N F U N$, NM,NTIHE

15 FORMAT (3I1T)

IFINFUN.NE.11 GO TJ 2

SEAO $17 ., 1$

$B=B I N T=A L P H A I=F R Q=C \cdot T$

SO TO 4

2 PEAO 17,A, BINT,FF G,ALPHAI,NSTEF, IWAVE

17 FORMAT (4FIU,2, 2I1L)

4 NSPF $=N M+1$

READ 25, NSTART, NIN, NCOF, NOR, UMU

C

25 FORMATII, 3II, EIL.21

C IF NINE I PEAD IN EACH MASS INDIVIDUALLY, TOGETHER WITH THEIR INITIAL

C DISPLACEMENTS, VELOCITIES AND ACCELERATIONS. c

IF (NINOEQ.2S GO TO 21

PEAD 15, (PH(I), I $=1$, NMT)

READ 1$\},(X I N T(I), I=1, N M)$

READ $1 E_{10}(D 1 X I N T I I, I I=1, N M)$

२EAD 1E, (D2XINT $(I), I=1, N M)$

15 FORMAT (12.FE.2)

C

C IF NIN=I REAO IN CATA FOR EACH INDIVIOUAL SPRING

C

DO $19 \mathrm{I}=1, \mathrm{NSPF}$

19 READ $2 C, N G A P(I), K(I, 1), K(I, 2), A 1(I), C(I), A 2(I)$

2: FORMATIIIE.5E1:.2)

C

C IF NIN=E HAVE SYMMETK IC PROBLEM. REAO IN OUTER RASSES ANO- INNER MASSES

C

50 To 22

C OUTER SPINGS FOR NINE2

C

C

21 READ 16,PAT(1, PAT 2$)$ 
C SECOVO AND NEXT-TO-LAST SPPINGS FOR NIN=?

C

READ $20, N G A P(1), K(1,1), X(1,2), A 1(1), C(1), A 2(1)$

READ 2i.NGAP $(2), K(2,1), K(2,2), A 1(2), C(2), A 2(2)$

C. INNER SPRINGS FOR NIN=2

C

READ 2C,NGAP(3),K(3,1),K(3,2), A1(3),C(3),A2(3)

$N I N N=N M-1$

DO $23 I=3, N I N N$

$P M(I)=P M(2) \& \quad N G A P(I)=N G A P(3) \subseteq K(I, \dot{I})=K(?, 1) \leq K(I, 2)=K(3,2)$

$A 1(I)=A I(3)$ S $A 2(I)=A 2(3) \quad C(I)=C(3)$

23 CONT INUE

PM(NA) =FM(1) \& NGAP(NSPR) =NGAP(I) $\$ K(N S P R, 1)=K(1+1)$

$K(N S P R, 2)=K(1,2) \& \quad \triangle 1(N S P F)=A 2(1) \quad \triangle 2(N S P F)=A 2(1) \quad C(N S P R)=C(1)$ NGAP (NM I =NGAP $(2)$ \& $K$ TNM, 1$)=K(2,1)$

$K(N M, 2)=K(2,2) \leq A 1(N M \quad)=A 1(2) \$ A 2(N M \quad)=A 2(2) \quad C(N M \quad I=C(2)$

2? CONTINUE

READ 41 , PEI, FINTIM,TINT, METH, ERR

REAL 41,SCAL,CPT

41 FORMAT I ZE1E.2, I 1C, E1C.ZI

RETURN

1 I STOP

END 
SUBROUTINE COEF

C THIS ROUTINE COMPUTES DAHFING COEFFTS. BETHEEN SPRINGS AND SROUNO

C DAMPEFS. COEF ONLY CALLED IF NGOF $=2$.

C

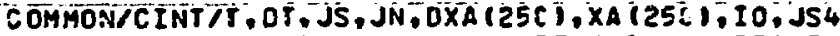

COMMON/CPR/NPR, NCPF, L (1E, 14), STP (12, 24),STR (5,250), NS, TPRNT, KOUT

TOMAONTOPOTXX1(32.26LC)

COMMON/PLT/POUT

COMMONTC ASETTITEE (B)

COHMON/T TME/PRI, F INTIM, NT IHE, TINT, METH, EPP, CPT

GOMHON/PET/A, GINT, $B$,FFQ,ÁLPHAL, NSTEP, NFUN

DOMYON CONST/ THOPI, TAU, I HAVE

EOMMONTCMA INI NOR, NCOF, NSTAOT

COHMON/M/NM, SCAL, PM(7L), NGAP(71),PK(71),C(71),K(71,2), XINT(7)

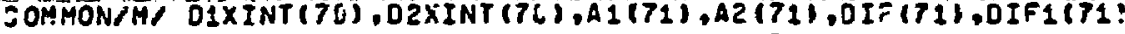

COMMON/M/ $01 \times(7 C), 02 \times(72), F(71), \times O L, \times O R, \times(70)$

COMMONICCOOEFIUMU. CHRTC:

LEVEL $2, \times \times 1$

TिEAL K

$N S P P=N M+1$

$P I=2 . Q * A S I N(I, C)$

CLEAR $=C \cdot C$

$B=B$ INT

DO 1 I=1, NSPR

1 CLEAK $=C L \equiv A \bar{K}-A I|I|$

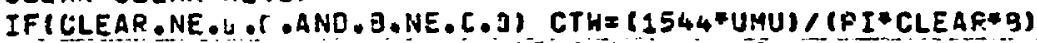

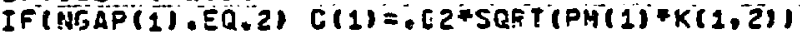

IF (NG AP INSPR) . EG. 2$) \quad C(N S P P)=. C 2 *$ SQPT $(P M(N H) * K(N S P F, 2)]$

$002 \mathrm{~N}=2, \mathrm{NM}$

IF (NGAP $(N), E Q \cdot Z) \quad C(N)=. C Z * S Q F T(K(N, 2)=(P H(N-1)+P N(N)), 2,0)$

Z $\mathrm{CW}(\mathrm{N})=\mathrm{CT}$ TनPH(N)

$C H(1 !=C T H+P M(1)$

C

$004 N=1, N S P C$

$C C(N)=C(N)=30$.

$T E M=B / 11.4$

$005 I=1, N M$

c

$5 \operatorname{CW}(I)=T E M * C H(I)$

RETUFN

END 
SUBROUTINE RESTART

G

THIS ROUI INE IS USEO TO RESTART A FUN FROM TIIE *PRI *NSTART

COMMON/CINT/T, CT, JS, JN, OXA (25) $1, \times A(250), I 0, J S 4$

COMMON/CPR/NPR, NC PE, L (1T,14),STP(16.24),STR (5,25ET,NS,TPRNT, KOUT COMMON/ORO/XX1(32,10J6)

TOHMON/PLT/POUT

SOMMON/CASE/TITLE (8)

COMMON/T IME/PRI, F INTI $\bar{M}, N T$ IME, TINT, METH, ERR, CPT

ZOMMON/PRT/A, BINT.B,FRO,ALPHA1_NSIEP,NFUN

EOMMON/CONST/ TWOPI, TAU, I HAVE

COMHON/CMAIN/NOF. NCOF, NSTAET

COMMON/MINM, SCAL, PMT7E), HGAP(71),PK(71),CT71),K(71,2),XINT(7E)

COMMON/M/ O1XIMT(7C),D2XINT (70),A1(71),A2(71),DIF(71),OIF2(71)

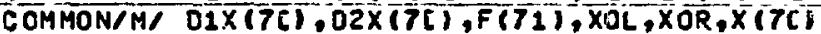

COHKON/CCOEF/UMU, CH(TO)

LEVEL $2, \times \times 1$

TSTART=NSTART * 1 H * FRI

MSTART =NSTART

001 I 1 I.MSTAPT

1 READ (4)

PEAD(4) T,XINT,O1XINT,OZXINT, F

$3 A C K S P A C E$ E

IFIABSIT-TSTARTI ILE - OE I) RETURN

NFITE 3.T.TSTAFT

3 FORMAT I* CHECK RESTART TIME T=*,F5.2,* TSTART = *,F5.21

STTP

ENO 
SUGPOUTINE SHOK (DELT,XOL,DIXL,XOR,O1XRI

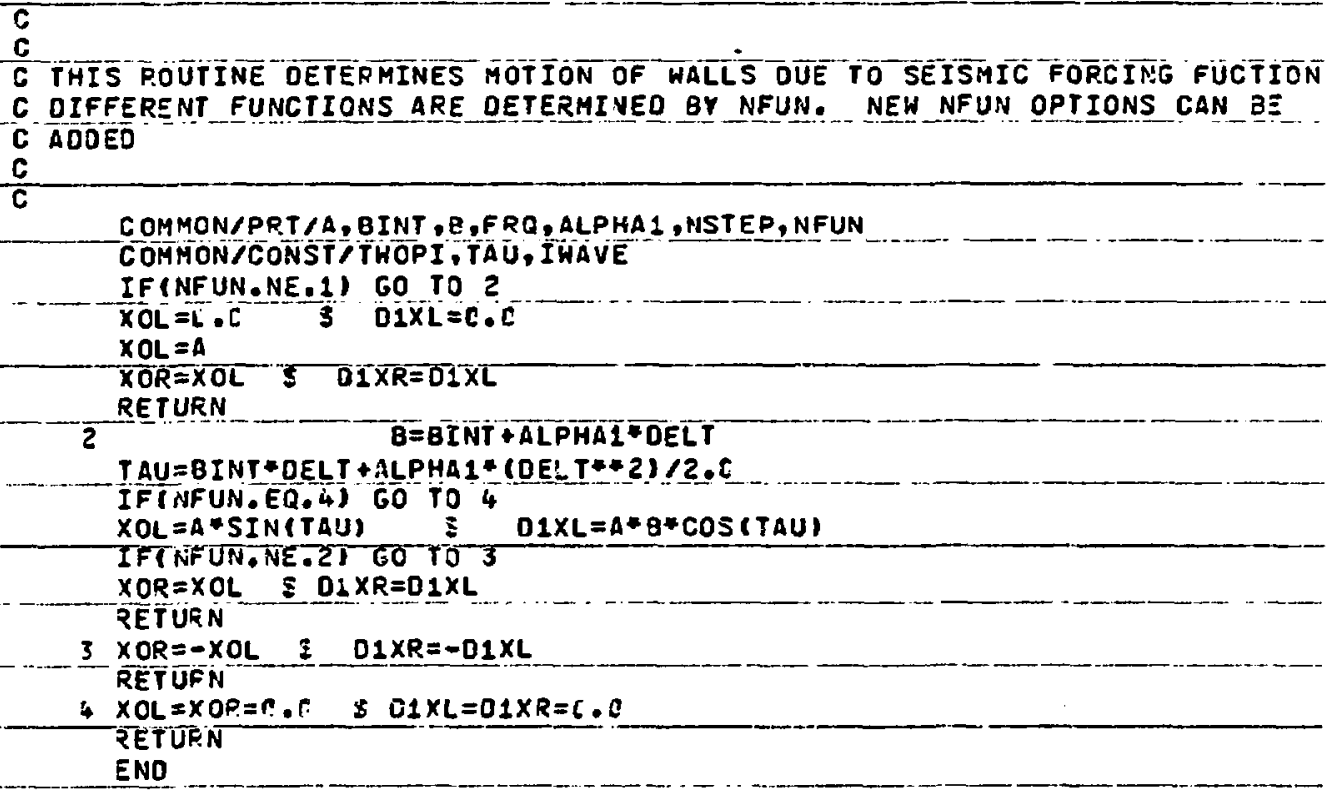


SUBROUTINE PROUT

6

C THIS ROUIINE OUTPUTS MASS AND SPRING DATA.

C

COMMON/CINT/T,DT,JS, JN,DXA $(25[), \times A(25[), I 0, J S 4$

GOMMON/CPRINPR, NCPF, L(1C,14), STP(1C,24),STR $5,25 E), N S, T P R N T, K O U T$ COMMON $O R D / X \times 1(32,16 \% 0)$

COMMON PLTIPOUT

COMMON/CASE/T ITLE (B)

COMMON/TIME P PRI, FINTIM,NTIME, TINT, METH, ERE, , CPT

COHMON

COMMON/CONST/THOPI, TAU, I HAVE

COMMON/CMAIN/NOR, NCOF, NST ART

COMMON/MINM,SCAL, PM(7C),NGAP(71),PK(71),C(71),K(71,2),XINT(7C)

COMMON/MI O1XINTI7C),02XINT (70),A2 (7:1),A2 (71),OLF(71),0IF1171)

COMMON/HI DIX(70),DEX(7C), F(72), XOL,XOR,X(7E)

COMMON/CEOEF/UMU, CH(7C)

LEVEL $2, \times \times 1$

P.EAL K

NSPP $=N M+1$

IFINFUN.NE. 1) 60 TO 2

PFINT 16

1. FORMAT (* STEP FUNCTION PAFAMETERS * 1

PRINT 11,A,NM,UMU

11 FORMAT I* AMPLITUDE $=*, F 10,2,1$,

3 . COEF OF FRIC $7, F 5.2,1$

50 TO 12

2 IFINFUN.NE.2) 60 TO 3

PFINT 2 ?

25 FORMATI SINUISOIDAL IN-PHASE FUNCTION PAPAMETERS GO TO 24

3 IF TNFUN.NE.3) GO TO 4

PFINT 36 S 60 TO 24

30 FORMATI SINUISOIDAL OUT-OF-PHASE FUNCTION PARAMETERS ,

4 PRINT $4 \mathrm{C}$

4i. FORMAT I FIXED WALL, SINUISOIDAL FORCE PARAMETERS

24 PRINT 17, A, 8INT, ALPHA1,NM

17 FORMATI* AMPLITUOE = ,F $10.2,1$,

1. OMEGAC $=*, F 1 \mathcal{C}, 2,1 C X, *$ ALPHA $=*, F 1 \mathrm{C} .2,1$.

2 NUPEEF OF MASSES $=7,13,11$

12 PRINT 18, (I,PM (I), I=1,NM)

19 FORMAT $(7,5(15,14,, F 8,3)$

PFINT 21,NSPR

21 FORMATI/, THERE ARE $\$$, I5, $\%$ SPRINGS $\%, \%$

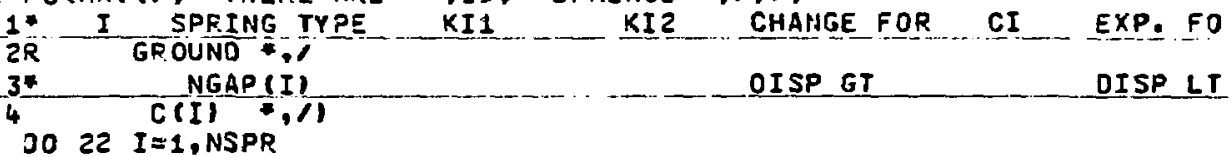

22 PPINT $23, I, N G A P(I), K(I, 11, K(I, 2), A I(I), C(I), A Z(I), C H(I)$

23 FORMATII5,I1], 2E10,2,4F10.3)

RETURN

END 
SUBROUTINE FORCE(NSPR)

G

C THIS ROUTINE, CALLEO BY DIFFUN, DETERMINES THE FORCES IN THE SPRINGS

C AS A FUNCTION OF DISPLACEMENTS. THE NATURE OF THE FORCE IS OETERMINED

C BY THE SPRING TYPE=NGAP(L). DIFFERENT SPRING RESPONCES CAN BE ADDED

G TO THIS ROUTINE.

C

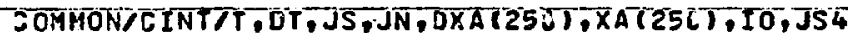

COMMON/CPR, NPR, NC PF, L $(1 \mathrm{~L}, 14)$, STP $\{1 \mathrm{C}, 24)$, STR $(5,250)$, NS, TPRNT , KOUT

COHMON/OROTXX1(32,16:S)

COMMON/PLT/POUT

COMMON/CASE/TITLETÉ

COMMON/T I IE/PR I, F INT IM, NT IME, T INT , METH, ERR , CPT

COMMON/PRT/A, BINT, B,F PO,ALPHA I,NSTEP, NFUN

COMMON/CONST/THOPI. TAU, IWAVE

COMMON C CMAININOF, NCOF, NSTAET

COMMON/M/NH, SCAL, PH(7C),NGAP(71),PK(71),C(71),K(71,2),XINT(7C)

COMMON/M/ D1XINTITC), O2XINT (7E),A1 (71), A2(71), DIF (71), DIF1(71)

COMMON/M/ $01 \times(70), 02 \times(70), F(71), \times O L, \times O R, \times 17 C)$

COMMON/CCOEFTUMU,CW (7T)

LEVEL $2, X \times 1$

QEAL K

DO $11 L L=1, N S P F$

NTY $=N G A P(L L)$

GD TO(1L, 2L, 3C), NTYP

1] IFCOIF(LL) .LT.AITLI I) 15.13

2: IF(DIF(LL),GT.AI(LLI) 12,25

15 IF (DIFTLL) OGTAAZ (LLIT 12,14

25 IF (DIF(LL) . GT .A2(LL) 13,14

$12 F(L L)=D I F(L L) * K(L L, 1)$ 50 TO 11

$13 F(L L)=K(L L, 2) *(D I F(L L)-A 1(L L))+K(L L, 1) * A 1(L L)$

Go TO 11

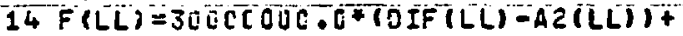

$1 K(L L, N T Y P) *(A 2(L L)-\{N T Y P-1) * A 1(L L))+(N Y Y P-1) * K(L L, 1) * A 1(L L)$

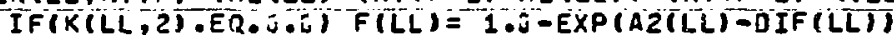

SO TO 11

3. $F(L L)=K(L L, 1)$ (OOIF $(L I T+7)$

11 CONTINUE

QTETURN

ENO 
SUSROUTINE DIFFUN (NN, TT, Y, YOOT)

c

THIS ROUTINE DETERMINES VECTOR YOOT AT TIME TT, GIVEN THE VALUE OF $Y$. C YOOT $=(01 X, 02 X)$ I.E. THE VELOCITIES AND ACCELERATIONS OF THE MASSES. C $Y=(X, 01 X)$ I.E. THE DISPLACEMENTS AND VELOCITIES.

C

COMMON/CINT/T, OT,JS,JN, DXA(250), XA(25C),IO,JS4

COMMON/C PR/NPR, NCPR, $(1 C, 14)$, STP $(16,24), S T R(5,25 H), N S, T P R N T, K O U T$ COMMON/ORO/XX1(32,10EO)

COMMON/PLT/POUT

COMMON/CASE/TITLE (8)

COMMON/TIME/PRI, FINTIM, NTIME, TINT, METH, ERF, CPT

COMMON/PRT /A, BINT, $B, F R Q$, ALPHA I, NSTEP, NFUN

COMMON/CONST/THOPI,TAU, I WAVE

COMMON/CMAIN/NOR, NCOF, NSTART

SOMMON/MINM, SCAL, PH 77 E), NGAP(71), PK(71), C(71),K(71, 21, XINT (7C)

COMMON/M/ D1XINT(7L),D2XINT (70),A1(71),A2(71),DIF(71),DIF1(71)

COMMON/M/ $01 \times(70), 02 \times(70), F(7), \times 0 L, X O R, X(70)$

COMMON/CCOEF/UMU, CH(70)

LEVEL $2, \times \times 1$

DIMENSION Y $(N N), Y D O T$ (NN)

TWOPI $=4$. C * ASIN $(1, C)$

$N S P F=N M+1$

G ALL SHOKITT, XOL, OIXL, XOF, $\overline{O 1} \overline{X R}$

DO $14 \quad I=1, N M$

$X(I)=Y\left(2^{*} I-I\right) \quad \& \quad 0 I X(I)=Y\left(Z^{*} I\right)$

14 SONTINUE

3 DIF $(1)=X(1)=X O L$ DIF $(N M+1)=X O R-X(N M)$

$\operatorname{OIF} 1(1)=01 \times(1)-D 1 \times L \quad \& \quad$ OIFI $(N M+1)=01 \times R-01 \times(N H)$

$001 \mathrm{i} I=2, \mathrm{NM}$

$\operatorname{DIF} 1(I)=01 \times(I)-01 \times(I-I)$

13 DIF $(I)=x(I)-x(I-1)$

CALL FOR CE (NSPP)

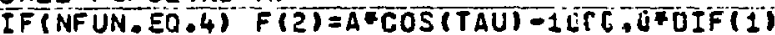

$D O 13 \mathrm{~N}=1$, NM

$\overline{S L}=C \overline{S N} \& \mathrm{CP}=\mathrm{C}(\bar{N} \overline{+} \overline{1})$

IF(NGAP(N) .EQ.2.AND.DIF (N), GT . A1 (N) CL $C$, I

IF(NGAP $(N+1), E Q-2 . A N D . O I F(N+1), G T . A I(N+1)) C R=0$.

$D 2 X(N)=(F(N+1)-F(N)-D I F I(N) * C L+D I F 1(N+1) * C R+(X D L-X(N)) * C H(N)) / P M(N$

1)

13 CONTINUE

$0015 \quad I=1$. NM

YDOT $(2 * I-1)=01 \times(I) \&$ YOOT $(2 * I)=02 \times(I)$

15 SONTINUE

RETUFN

END 
$c$

C IHIS ROUTIHE PLOTS THE QUANTITIES STORED IN $X \times 1$. THE VARIABLES STOREU

C IN XXI AFE DETERMINED IN SUBPOUTINE ZSTOPE\#.

C

COMHON/ORO/XX1 $132,1 \mathrm{CE}$

COMMON/CASE/TI TLE (8)

COMMON/PRT/A,BINT, B,FRO, ALPHA I, NSTEP,NFUN

COMMON/M/NM, SCAL

COMMON/CMAIN/NOP, NCOOF, NSTART

DIMENSION HX1(121),SYMBOL (32)

LEVEL $2, \times \times 1$

LOG ICAL EO

DAT A SYMBOL/1H $, 1 \mathrm{H}, 1 \mathrm{H}, 1 \mathrm{1H}, 1 \mathrm{H}, 1 \mathrm{HD}, 1 \mathrm{HE}, 1 \mathrm{HF}, 1 \mathrm{HG}, 1 \mathrm{HH}, 1 \mathrm{HJ}, 1 \mathrm{HK}, 1 \mathrm{HL}$

$11 \mathrm{HM}, 1 \mathrm{HN}, 1 \mathrm{HO}, 1 \mathrm{HP}, 1 \mathrm{HQ}, 1 \mathrm{HF}, 1 \mathrm{HS}, 1 \mathrm{HT}, 1 \mathrm{HU}, 1 \mathrm{HV}, 1 \mathrm{HH}, 1 \mathrm{HX}, 1 \mathrm{HY}, 1 \mathrm{HZ}, 1 \mathrm{HA}, 1 \mathrm{HB}, 1 \mathrm{H}$

$2 \mathrm{C}, 1 \mathrm{H/}, 1 \mathrm{H} / \mathrm{H}$

$E D=$. F ALSE。

PRINT 5

5 FORMAT (1H1)

PRINT 18.TITLE

18 FORMAT (BALE)

PRINT 29

29 FOPMAT $1 / .1,11$

CALL PROUT

PFINT 29

PRINT 11

11 FORMAT $(/, 4 \times, 6 \mathrm{H} \times \mathrm{OL}=-, 5 \times, 6 \mathrm{H} \times O P=, .5 \times, 5 \mathrm{H} \times 1=., 5 \times, 5 \mathrm{H} \times 2=*, 5 \times, 5 \mathrm{H} \times 3=+$

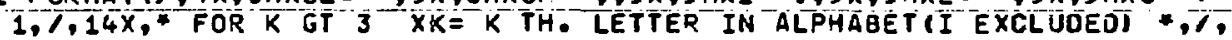
$2 / .11$

$280013 \mathrm{~L}=1,121$

$13 H \times 1(L)=1 H$

$0023 \mathrm{~L}=1,7$

$23 H \times 1(L)=(L-4) * S C A L=2$

PRINT $24, T(\bar{H} X \overline{1}(\mathrm{~L}), L=1, \overline{7})$

24 FOPMAT $(4 X, F 1 C, 1,6 F 2 C .1)$

IF (ED) GO TO 14

DO $1 K=1$, IFINTIM

$300-2 \mathrm{~L} \equiv 1,12 \mathrm{C}$

$H \times 1(L)=1 H$

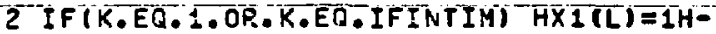

$4 \times 1(61)=1 H I \& H \times 1(1)=1 H I$ \& $H X 1(121)=1 H I$

IIM $=(K-I)$ *TINT +NSTAFT * I * TINT

IF (K.EO. IFINTIM) GO TO 51

$L L=\bar{H} D(K-1,4.7)$

IF (LL.GT , II GO TO 22

$510021 \quad C=11,111,1 \mathrm{C}$

$21 H \times 1(L)=1 H I$

22 CONTTINUE

DO $31 \quad I=1,2$

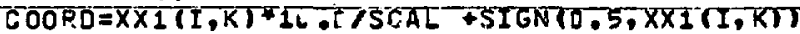

$J=I N T(C O O F D)$

IF (IABS $\left(\sqrt{1} \cdot 6 E_{0} 6 C\right)$ GO TO 31

$J=J+61$

HXI $(J)=S Y M B O L(I)$

31 CONTINUE

DO 9 I =MF F'ST, MLEST

$C O O R D=X \times 1(I+2, K) * 10.0 / S C A L+S I G N(R, 5, \times x 1(I+2, K))$ 
$J=I$ NT (COOR.O)

IF(IASS (J).GE.60) GO TO 9

$J=J+61$

$H X I(J)=S Y M B O L(I+2)$

$\exists$ CONTINUE

$l=M O 0(K-1,10)$

IFIL.GT.O) GO TO 8

PFINT $4, T I M, H \times 1$

4. FORMAT (1 $x, F 1,2,2,2 x, 121 \mathrm{~A} 1)$

GO TO 1

8 PRINT $6,4 \times 1$

E FOPMAT (13X,121A1)

1 CONTINUE

$E D=$.TRUE.

GO TO 28

14 RETUFN

END 
SUGROUTINE CLEAN

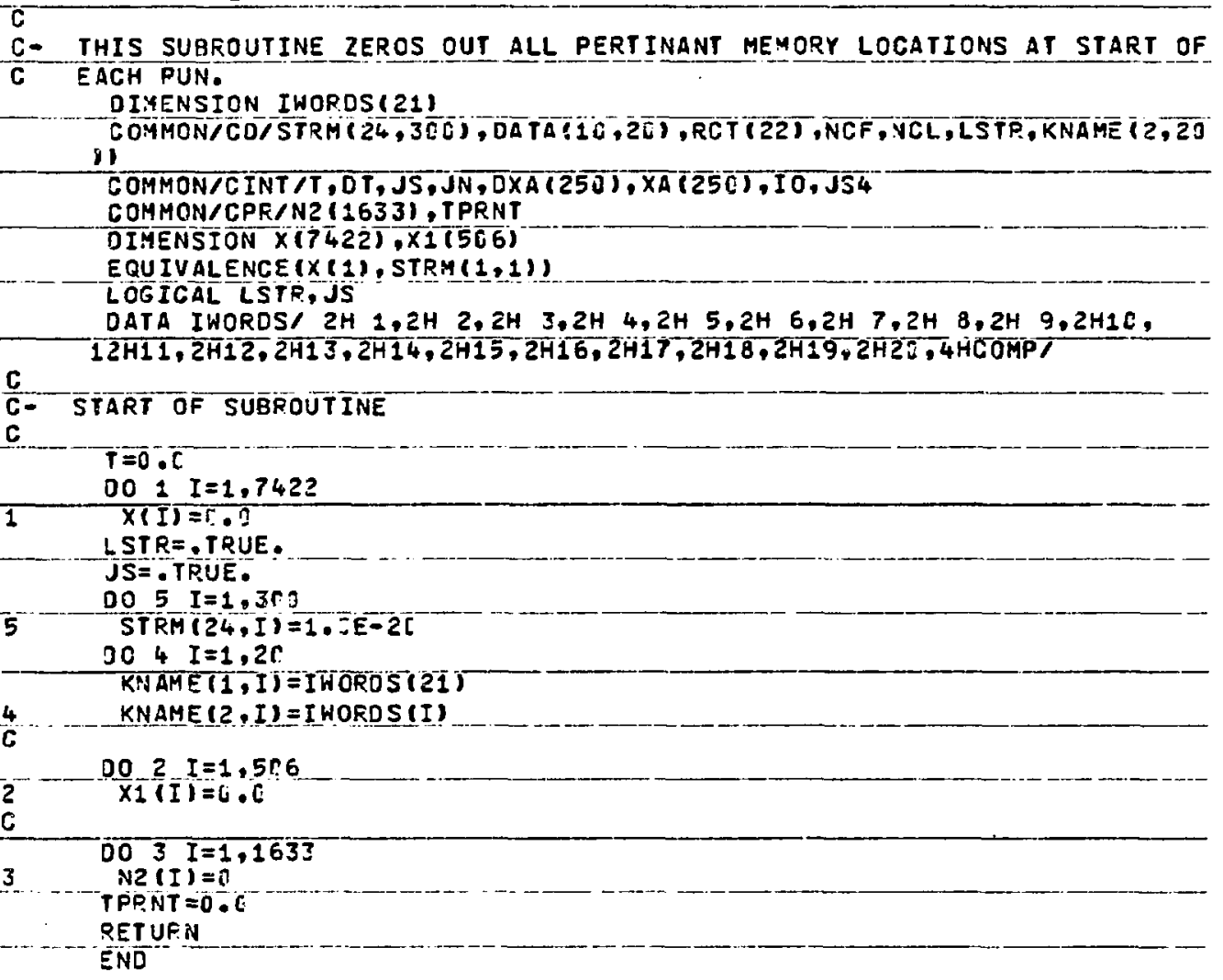


SUBROUTINE PRNTF(PEI,FINTIM,DONE, $A, B, C, D, E, F, G, O, P, Q)$

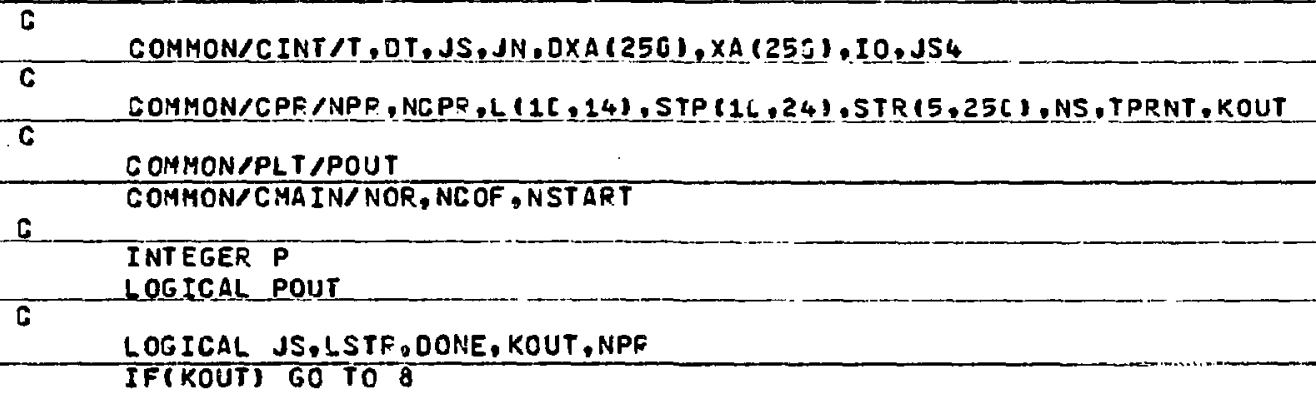

\section{C- START OF SUBROUTINE \\ C.}

NPR $=$. FALSE.

IF(TPRNT.EQ.0.L) GO TO 4

IF(T.GE.FINTIM-(C.5\%OT) GO TO 1

3 IF (JS) GO TO 5

IF $(S S 4 . E Q .4)$ GO TO 5

60 TO 9

4 DONE = FALSE.

IFITPRNT EEQ.C.C) TPRNT=TPRNT+NSTART III FRT

$5 \quad$ TPRNT $=$ TPRNT +PRI

8 WRITE $(3,1, A, A, B, C, D, E, F, G, 0, P, Q$

POUT = . TRUE.

1) FORMAT $(1 X, 8 E 13.4, I 13, E 13, \overline{4})$

$N P R=$.TFUE.

GO TO 9

1 IF(JS) 60 TO 6

IF $\left(J 54, N \bar{C}_{0} 4\right)$ GOTO 2

C- THIS SECTION CLEARS THE SYSTEN AT THE END OF THE RUN

6 JONTINUE

TPRNT $=i \cdot \hat{U}$

DONE=.TRUE.

$007 j=1,250$

$7 \times 1 \mathrm{X}=\mathrm{C} . \mathrm{C}$

60 ro 8

C

9 RETUPN

END 